\title{
Der osteuropäische Arbeitsschlitten bei den Ostseefinnen.
}

Es dürfte eine wohlbekannte Tatsache sein, dass in Finnland heutzutage zwei verschiedene Grundkonstruktionen des Arbeitsschlittens auftreten, von welchen die eine für den Osten und die andere für den Westen des Landes charakteristisch ist. Schon ziemlich früh ist auch eine summarische Grenze zwischen den angeblichen Verbreitungsgebieten derselben gezogen worden, ${ }^{1}$ und später hat Kustaa Vilkuxa dazu eine Verbreitungskarte über ein Detail, charakteristisch für die östliche Konstruktion, vorgelegt, welche das Vordringen dieser Konstruktion gegen Westen mit einer grossen Genauigkeit feststellen lässt ${ }^{2}$. Hauptsächlich auf Grund der genannten Verbreitungskarte $^{3}$ erhalten wir eine Linie, die zuerst von der Mündung des Flusses Kymi am Finnischen Meerbusen im östlichen Uusimaa (Nyland) nach Norden der Grenze zwischen den Kirchspielen Mäntyharju und Hartola im südlichen Häme (Tavastland) zustrebt. Von dort setzt die Grenze unter einem ziemlich scharfen Winkel nach Nordwesten bis zum Kirchspiel Jämsä im mittleren Teil der Landschaft fort, greift dann in dem nördlichen Teil derselben Landschaft in einem Halbzirkel nach Osten bis zum Kirchspiel Rautalampi im westlichen Savo (Savolaks) zurück, und läuft schliesslich durch den Kirchspiel Pylkönmäki im nordwestlichen Häme, weiter durch Soini,

1 Suomen Kartasto. Helsinki 1925, harte 23: 10.

2 Kusta Vilkuna, Uusia aineksia Suomen kieli- ja kansatieteelle. Suomalainen Tiedeakatemia. Esitelmät ja pöytäkirjat 1939. Helsinki 1940, S. $92-93$.

3 Eine gewisse Berichtigung hat sich in dem südlichen Teil der Grenzlinie laut späterhin zugekommenen Materials notwendig erwiesen. 
Lappajärvi, Terijärvi und Kronoby im nördlichen Satakunta und südlichen Ostbottnien dem Bottnischen Meerbusen in der Umgebung der Stadt Kokkola zu. - Das Land wird also durch diese Grenze halbiert. Der grösste Teil des Territoriums wird dabei von dem östlichen Schlittentypus beherrscht, dessen Verbreitungsgebiet sich über beträchtliche Teile von Häme, ganz Savo und Karelien, und dazu noch den grössten Teil Ostbottniens bis zu der Reichsgrenze im hohen Norden erstreckt.

Eine gleiche Zweiteilung des Territoriums zwischen einem östlichen und einem westlichen Arbeitsschlittentypus tritt auch in Estland südlich des Finnischen Meerbusens auf. Auch hier kann wie in Finnland das Vordringen des östlichen Typus gegen Westen mit Hilfe des obengenannten Details in der Schlittenkonstruktion fixiert werden. Die Grenze beginnt im Kirchspiel Jõelehtme an der Nordküste des Landes, zieht durch den nordwestlichen Teil der Landschaft Harjumaa (Harrien), folgt dann in grossen Zügen der Ostgrenze der Landschaft Läänemaa (Wiek), und läuft schliesslich durch den, im südwestlichen Teil der Landschaft Pärnumaa (Kreis Pernau) gelegenen Kirchspiel Tõstamaa, dem Rigaer Busen zu. Somit umfasst auch in Estland das Verbreitungsgebiet des östlichen Schlittentypus den grössten Teil des Landes. Nur die westlichsten Teile des Festlandes nebst den Inseln haben sich der Verbreitung entzogen. Die Grenze zwischen den beiden Schlittentypen, welche am Bottnischen Meerbusen in Ostbottnien beginnt, verläuft von Finnland quer über den Finnischen Meerbusen nach Estland herüber, wobei sie die westlichen Teile der beiden Länder von dem übrigen Territorium abtrennt. In dieser Ausdehnung ist die Grenze auf der Verbreitungskarte über Schlittenvarianten unten, Fig. 1: 13, verzeichnet worden. ${ }^{1}$

Eine Grenze, die das Territorium der ostseefinnischen Völker

1 In Estland ist die Grenze auf Grund des Materials in ERM = Estnisches Nationalmuseum, Tartu, AES = Akademische Gesellschaft für Muttersprache, Tartu, und Privatsammlungen von Prof. A. SaAreste, Uppsala, verzeichnet worden. - Für das freundliche Entgegenkommen, mir seine Sammlungen zur Verfügung zu steilen, spreche ich Herrn Prof. SaAreste hiermit meinen Dank aus. 
derart durchkreutzt, muss von dem Gesichtspunkte der kulturgeographischen Gliederung aus für die betreffenden Länder als höchst bedeutungsvoll angesehen werden. In Finnland ist die Schlittengrenze schon oft als ein typisches Beispiel für die kulturgeographische Zweiteilung des Landes angeführt worden. ${ }^{1}$ In Estland fällt dieselbe Grenze sehr nahe mit einem ganzen Bündel anderer Verbreitungsgrenzen gleicher Richtung zusammen, welche alle dazu beitragen, die westlichen Teile des Landes vom übrigen Festlande abzuschneiden. ${ }^{2}$ Es geht hier schlechthin um die Frage der sog. östlichen Kulturpenetrierung im Baltikum und Finnland. Der Arbeitsschlittentypus, welcher östlich von der aufgezeichneten Grenze auftritt, wird ja in der ethnologischen Literatur ganz bezeichnenderweise für den osteuropäischen Arbeitsschlitten genannt, und es ist auch allgemein bekannt, dass der Schwerpunkt seiner Verbreitung heutzutage auf dem breiten osteuropäischen Kontinent $\mathrm{zu}$ suchen ist.

1 Z.B. Vilkuna, op.cit. - Veikko Ruoppila, Itä ja Länsi Suomen kansankulttuurissa. Hyvä Tuomas. Kansankulttuuria. JyväskyläHelsinki 1938, S. 54 .

2 Helmut Hagar, Ida ja lääne küsimusi Eesti ainelises rahvakultuuris. Minevikust Tulevikku. Stockholm 1954, S. 145-146. - Gustav Rä̀k, Vanha Viro. Turku 1955, S. 46, 69.

Fig. 1. Verbreitunskarte über Schlittenkonstruktionen. 1) Osteuropäischer Schlitten, Fig. 2. - 2) Eigentlicher Bindeständerschlitten, Fig. $3 \mathrm{u}$. 5. - 3) Ders. mit Astständerkonstruktion, Fig. 4. u. 6. - 4) Bindeständerschlitten mit Querleisten zwischen den Bindeständern, Fig. 9. - 5) Ders. mit Astständerkonstruktion, Fig. 8. - 6) Schlitten mit dem zweigeteilten Ständersystem und den östlichen Querverbindungen, Fig. 10. u. 11. - 7) Ders. mit Astständerkonstruktion. - 8. Schlitten mit dem zweigeteilten Ständersystem, östlichen Querverbindungen $\mathrm{u}$. Rutenbändern, Fig. 12. - 9) Schlitten mit den langen, westlichen Seitenstängen u. östlichem Ständersystem, Fig. 13. - 10) Schlitten mit den langen Seitenstängen $u$. einem einheitlichen, westlichen Ständersystem, Fig. 15. - 11) Ders. mit Astständerkonstruktion, Fig. 14. - 12) Bindeständerschlitten mit den östlichen Querverbindungen, Fig. 16. u. 17. - 13) Westgrenze des Verbreitungsgebietes des osteuropäischen Schlittens. - 14) Ältere Westgrenze des osteuropäischen Schlittens in Estland. 


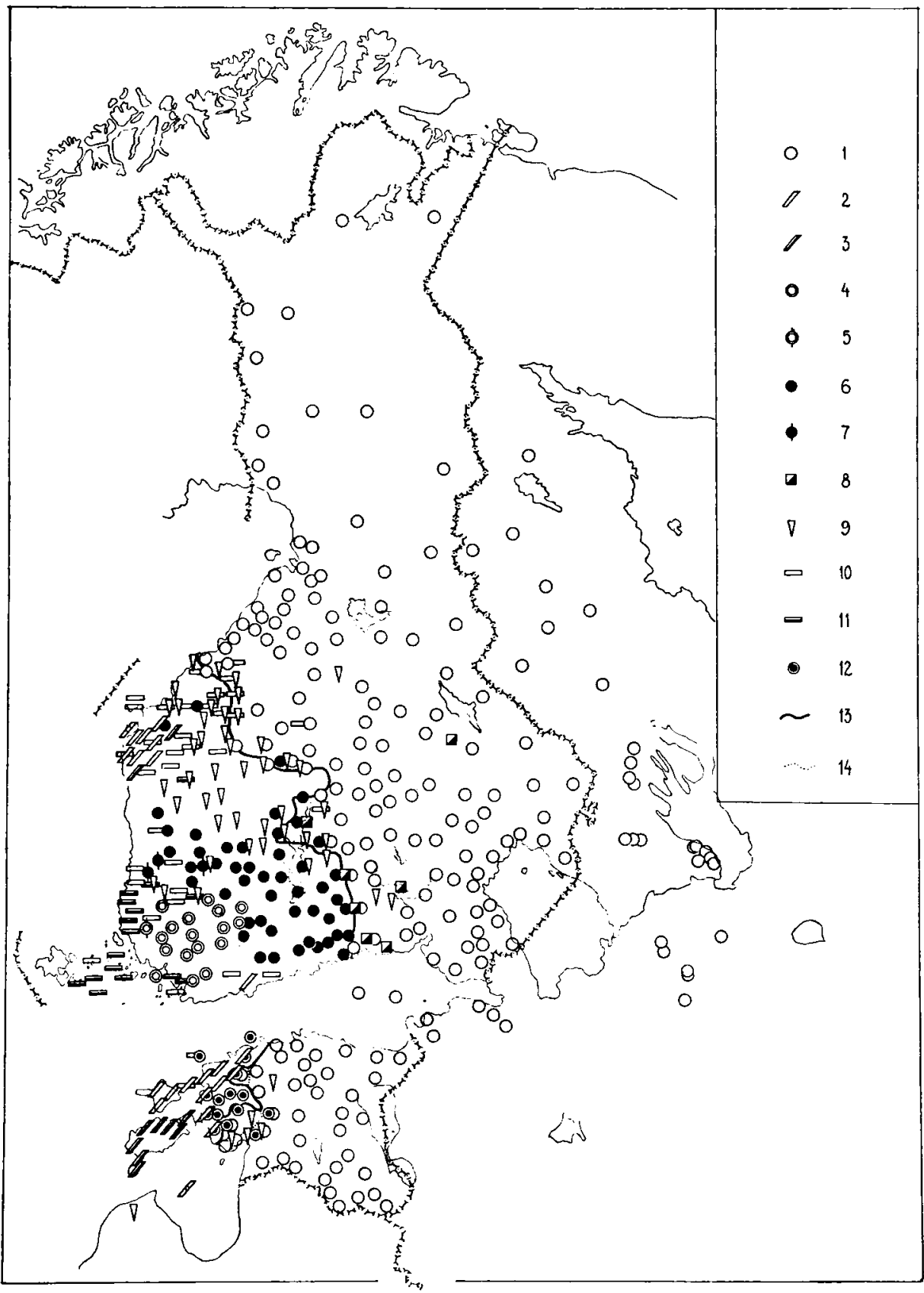


Das gesamte Verbreitungsgebiet desselben umfasst namentlich ausser Ostkarelien, das sich dem finnischen Territorium direkt anschliesst, ganz Grossrussland mit sowohl slavischen als nichtslavischen Gebieten und ist sogar bis zum innerasiatischen Festlande vorgestossen. Südlicher schwingt sich die Verbreitungsgrenze durch die Ukraine nach Westen, macht dann durch die östlichen Teile Polens wieder eine kräftige Wendung nach Norden, und strebt schliesslich durch das südliche Baltikum der Ostsee zu. ${ }^{1}$ Sowohl Baltikum als Finnland befinden sich also in der westlichen Peripherie eines riesengrossen und wenigstens heutzutage - wohl abgeschlossenen Verbreitungsgebietes. Westlich der Ostsee und des Bottnischen Meerbusens ist die Konstruktion mit Ausnahme der nördlischsten Teile Norrbottens in Schweden sowie Finnmark und Troms in Norwegen nicht mehr anzutreffen. Die letztgenannte Ausweitung des Verbreitungsgebietes ist indessen durch eine finnische Kolonisation erklärt worden ${ }^{2}$ und soll also als eine sekundäre Fortsetzung der östlichen Verbreitung aufgefasst werden.

Das oben abgegrenzte Verbreitungsgebiet ist von der neueren Forschung dermassen ausgedeutet worden, dass der osteuropäische Arbeitsschlitten nach den Ostseeländern als eine Novation aus dem Osten, und zwar vor allem durch die Vermittlung der Russen, eingedrungen sei. ${ }^{3}$ Es kann nicht geleugnet werden, dass das rezente Verbreitungsbild auf den ersten Blick auch tatsächlich für eine solche Auffassung spricht. Indessen ist die Frühgeschichte des osteuropäischen Schlittens in der westlichen Peripherie seines Verbreitungsgebietes noch so gut wie unbekannt. Aus Veranlassung der Publizierung der obenzitierten Verbreitungskarte hat VILKUNA die Frage gestellt, wie alt die Verbreitungsgrenze des osteuropäischen Schlittens in Finnland sein könnte. Einige weiteren Fragen in derselben Richtung lassen sich nicht vermeiden. Wo ist die früheste Grenze dieser Schlittenkonstruktion innerhalb des ostseefinnischen Sied-

1 H. HAGAr, Två slädtỵper i Estland. Svio-Estonica 1944-48. Lund 1948, S. $105-106$.

2 Gösta Berg, Sledges and wheeled vehicles. Uppsala 1935, S. 60. Asbuörn Nesheim. An Ancient Type of Sledge in Ullsfjord, Northern Norway. Arctica. Studia Ethnographica Upsaliensia XI, S. 49-50.

3 BERG, op.cit. S. 58 . 
lungsgebietes verlaufen? Müssen die Verbreitungsgebiete in Finnland und Estland als irgendwie historisch zusammenhängend angesprochen werden? Eine Antwort auf diese Fragen würde ganz warscheinlich auch zum Aufdecken der frühesten Verbreitungsbasis des osteuropäischen Schlittens in bezug auf Finnland und Estland führen, womit auch erst der Frage der kulturhistorischen Orientierung des Schlittentypus in diesen Ländern mit einer grösseren Sicherheit als bisher herangetreten werden kann. Es ist ausserdem nicht ausgeschlossen, dass die Behandlung des Problems eine grössere Tragweite über das rein Schlittenhistorische heraus erhalten würde und in die Problematik der Kulturverhältnisse des frühen ostseefinnischen Besiedlungsraumes überhaupt eingreifen könnte.

Im folgenden wird ein Versuch gemacht, einiges Licht über die Frühgeschichte des osteuropäischen Schlittens zu werfen und eine Antwort auf die oben aufgeworfenen Fragen zu finden. Das kann aber nicht geschehen, ohne dass die ganze Schlittenfrage in den östlichen Ostseeländern, bzw. in Estland und Finnland, in ihren Hauptzügen aufgerollt wird. Das zu tun dürfte es nicht unangebracht sein, da z.B. für Finnland bisher noch keine überschauliche Konstruktionsanalyse der Schlittenformen vorliegt. Zumal die Prioritätsfrage zwischen dem osteuropäischen Schlitten und den westlichen Konstruktionen ist daselbst noch nie auf Grund eines Detailmaterials geprüft worden. Es soll in diesem Zusammenhange erwähnt werden, dass der osteuropäische Schlitten laut einer älteren Auffassung, im Gegensatz zu dem oben angedeuteten Standpunkte, in den östlichen Ostseeländern noch kürzlich als die ältere von den beiden Konstruktionen angesehen wurde. ${ }^{1}$ Die folgende Behandlung geht deshalb von einer Verbreitungskarte heraus welche ganz Finnland und Estland nebst anderen ostseefinnischen Besiedlungsgebieten in Nordrussland umfasst, und welche somit erst die Voraussetzung herbeisckafft, den osteuropäischen Schlitten konstruktionsmässig auf einer breiten Front den westlichen Erscheinungen gegenüberzustellen. ${ }^{2}$

1 Vgl. z.B. I. Maxisex, Kulku- ja kuljetusneuvot. Suomen Suku II J. Helsinki 1934, S. 223.

2 Die Verbreitungskarte stütat sich in seinem estländischen Teil auf Materialien in ERM, AES, E.C. = Archiv der Ethnologischen Unter- 
Wir werden die Analyse der Verbreitungskarte über Sclllittenkonstruktionen mit einem kurzen Bericht über den osteuropäischen Schlitten einleiten. Der Schlitten wird in seiner normalen Form, Fig. 2, vor allem durch die hochgebogenen Kufenenden gekennzeichnet, welche - um der Ausrichtung derselben vorzubeugen - mit den ersten Ständern durch besondere Rutenbänder verbunden sind. An der Hand des letztgenannten Details ist eben die obenbehandelte, westliche Verbreitungsgrenze des Schlittens in Finnland und Estland auf der Karte, Fig. 1, verzeichnet worden. Die Ständer, deren Anzahl mindestens drei Paar beträgt, sind in den Kufen eingelassen und ron unten her festgekeilt, während die oberen Enden derselben ein Stückchen durch die entsprechenden Öffnungen in den Seitenstängen des Schlittens hervorreichen, wo sie gewöhnlich mit Hilfe von kleinen Querpflöckchen befestigt sind. Es ist zu bemerken, dass die Seitenstänge, welche normalerweise einen rechteckigen Querschnitt aufweisen, vorne nur bis ungefähr zu dem ersten Ständerpaar des Schlittens reichen, und in keinerlei unmittelbarem Kontakt mit den gekrümmten Kufenenden stehen. Die Verbindung zwischen den hochgebogenen Kufenenden und dem hinteren Teil des Schlittens wird dann erst mittelbar durch die obenerwähnten Rutenbänder besoryt. Ein überaus wichtiges Konstruktionsdetail ist weiter in den Querverbindungen zu erblicken, welche in einer besonderen Technik hergestellt werden. Die Querverbindungen bestehen nämlich aus langen Hölzern, welche gedämpft und dann derart um die oberen Teile der Ständer geschwungen werden, dass die nach innen zurückgebogenen Enden derselben in der Mitte des Schlittens an-, bezw. übereinander liegen kommen, wo sie entweder mit Holzpflöcken oder Nieten befestigt, oder

suchungen im Nordiska museet, Stockholm, Samml. von Prof. A. SA AREste und Feldaufz. des Verf.; die Belege für Finnland nebst angrenzenden östl. ostseefinnischen Besiedlungsgebieten aus den Samml. von $\mathrm{KM}=$ Finnisches Nationalmuseum, $\mathrm{SS}=$ Archiv der Wörterbuchstiftung, Helsinki, SKS = Finnische Literaturgesellschaft, Helsinki, und SLS = Svenska Litteratursällskapet, Helsinki. 


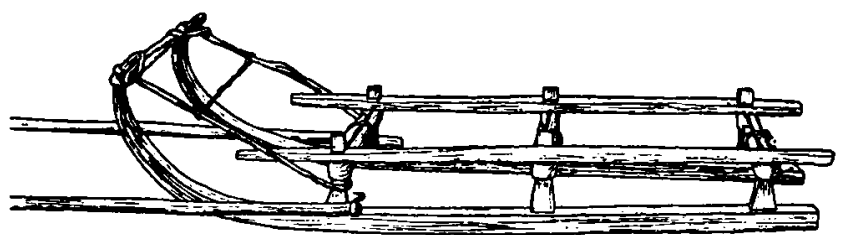

Fig. 2. Osteuropäischer Arbeitsschlitten aus Nord-Savo. Nach dem Photo von Ahti Rytkönen gez. Margaret Bengtsson.

auch einfach umbunden werden. Da die Querhölzer an den Verbindungspunkten bei den Ständern mit rechteckigen Einkerbungen versehen sind, die bei dem fertigen Zustande der Querverbindungen die Ständer dicht umschliessen, und da sie sich weiter auf die Absätze stützen, welche an den innenseiten der Ständer zurückgelassen worden sind, können sie zuletzt mit Hilfe der beiden, daraufliegenden Seitenstänge des Schlittens fest in ihrer Lage zurückgehalten werden. Es ist wohl zu bemerken, dass wir es hier mit einer einfachen, aber jedoch sinnreichen Konstruktion zu tun haben, wo alle wichtigsten Elemente des Schlittens: die Kufe, das Querholz und die Seitenstange, durch den Ständer zusammengebunden werden. Ein in derselben Technik hergestelltes Querholz befindet sich zuletzt als eine zusammenhaltende Verbindung zwischen den hochgebogenen Kufenspitzen vorne. - Das Resultat ist eine ganz ungemein geschmeidige und haltbare Konstruktion, wo alle Bestandteile fest, aber zugleich elastisch miteinander verbunden sind. In dieser Normalgestalt kann der Schlitten überall innerhalb seines oben abgerissenen Verbreitungsgebietes vorgefunden werden. Ich lasse hier indes einige lokalgeprägte Einzelheiten der Konstruktionstechnik aus, denen entweder bloss eine untergeordnete Bedeutung zukommt, oder die erst später zu besprechen sind. Es muss aber gleichzeitig betont werden, dass es neben der vorgeführten Normalvariante noch eine weit primitivere Form desselben Schlittens gibt, die innerhalb des gesamten Verbreitungsgebietes ihre eigene Verbreitung aufweist. Diese Variante soll jedoch erst späterhin in die Erörterung eingezogen werden. 
Man braucht nur einen flüchtigen Blick auf die Verbreitungskarte über Schlittenkonstruktionen, Fig. 1, zu werfen, um gewahr zu werden, dass das Verbreitungsbild als ganzes genommen das einheitlichste Gepräge im Osten des kartierten Gebietes aufweist. Es ist hier, in Ostkarelien, in den lüdischen Besiedlugsgebieten zwischen dem Ladoga- und Onegasee, weiter südlich und südwestlich in den wepsischen, ingrischen und wotischen Gebieten, sowie schliesslich im östlichen Finnland und Estland, wo der soeben beschriebene osteuropäische Schlitten einsam dominiert. Je weiter nach Westen man vorrückt, desto zahlreicher werden Einschläge von andersartigen Konstruktionen, die von dem osteuropäischen Schlitten abweichen und das Verbreitungsbild allmählich zu einem vermischten verwandeln. Auf der anderen Seite der Westgrenze des osteuropäischen Schlittens, wo derselbe Schlitten selbst also nicht mehr vorkommt, tritt uns schliesslich ein ganzes Gewimmel von verschiedenen Konstruktionen entgegen. Man konstatiert mit anderen Worten, dass der westliche Teil des Gebietes, wo der Antipode des osteuropäischen Schlittens zu finden sein sollte, in seiner Konsistenz garnicht einheitlich, sondern aus mehreren kleinen Verbreitungsgebieten zusammengesetzt ist. Um den osteuropäischen Schlitten in eine richtige kulturhistorische Perspektive stellen zu können, müssen die Schlittenvarianten in allen diesen Verbreitungsgebieten im Westen erst kurz analysiert werden.

Wir greifen zuerst eine Konstruktion heraus die in mehreren, von einander weit isolierten Gruppierungen in der äussersten Peripherie des Westens vorkommt. Der Schlitten, Verbreitungskarte Fig. 1: 2-3, erscheint als eine wohl abgegrenzte Lokalgruppe in einigen Küstenkirchspielen Süd-Ostbottniens, dann, auf der Karte nur durch einen vereinzelten Beleg verzeichnet, im mittleren Uusimaa am Finnischen Meerbusen, und schliesslich, wieder als eine ganz umfangsreiche Gruppe, auf den westestnischen Inseln, von wo aus das Verbreitungsgebiet unmittelbar auch nach den Küstenstrichen des estnischen Festlandes herübergreift. Es ist offenbar, dass man hier auf eine Randerscheinung stiesst, welcher schon an der Hand ihres Verbreitungsgebietes innerhalb der vorliegenden zwei Länder ein 


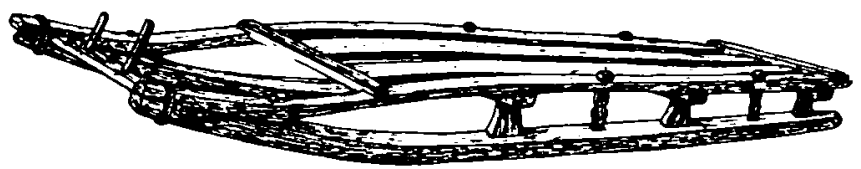

Fig. 3. Arbeitsschlitten aus Petlax, Finnland. SLs 548. Nach dem Photo gez. Margret Bengtsson.

beträchtliches Alter zugesprochen werden könnte. Der Schlitten, welcher in bezug auf gewisse Details in der Grundkonstruktion nicht ganz einheitlich auftritt, wird hier in vier exemplaren abgebildet, von welchen die zwei ersten, Fig. 3 und 4, aus Ostbottnien in Finnland, das dritte, Fig. 5, aus dem Kirchspiel Keila auf dem nordwestestnischen Festlande, und das vierte, Fig. 6, von der Insel Öse] bei der estnischen Westküste, herstammt.

Die vorgeführten Konstruktionen scheinen schon auf Grund ihrer äusseren Merkmale dem osteuropäischen Schlitten ganz ungleich. Es ist geeignet, zuerst das Exemplar aus dem finnlandschwedischen Küstenkirchspiel Petlax in Ostbottnien etwas näher ins Auge zu fassen. Die Abbildung, Fig. 3, repräsentiert einen niedrig gebauten Schlitten, dessen Kufen vorne nur haum merklich gekrümmt sind. Die Oberfläche des Schlittens erscheint deshalb flach. Im Gegensatz zum hohen Vorderteil beim osteuropäischen Schlitten läuft hier der Vorderteil eher schräg nach unten zu. Die Seitenstänge strecken sich längss des ganzen Schlittens hin und sind vorn unmittelbar mit den Kufen verbunden. Die grösste Aufmerksamkeit ist indes den Querverbindungen und ror allem dem Ständersystem zuzuwenden, welche von den entsprechenden Details bei dem osteuropäischen Schlitten vollständig abweichen. Wie es von der Abbildung hervorgeht, ist der Schlitten aus Petlax mit fünf Paar Ständer ausgerüstet. Dieselben sind doch, was die Form betrifft, untereinander garnicht gleich, sondern können leicht in zwei verschiedene Gruppen aufgeteilt werden. Die eine Gruppe besteht aus zwei Paar breiten, kräftigen Stollen, die oben von klotzartigen Querhölzern zusammengehalten werden, in welche sie fest eingezapft sind. Diese Ständer stehen in kein- 
erlei direktem Kontakt mit den Seitenstängen des Schlittens, es ist nicht ihre Aufgabe, etwa die Verbindung zwischen den Seitenstängen und Kufen herzustellen. Die oberen Enden der Ständer reichen garnicht durch die massiven QuerhöIzer in die daraufliegenden Seitenstänge hinein, weshalb sie auch kein verbindendes Element in der Schlittenkonstruktion darstellen können. Ihr Zweck ist vielmehr, nur eine Stütze für die Querhölzer zu bieten und damit den ganzen Schlittenboden aufzutragen. Wir möchten sie daher in der Fortsetzung als Trags t ä n$\mathrm{d}$ e $\mathrm{r}$ bezeichnen. Die Aufgabe, als ein verbindender Bestandteil zwischen den Kufen und Seitenstängen zu dienen, und damit den ganzen Schlitten zu einer festen Konstruktion zusammenzuschliessen, kommt dagegen erst der anderen Gruppe von Ständern zu, welche in einer Anzahl von zwei Paar vorhanden sind. Diese Ständer, die bei dem behandelten Schlittenexemplar übrigens eine verzierende Profilierung aufweisen, sind im Vergleich mit den Tragständern von einer weit dünneren und feineren Beschaffenheit. Im Gegensatz zu den letzterwähnten reichen sie weiter durch die entsprechenden öffnungen in den Seitenstängen des Schlittens empor, wo sie mit der Hilfe von dicken, oberhalb der Seitenstänge liegenden Knöpfen zurückgehalten werden. Da nun die Ständer andererseits in die Kufen eingelassen und mit Querpflöckchen an denselben befestigt sind, wirken sie wie eine Art Klemmen, welche die Seitenstänge und Kufen miteinander fest zusammenschliessen. Irgendwelche Querverbindungen sind bei diesen Ständern überhaupt nicht vorhanden. Es muss deshalb ganz ausser Rede gestellt werden, dass sie, wie es bei der vorhergehenden Ständergruppe der Fall war, etwa zum Auftragen des Schlittenbodens beitragen könnten. Ihre einzige Aufgabe in der Schlittenkonstruktion kann demnach nur diejenige sein, die Seitenstänge mit den Kufen zu verbinden. Diese Gruppe von Ständern nennen wir deshalb B i n d e s t änd e r.

Bei den analysierten Schlitten aus Petlax tritt also eine Zweiteilung der Ständer nach ihrer Funktion zum Vorschein. Diese konstruktive Eigenart - nebst den übrigen, oben besprochenen Typmerkmalen - kann innerhalb des oben abgerissenen Verbreitungsgebietes überall festgestellt werden. Man 


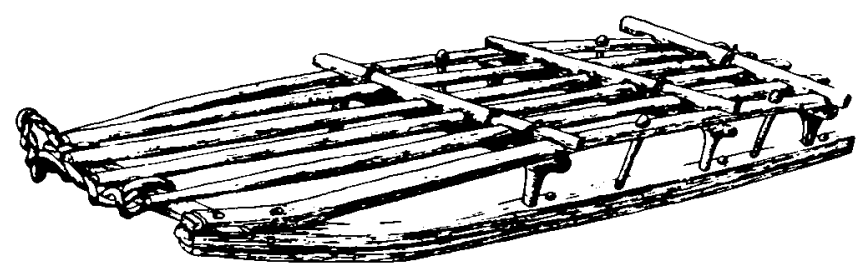

Fig. 4. Arbeitsschlitten aus Närpes, Finnland. KM Kk 1178: 327. Nach dem Photo gez. Margret Bengtsson.

darf dabei jedoch nicht, sobald es andere Lokalgruppen, oder sogar gewisse andere Kirchspiele einer und derselben Lokalgruppe des Verbreitungsgebietes gilt, mit einer vollständigen Identität aller Einzelheiten rechnen. Andere Beispiele desselben Schlittens, die bis zu den kleinsten Details mit dem soeben behandelten Exemplar übereinstimmen, können zwar noch aus einigen Nachbarkirchspielen des Petlax herangezogen werden. ${ }^{1}$ Es gibt auch Exemplare, bei denen zwar einige kleinere $A b-$ weichungen von dem oben angeführten Typbeispiel wahrgenommen werden können, die aber im wesentlichen immer noch denselben Umriss aufweisen. ${ }^{2}$ Aber schon in einem etwas südlicher liegenden Kirchspiel derselben Landschaft, namentlich Närpes, tritt ein Schlitten hervor, welcher gewisse bemerkenswertere Abweichungen aufweist, die näher ins Auge gefasst werden müssen.

Der Schlitten, Fig. 4, erscheint in seinem allgemeinen Umriss dem vorhergehenden gleich. Bei den Tragständern, deren Anzahl ebenfalls drei Paar beträgt, nebst den diese verbindenden Querhölzern, ist hier aber ein spezieller Zug wahrzunehmen, dem wir beim früher behandelten Schlittenexemplar nicht begegnet sind. Nur das hinterste Paar der Tragständer erscheint hier nämlich Tragständern an jenem Schlitten aus

1 Malax, FMK $63=$ Folkmålskommissionen, Svenska Litteratursällskapets Folkkultursarkiv, Helsingfors; Övermark. SLS 547; Korsnäs, FMK 142; Bergö, FMK 63. - Für das finnlandschwedische Material bin ich fil.dr. RAGNa Aнцвӓск, Helsingfors, zu Dank verpflichtet.

2 Z.B. Vähäkyrö, KM Kk 1971: $124=$ Bildarchiv der Volkskundlichen Abteilung im Finnischen Nationalmuseum. 
Petlax identisch. Die vorderen zwei Paare sind dagegen dermassen hergestellt worden, dass die Ständer aus natürlichen, an den Querhölzern angewachsenen Ästen bestehen. Die Ständer weisen dementsprechend eine fast unbearbeitete Form mit rundem Querschnitt auf. Ein anderer Unterschied ist bei den Bindeständern zu erblicken. Diejenigen sind hier der Form nach nämlich nicht flach, sonder bestehen aus dünnen, runden Stäbchen, die oben ebenfalls mit jenen dicken Knöpfen versehen, unten aber in den Kufen nur eingebohrt und festgekeilt sind, ohne mit irgendwelchen Querpflöckchen befestigt zu sein. Beiden soeben besprochenen Konstruktionsdetails kommt eine wichtige schlittenhistorische Rolle zu. Besonders zu der bei diesen Schlitten angetroffenen Tragständerkonstruktion, welche übrigens auch auf der Verbreitungskarte einen Ausdruck findet, wird noch späterhin mehrmals zurückzukommen sein. Die Konstruktion ist ausser dem Kirchspiel Närpes noch aus dem etwas nördlicher liegenden Kirchspiel Isokyrö bezeugt. ${ }^{1}$ Die runden Bindestäbchen, welche auf der Karte nicht besonders verzeichnet sind, treten noch auf einigen anderen Stellen Ostbottniens auf, ${ }^{2}$ können aber dagegen bei dem vereinzelten Beleg desselben Schlittens im mittleren Uusimaa im Süden nicht mehr vorgefunden werden. Auch weicht dieser Schlitten durch gewisse andere Einzelheiten von den ostbottnischen Exemplaren ab. $^{3}$

Mit verschiedenen Detailunterschieden hat man weiter zu rechnen, wenn man Finnland verlässt, und sich dem südlichen Teil des Verbreitungsgebietes in Westestland zuwendet. Eine ganz typische Konstruktion für die nordwestliche Festlandsküste des Landes wird in dem aus Kirchspiel Keila abgebildeten Ochsenschlitten, Fig. 5, zu erblicken sein. Der Schlitten, dessen

1 SS 109.

2 I s o k y rö, J u r va, SS 109; La i h a, ebenda, auch KM Sk 45: 19 = Samml. zum Atlas über Finnland im Finnischen Nationalmuseum, und SKS E 35, 42 = Volkskundliche Samml. der Finnischen Literaturgesellschaft, Helsinki.

${ }^{3}$ So ist die Verteilung der Bindeständer, die hier also von einer einfachen flachen Form sind, im Verhältnis zu den Tragständern eine ganz andere, $\mathrm{k}$ y r k s lä t $\mathrm{t}, \operatorname{SLS} 568$. 


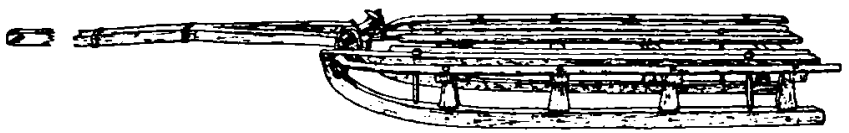

Fig. 5. Ochsenschlitten aus Keila, Estland. Nach dem Photo von Kustaa Vilkuna gez. Margret Bengtsson.

()berfläche auf beiden Seiten durch bogige Flügelstänge erweitert ist, weist im übrigen denselben niedrigen und flachen Bau auf, der für die Exemplare aus Finnland charakteristisch war. Man unterscheidet auch ganz leicht die kräftigen Tragständer, welche in die klotzartigen Querhölzer eingezapft und hier in einer Anzahl von vier Paar vorhanden sind. Die Bindeständer, von welchen ein Paar ganz vorne, und ein anderes unmittelbar vor den hintersten Tragständern zu finden ist, sind der Form nach rund und ähneln in allen Einzelheiten denjenigen am Schlitten aus Närpes in Ostbottnien. Dieselben Bindeständer in ihrer Stäbchenform sind innerhalb des ganzen Verbreitungsgebietes der Schlittenvariante in Estland bezeugt. Sie sind jedoch nicht alleinherrschend. Neben den runden Bindestäbchen kommen auch flache Bindeständer vor, und zwar in einer Kombination miteinander in ein und demselben Schlitten. Die gewöhnlichste Konstruktion dieser Art, welche aus dem nördlichen Teil des Verbreitungsgebietes auf dem Festlande nebst den Westinseln belegt werden kann, liegt in der Form des älteren, jetzt schon im Verschwinden begriffenen, Pferdeschlittens vor, wo ausser den runden Bindestäbchen im hinteren Teil des Schlittens stets auch ein Paar flache Bindeständer ganz. vorne beobachtet werden kann. Die genannten Bindeständer welche von einer ziemlich kräftigen Ausführung sind, dienen zugleich dazu, die Femerstänge festzuhalten.' Neben dieser

1 Die runden Bindestäbchen bezeugt, Festland: $R$ is ti, HaGar, op.cit., S. 116, Fig. 7; N is si, ERM Kv 54: 157 $=$ Antworten der Korrespondenten im Estnischen Nationalmuseum; L ä ä n e - N i g u l a, Samiml. von Prof. A. SaAreste; R i d a la, briefl. Mitteil. vom Herrn A. Máker, Schweden, den 15. 3. 54; H a $\mathrm{n}$ i l a, briefl. Mitteil. vom Herrn J. Päri, Schweden, den 21. 3. 54; Var b la, briefl. Mitteil. vom Herrn W. Altmäe, Schweden, den 28. 3. 54. - Inseln: Mohn, 


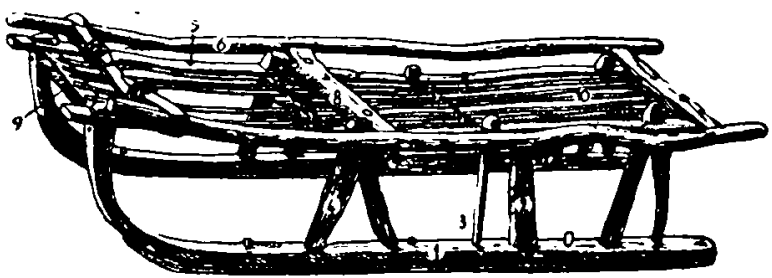

Fig. 6. Arbeitsschlitten aus Kihelkonna, Ösel, Estland. ERM A 346: 5.

Konstruktion kommt sodann schliesslich - obwohl ganz selten - noch eine weitere vor, wo die flachen Bindeständer ausser vorne auch im hinteren Teil des Schlittens, doch immer nur in Kombination mit den runden Bindestäbchen, angetroffen werden können. Ein Schlitten dieser Art wird hier aus dem Kirchspiel Kihelkonna auf Ösel abgebildet, Fig. $6^{\mathbf{1}}$. Bei diesem Pferde schlitten, der wohl ohne einen näheren Kommentar bloss an Hand der Abbildung studiert werden kann, tritt indes wieder dieselbe Tragständerkonstruktion auf, von welcher wir schon oben bei der Besprechung des Schlittens aus Närpes in Ostbottnien gesprochen haben. Jedes Tragständerpaar, von welchen es drei gibt, ist bei dem angeführten Schlitten nämlich dermassen hergestellt worden, dass der eine von den beiden Ständern aus einem natürlichen, an dem Querholze angewachsenen Aste

Samml. von Prof. A. SaAreste; R u n ö Aufzeichn. des Verf. im J. 1954 in Lidingö, Schweden, nach Herrn J. Österman aus Runö. Zu dem estlandschwedischen Küsten- und Inselgebiet vgl. weiter C. Russwur M, Litographierte Beilage zu Eibofolke oder die Schweden an den Küsten Ehstlands und auf Runö. Reval 1855, Taf. XI: 8. - Runde Bindestäbchen nebst einem Paar flachen Bindeständern am vorne des Schlittens bezeugt, Festland: Ke i la, Samml. von Prof. K. Vilkuna, Helsinki; N o a r o o ts i (Nuckö), E. U. Inseln: Ösel: M u s t j a I a, Samml. von Prof. A. SaAreste; Pö ide, AES L; K a r ja, ERM Pd 463: 8 = Bildarchiv im Estnischen Nationalmuseum; $\mathbf{J}$ a a $\mathbf{n} \mathbf{i}$, EAS $\mathrm{KT}$ XI: 111; A n sek üla, Samml. von Prof. A. SaAreste; Jä ma ja, ebenda, D a g ö, Hagar, op.vit., S. 113; W o r m s ö, Aufzeichn. des Verf. im J. 1947 auf der Insel Ramsö, Schweden, nach IIerrn J. ApPELBLOM aus Wormsö.

1 Die Konstruktion noch aus dem Kirchsp. K ä in ä auf Dagö belegt, KM Kk 201: 99, 100. 
besteht, während nur der andere in dasselbe eingelassen ist. Es liegt hier zwar im Vergleich mit dem Beispiel aus Närpes derjenige Unterschied vor, dass dort nicht nur der eine, sondern die beiden Ständer aus den natürlichen Aststümpfen bestehen, doch wird man sich kaum irren, wenn man die beiden Erschei-

Fig. 7. Astständerkonstruktion aus Pöide, Ösel, Estland. AES.

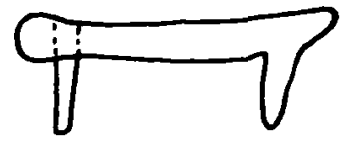

nungen als Varianten einer und derselben Konstruktion hinstellt. Da die Konstruktion von der Schlittenabbildung aus Kihelkonna nicht ganz klar hervorgeht, bilde ich sie noch in einer schematischen Ausführung aus einem anderen Kirchspiel Ösels, Fig. 7, ab. ${ }^{1}$

Die beiden vorgeführten Belegstellen repräsentieren den westlichsten bzw. den östlichsten Kirchspiel Ösels. Auf der Verbreitungskarte sind - wie auch schon oben hingedeutet wurde die Belege über diejenigen Schlitten, bei welchen die behandelte Tragständerkonstruktion vorkommt, besonders verzeichnet worden, Fig. 1: 3. Man kann daraus entnehmen, dass die Konstruktion ganz Ösel umfasst, und dass sie durch ein paar Belege auch in der ostbottnischen Enklave der Schlittenvariante repräsentiert ist. Wir werden späterhin dieselbe Tragständerkonstruktion noch innerhalb der Verbreitungsgebiete anderer Schlittenvarianten in Finnland vorfinden können. Die Konstruktion kann deshalb kaum als eine lokalgeprägte oder gar zufällige Erscheinung abgefertigt werden. Dieselbe Auffassung wird noch um ein bedeutendes unterstützt, wenn wir - wie es in der Fortsetzung geschehen wird - beweisen können, dass die in Frage stehende Konstruktion sogar weit ausserhalb der Grenzen des Baltikums und Finnlands wieder auftaucht. Man kommt unter solchen Umständen also nicht umhin, der berührten Tragständerkonstruktion ein weitumfassendes, aber zur gleichen Zeit zersplittertes Verbreitunsgebiet, und damit

1 P ö id e, AES L. 
auch ein bedeutendes Alter zuzusprechen. Der behandelten Konstruktion mit ihrem angedeuteten Hintergrund kommt nun, was die in den Blickpunkt gezogene westliche Schlittenvariante in Finnland und Estland angeht, eine ganz entscheidende konstruktionshistorische Rolle zu. Es dürfte nämlich nicht abzusprechen sein, dass das Vorhandensein der besonderen Bindeständer und somit der ganzen Zweiteilung des Ständersystems bei der Schlittenvariante durch sie als eine konstruktive Notwendigkeit erscheinen muss. Soweit das Querholz mit den an ihm angewachsenen, natürlichen Astständern der Schlittenvariante eigen und bei ihr alt ist, können die für sich stehenden, besonderen Bindeständer irgendwelcher Art immer vorausgesetzt werden. Denn ein Ständerpaar, das aus Ästen gebildet wird, kann ja nicht selbst ein Bindeelement zwischen den Seitenstängen und Kufen herstellen, da die Ständer in diesem Falle natürlicherweise überhaupt nicht durch das Querholz emporreichen können. Einer von den grundlegenden Unterschieden zwischen dem osteuropäischen und dem hier behandelten Schlitten aus dem äussersten Westen wird damit ins klarste Licht gerückt. Die zwei verschiedenen Funktionen, die im Osten zufolge einer speziellen Technik der Querverbindung von ein und demselben Ständer geleistet werden konnten, erscheinen hier - ebenfalls von einer speziellen Technik desselben Konstruktionsdetails bedingt - auf zwei verschiedene Arten von Ständern übertragen. Dass die in Frage stehende Konstruktion - sie wird am treffendsten A st stä n derkonstrukt i o n zu nennen sein - in Finnland und Estland alt ist, glaubten wir schon oben annehmen zu dürfen. ${ }^{1}$ Zur Beweisfüh-

1 Es widerspricht unsere Auffassung nicht, dass man auf der anderen Seite aus anderen Gebieten sogar frühhistorische Belege derselben Schlittenkonstruktion vorführen kann, wo man von der primitiven Astständerkonstruktion nichts verspürt. Ich ziele hier vor allem auf den hochentwickelten Schlitten aus dem Osebergsfunde, der noch später zu besprechen sein wird. Solche Gegensätze in der Entwicklung sind nicht geeignet $\mathrm{C}$ berraschung hervorzurufen, sowejt man mit reliktmässigen Gebieten von Bauernkultur zu tun hat. Es könnte leicht erwiesen werden, wie die Technik, die Ständer aus besonderen Stücken herzustellen, in Finnland auf Kosten der Astständerkonstruktion noch in der Gegenwart Boden gewinnt, z.B. Isokyrö, SS 109. 


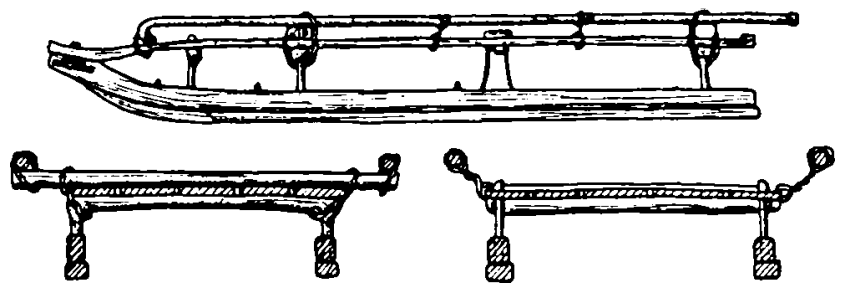

Fig. 8. Arbeitsschlitten aus Mynämäki, Finnland. Nach Kustaa Vilkuna. ${ }^{30}$

rung der alten Provenienz derselben in unserem Gebiet kann aber noch ein frühhistorisches und vergleichendes Material beigebracht werden. Wir kommen auf dies etwas später zurück.

Wir haben uns bei der betrachteten Schlittenvariante, die wir in der Fortsetzung "der eigentliche Bindeständerschlitten» nennen möchten, ziemlich ausführlich aufgehalten, weil sie sich als eine Schlüsselkonstruktion bei der Analyse der übrigen westlichen Schlittenvarianten in Estland und Finnland auswerten lässt. Wie es hervorgegangen sein dürfte, tritt dieser Schlitten innerhalb seines zersplitterten Verbreitungsgebietes durchaus nicht vollständig einheitlich auf. Ich habe dabei noch das Verhältnis zwischen Trag- und Bindeständern, was nämlich ihre Anzahl und besonders ihre Verteilung zu einander angeht, nicht zu einer näheren Betrachtung herangezogen. Wenn man es tun wollte, würde sich als Resultat ein ziemlich buntes Bild ergeben. ${ }^{1}$ Es besteht aber auf der anderen Seite kein Zweifel, dass es hier um eine Gruppe von Schlitten handelt, die von einem gemeinsamen Konstruktionsprinzip bestimmt wird. Die Zweiteilung des Ständersystems kann überall festgestellt werden, die Tragständer treten mit klotzartigen Querhölzern ausgerüstet oder auch in der Gestalt von Astständerkonstruktion auf, während bei den Bindeständern keine Querverbindungen vorhanden sind. Die flache Oberfläche des Schlittens mit den unmittelbar bis zu den schwach gekrümmten Kufenenden hinlaufenden Seitenstängen ist ebenfalls überall unverkennbar. Manche von diesen Typmerkmalen werden bei den übrigen

1 Vgl. Hagar, op.cit., S. 113, wo einige diesbezügliche Notizen aus Ösel und Dagö angeführt worden sind. 
Schlittenvarianten im Westen und weiter ostwärts wieder auftauchen, andere werden verschwinden, sobald man das soeben behandelte, zersplitterte Verbreitungsgebiet verlässt, einige werden aber noch im Osten, auf der anderen Seite der Westgrenze des osteuropäischen Schlittens, anzutreffen sein. Von einer solchen Einheitlichkeit der Konstruktionen, die früher besonders bei dem osteuropäischen Schlitten und dann auch immer noch bei dem eben behandelten eigentlichen Bindeständerschlitten in den beiden Ländern zu Tage gelegt werden konnte, ist in der Fortsetzung jedoch keine Rede mehr. Der springende Punkt bei der Behandlung der zwischen dem äussersten Westen und dem Osten liegenden Gebieten wird derjenige sein, dass die daselbst auftretenden Schlittenvarianten auf den beiden Seiten des Finnischen Meerbusens im grossen und ganzen nicht miteinander zusammenfallen, dass sie aber doch aus gemeinsamen konstruktionsmässigen Voraussetzungen hergeleitet werden können. Wir haben mit anderen Worten mit einer Reihe von Kontaminationsformen zu tun.

Estland und Finnland müssen deshalb in der Fortsetzung gesondert behandelt werden. Wir wenden uns zuerst Finnland zu. Im Südwesten des Landes, namentlich in einem beträchtlichen Teil vom Eigentlichen Finnland, in den südlichsten Kirchspielen vom unteren Satakunta, und in dem südwestlichen Teil der Landschaft Häme tritt ein Schlitten hervor, welcher der obenbehandelten Variante besonders nahe steht, Fig. 1:4-5. Diese Variante kommt in Estland nicht vor. Sie wird hier in zwei Exemplaren abgebildet, von welchen das eine, Fig. 8, aus dem Kirchspiel Mynämäki im Eigentlichen Finnland im Westen, und das andere, Fig. 9, aus dem Kirchspiel Renko in Häme im Osten des Verbreitungsgebietes herstammt. Die Abbildung aus Mynämäki stellt den Schlitten in Seitenansicht nebst zwei Querschnitten dar. Wir finden hier im grossen und ganzen dieselbe niedrige und flache Schlittenform mit langen Seitenstängen vor, die schon oben beschrieben wurde. Auch die Zweiteilung des Ständersystems tritt klar zum Vorschein. Die Tragständer sind in drei Paar vorhanden und repräsentieren die von oben her bekannte Astständerkonstruktion, welche durch den Querschnitt links auf der Abbildung beleuchtet wird. 


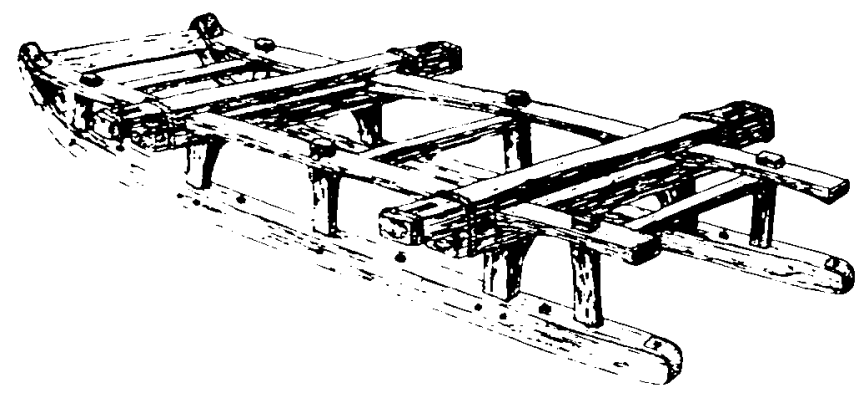

Fig. 9. Arbeitsschlitten aus Renko, Finnland. KM Kk 2363: 583. Nach dem Photo gez. Margret Bengtsson.

Diese Konstruktion kommt, wie es aus der Verbreitungskarte hervorgeht, nur in der westlichen Peripherie des Verbreitungsgebietes vor. In der Mitte des Schlittens erblickt man ein Paar flache, mit dicken Knöpfen ausgerüsteten Bindeständer, welche durch den Querschnitt rechts im einzelnen dargestellt sind. Es ist hier, wo diejenige Abweichung von der vorherbeschriebenen Konstruktion zur Erscheinung kommt, die uns veranlasst hat, den Schlitten als eine besondere Variante zu kartieren. Die Bindeständer werden nämlich von einer Querverbindung zusammengebunden, die aus einer ganz schmalen Leiste besteht und durch die entsprechenden, in den Ständern eingemeisselten Öffnungen hindurchgezogen ist, wo sie mit Hilfe von Querpflöckchen zurückgehalten wird. Das aus Renko abgebildete Exemplar weicht von dem soeben besprochenen nur insofern ab, dass die Proportion zwischen den beiden Ständergruppen eine andere ist, und dass die Astständerkonstruktion nicht vorkommt. Die Querleiste zwischen den Bindeständern kann auch hier beobachtet werden. Wir stellen hier also ein Detail fest, das bei der vorherbehandelten Schlittenvariante nicht vorgefunden werden konnte. Es steht aber zugleich ausser Zweifel, dass dieser Abweichung bei einem typologischen Vergleich nur eine untergeordnete Rolle zukommt. Wir haben mit anderen Worten eine Abart vom eigentlichen Bindeständerschlitten vor uns, deren Verbreitungsgebiet sich dem vereinzelten Beleg über demselben Schlitten im mittleren Uusima anschliesst 
und so das gesamte Verbreitungsgebiet der ganzen Konstruktion im Südwesten des Landes um ein beträchtliches erweitert.

Östlich und nördlich von den Gebieten wo die soeben besprochene Konstruktion bezeugt wurde, fällt weiter eine andere Schlittenvariante auf, deren Verbreitungsgebiet Mittel- und Ost-Uusimaa, einen grossen Teil von Häme und beträchtliche Teile ron Ost- und Mittel-Satakunta umfasst, Fig. 1:6-7. Im östlichen Häme überschreitet die Variante an ein paar Stellen etwas die Westgrenze des osteuropäischen Schlittens, und durch die südlichen Teile Ostbottniens stiesst sie, obschon nur durch vereinzelte Belege bezengt, bis zum Bottnischen Meerbusen ror. Diese Schlittenvariante nimmt auf der Karte im Verhältnis zu den obenbehandelten Varianten eine zentrale Stellung ein. Die Basis des Verbreitungsgebietes liegt im östlichen Häme und Uusimaa im Osten, während die Spitze durch die Landschaften Satakunta und Süd-Ostbottnien tief nach Westen vordringt. Es ist mit anderen Worten ein Verbreitungsgebiet, das die beiden obenbehandelten, konstruktionsmässig miteinander nahe zusammengehörenden Variantgruppen in Süd-Ostbottnien einerseits, und im Eigentlichen Finnland nebst den angrenzenden Teilen von Häme und Satakunta andererseits, von einander abtrennt. Wie sieht diese agressive Schlittenvariante aus?

Sie wird hier aus dem Kirchspiel Hausjärvi im südlichen Häme, Fig. 10, und aus Liljendal im östlichen Uusimaa, Fig. 11, abgebildet. Das Exemplar aus Häme repräsentiert einen Schlitten mit einem etwas erhöhten Vorderteil, ist aber mit denselben langen, über den ganzen Schlitten hinlaufenden Seitenstängen, welche schon aus dem vorigen bekannt sind, ausgerüstet. Im zweiten und vierten Ständerpaar erkennen wir leicht dieselben kräftig gebauten ständer die oben als Tragständer bezeichnet wurden. Die klotzartigen Querhölzer, in welche die Ständer eingelassen sind, werden hier nur von daraufliegenden Holzblöcken mit aufrechtstehenden Stäbchen überdeckt, welche dem Überbau des Schlittens zugehören und in diesem Zusammenhange also nicht in Betracht kommen. Bei den übrigen Ständern, von welchen drei Paar vorhanden sind, beobachten wir aber ein Detail, das bei den bisher betrach- 

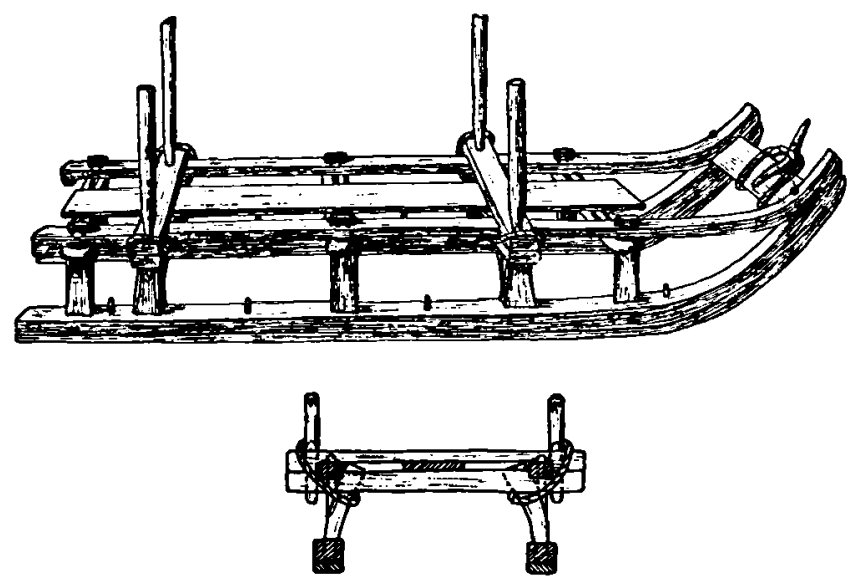

Fig. 10. Arbeitsschlitten aus Hausjärvi, Finnland. SS 109.

teten westlichen Schlittenvarianten noch nicht vorgefunden werden konnte. Es ist die, in einer speziellen Technik hergestellte, um die Ständer geschwungene Querverbindung, die oben bei dem osteuropäischen Schlitten beschrieben und als ein charakteristischer Bestandteil dieser Schlittenform hingestellt wurde. Man stellt hier also ein östliches Konstruktionsdetail fest, das, von seinem ursprünglichen Zusammenhange gleichwie ausgerückt und weit nach Westen vorgeschoben, sich einer ganz anderen Grundkonstruktion angeschlossen und eine Mischform von Schlitten hervorgerufen hat. Denn es ist ganz sicher, dass die in Frage stehende Schlittenvariante durch ihre ausschlaggebenden Typmerkmale sich immer noch sehr nahe den obenbetrachteten westlichen Formen anschliesst. Ausser den langen Seitenstängen bezeugt davon vor allem die Zweiteilung des Ständersystems, welche aus dem abgebildeten Querschnitt des Schlittens klar hervorgeht. Es ist daraus zu entnehmen, dass den obenberührten Tragständern, obwohl sie hier ein Stückchen durch die massiven Querhölzer hindurchreichen, keine Rolle als ein etwaiges Bindeelement in der Konstruktion zukommt. Die Tragständer beugen sich nämlich etwas nach innen ab und schiessen den Seitenstängen vorbei, während nur die anderen, mit den geschwungenen Querverbindungen ausgerüsteten 
Ständer durch die Seitenstänge hervorragen und oberhalb derselben mit Querpflöckchen befestigt sind. Wir finden also dieselbe Konstruktion mit einem aufgeteilten Ständersystem vor uns, die schon oben aus dem äussersten Westen bezeugt wurde. Der Unterschied liegt nur darin, dass die Bindeständer ein neues Komplement - die von dem osteuropäischen Schlitten bekannte Querverbindung - erhalten haben.

Die in der Frage stehende Schlittenvariante soll also als eine Kontaminationsform zwischen dem osteuropäischen Schlitten und der obenbehandelten westlichen Grundkonstruktion aufgefasst werden. Dass die letztgenannte früher über ein weit grösseres Gebiet verbreitet gewesen und höchst wahrscheinlich auch den Bereich der gegenwärtigen Variante bedeckt haben muss, kann schon aus ihrem reliktmässigen Verbreifungsbilde entnommen werden. Die Annahme kann dazu noch durch rein typologische Kriterien unterstützt werden. Das andere, aus Liljendal in Ost-Uusimaa herstammende Exemplar derselben Schlittenvariante, Fig. 11, weist nämlich gewisse Einzelheiten auf, die sich noch direkt zu dem westlichen Bindeständerschlitten anschliessen lassen. Erstens treten die mit den geschwungenen Querverbindungen ausgerüsteten Bindeständer hier wenigstens teilweise mit dicken, oberhalb der Seitenstänge des Schlittens klar ersichtlichen Knöpfen versehen auf, und zweitens ist bei dem vordersten Bindeständerpaar irgendwelche Querverbindung überhaupt nicht vorhanden. Die beiden Merkmale sind für den eigentlichen Bindeständerschlitten in der westlichen Peripherie des Landes charakteristisch. Der Schlitten aus Liljendal stellt mit anderen Worten eine unvollbrachte İbergangsform zwischen dem westlichen Prototyp und seiner eigenen Variantgruppe dar. Es ist nun wichtig festzustellen, dass dieselbe Übergangsform nicht etwa als eine zufällige Erscheinung in dem gesamten Material dasteht. Ausser einigen Nachbarkirchspielen Liljendals im östlichen Uusimaa ${ }^{1}$ können vollständig identische Konstruktionen noch aus Nastola und Jaala in Südost- und aus Hauho in Südwest-Häme bewiesen

1 Mörsком, FMh 131; Pytris, SLS 500. - Bei dem zuletztgenannten Schlitten tritt das mittlere Ständerpaar ohne Querverbindung auf. 


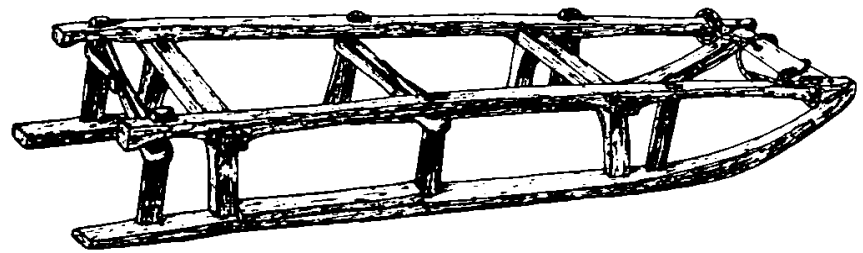

Fig. 11. Arbeitsschlitten aus Liljendal, Finnland. FMK 131. Nach dem Photo gez. Margret Bengtsson.

werden. ${ }^{1}$ Bei allen diesen Schlitten treten also neben den mit den geschwungenen Querverbindungen ausgerüsteten Bindesständern auch solche ohne jegliche Querverbindung auf. Die Bindeständer selbst sind mit dicken, oberhalb der Seitenstänge liegenden Knöpfen versehen. Das letztgenannte Detail kann dazu noch innerhalb eines weit grösseren Gebietes verspürt werden. Es umfasst - obschon nur ziemlich sporadisch belegt - das ganze östliche Uusimaa, südliche Häme, und die östlichen Teile der Landschaft Satakunta. ${ }^{2}$ Es kann deshalb kaum einen Zweifel darüber geben, dass die behandelte Schlittenvariante, die auf der Verbreitungskarte als eine einheitliche Masse erscheint, innerhalb ihres Verbreitungsgebietes tatsächlich Übergangsformen solcher Art verbirgt, die direkt auf den westlichen Ursprung der ganzen Variantgruppe zurückweisen. Es ist zuletzt nicht ohne Bedeutung, festzustellen, dass auch die von oben her bekannte Astständerkonstruktion hier, nämlich an dem Westrande des Verbreitungsgebietes, wieder auftaucht.

Wie schon oben kurz bemerkt wurde, überschreitet die soeben behandelte Schlittenvariante an ein paar Stellen in OstHäme etwas die Westgrenze des osteuropäischen Schlittens. Ganz auf der anderen Seite derselben Grenze bleibt nun das Verbreitungsgebiet einer anderen Schlittenvariante, die mit der vorhergehenden eine deutliche konstruktive Verwandtschaft aufweist. Sie kommt im östlichen und südöstlichen Häme, im

1 Nastola, SS 109; JaAla, SS; Hacho, KM Kk 1379: 144.

2 Uusimaa: Tuusula, SS 109; Askola, SKS E 45; siehe auch oben. Häme: IıтT, KM Kk 2100: 364, 482; РÄLK̈̈NE, KM Kk 1741; AKAA, SS 109. - Satakunta: YlöjÄrvi, SS 109; Teisko, SS 109. 
östlichen Uusimaa nebst einem angrenzenden Teil vom südwestlichen Karelien, im südlichen Savo, und schliesslich, durch einen vereinzelten Beleg anf der Karte verzeichnet, in NordKarelien (Polvijärvi) vor, Fig. 1: 8. Das Verbreitungsgebiet ist also sporadisch und überall von dem osteuropäischen Schlitten durchsetzt. Diese Variante, die hier aus dem Kirchspiel Taipalsaari in Süd-Savo, Fig. 12, abgehildet wird, scheint auf den ersten Blick in einer augenscheinlichen Übereinstimmung mit ihrer weit nach Osten vorgeschobenen Position zu stehen, denn wir haben eigentlich einen osteuropäischen Schlitten mit den hochgebogenen Kufenenden und wohlbekannten Rutenbändern zwischen denselben und den vordersten Ständern vor uns. Bei einer näheren Betrachtung der Abbildung erkennt man jedoch auch hier eine Zweiteilung des Ständersystems derselben Art, wie sie bei der vorhergehenden Variantgruppe festgestellt werden konnte. Die zwei verschiedenen Ständergruppen sind deutlich von einander zu unterscheiden. Die eine von ihnen besteht aus drei Paar Ständern, welche mit den bekannten geschwungenen Querverbindungen ausgerüstet sind und zur gleichen Zeit durch die Seitenstänge des Schlittens emporreichen, während die andere Gruppe von zwei Paar in die massiven, klotzartigen Querhölzer eingelassenen Stollen repräsentiert wird. Das Typexempel aus Taipalsaari ist also ganz wie die Repräsentanten der vorhergehenden Variantgruppe als eine Kontaminationsform aufzufassen. Der Unterschied liegt nur darin, dass der konstruktive Anteil des osteuropäischen Schlittens hier viel stärker hervortritt. Die Zweiteilung des Ständersystems die zuerst im äussersten Westen des Landes kennen gelernt werden konnte, ist bei den beiden Variantgruppen die gleiche. Es folgt daraus, dass die soeben vorgeführte Schlittenvariante als ein im Osten des Landes auftretender Abkömmling einer westlichen Konstruktion zu betrachten ist.

Wir haben, an Hand der zwei zuletztbehandelten Schlittenvarianten der westlichen Zweiteilung des Ständersystems folgend, die Grenze des osteuropäischen Schlittens überschritten und sind ziemlich weit nach Osten vorgestossen. Zu demselben Ergebnis gelangen wir, wenn wir nun einem anderen von Westen her kennengelernten Typmerkmal nachgehen wollen, welches 


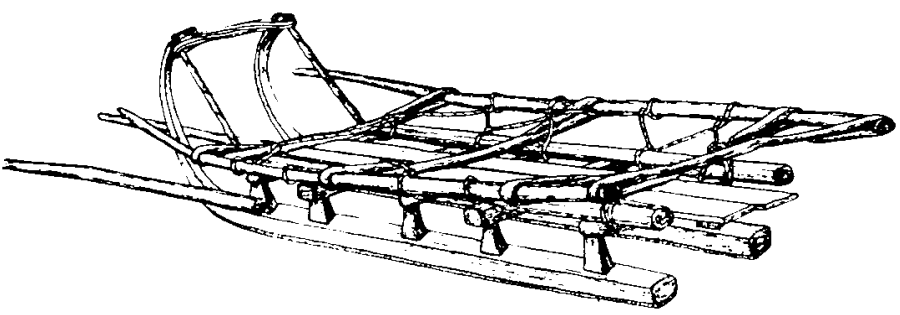

Fig. 12. Arbeitsschlitten aus Taipalsaari Finnland, KM Kk 2097: 78. Nach dem Photo gez. Margret Bengtsson.

in einer weiteren Schlittenkonstruktion. Fig. 1: 9, enthalten ist. Wie es aus der Verbreitungskarte ersichtlich ist, tritt diese Konstruktion mit höchster Frequenz im südlichen Ostbottnien auf, ist aber auch sonst sporadisch innerhalb eines bedeutenden Teils des westlichen Gebietes diesseits der Westgrenze des osteuropäischen Schlittens anzutreffen, und stiesst im Südwesten bis zum südlichen Teil der Landschaft Satakunta vor. Obschon das gesamte Verbreitungsgebiet der Variante also ein ziemlich umfassendes und dazu etwas unklar umrissenes ist, weist es eine augenfällige Konzentration in den Regionen der Westgrenze des osteuropäischen Schlittens auf, wie es nicht nur in Ostbottnien, sondern auch in dem nördlichsten Teil von Satakunta und im östlichen Häme beobachtet werden kann. Das Verbreitungsgebiet kann in diesem Zusammenhange in allen seinen Aspekten nicht interpretiert werden, wir haben Anlass, noch später auf dasselbe zurückzukommen. Wie es aus der Verbreitungskarte zu entnehmen ist, kommt diese Variante übrigens auch in Estland vor. Hier gilt es vorerst nur zu konstatieren, dass sie in Finnland an mehreren Stellen die Westgrenze des osteuropäischen Schlittens überschreitet und sporadisch noch im östlichen Häme wie sogar in den nordwestlichen Teilen der angrenzenden Landschaft Savo vorkommt. Die Konstruktion wird aus Vimpeli in Ostbottnien, einem Kirchspiel, der eben auf der östlichen Seite der Westgrenze des osteuropäischen Schlittens liegt, abgebildet, Fig. 13. Wir erkennen einen für die westlichen Teile des Landes typischen, flachen Schlitten, dessen Oberfläche mit einem provisorischen Verbrei- 


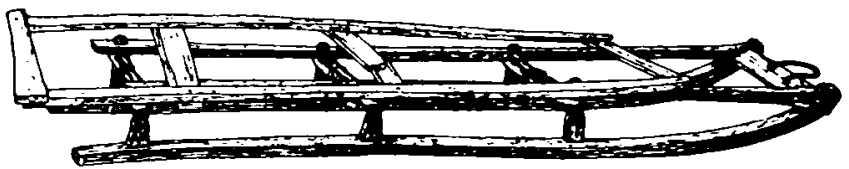

Fig. 13. Arbeitsschlitten aus Vimpeli. Finnland. KM Kk 1971: 265. Nach dem Photo gez. Margret Bengtsson.

tungsrahmen ausgeweitet ist. Auf den westlichen Ursprung deuten die langen Seitenstänge hin, die vorne unmittelbar mit den Kufenenden verbunden sind. Das Ständersy̧stem gehört dagegen dem osteuropäischen Schlitten zu. Die drei Paar Ständer, aus welchen der Ständerbestand des Schlittens zusammengesetzt ist, sind alle mit geschwungenen Querverbindungen östlicher Herkunft ausgerüstet, und die Ständerenden reichen durch die Seitenstänge empor. In derselben Ausführung kann der Schlitten in grossen Zügen überall innerhalb seines Verbreitungsgebietes angetroffen werden. Die lokalen Abweichungen berühren nur die Anzahl von Ständerpaaren die mitunter vier beträgt, und die äussere Gestalt des Vorderteils des Schlittens, welcher in einigen südöstlichen Kirchspielen des Verbreitungsgebietes eine ganz bemerkenswerte Erhöhung aufweist. ${ }^{1}$ Diesen Abweichungen kommt in unserem Zusammenhange nur eine untergeordnete Rolle zu. Die in der Frage stehende Schlittenvariante stellt nach allem zu beurteilen, ganz wie die zwei vorhergehenden, eine Kontaminationsform zwischen dem osteuropäischen Schlitten und einer westlichen Schlittenkonstruktion dar. Darauf deutet nicht nur die Konstruktion sondern auch das Verbreitungsgebiet des Schlittens, das im grossen und ganzen ein İbergangsgebiet zwischen den östlichen und den westlichen Teilen des Landes einnimmt.

An Hand der drei zuletztbehandelten Schlittenvarianten haben wir also gewisse Typmerkmale, die zuerst im äussersten Westen des Landes kennen gelernt werden konnten, bei den Schlittenkonstruktionen im Osten, auf der anderen Seite der Westgrenze des osteuropäischen Schlittens, wieder vorgefunden.

1 Z.B. Kos ke n p ää, KM Kk 2403: 32: J ä m s ä, ebenda, 2453: 60. 
Dies besagt mit anderen Worten, dass dieselbe Grenzlinie nur das Vordringen des betreffenden osteuropäischen Schlittens selbst, nicht aber etwa eine historische Ostgrenze für die westlichen Schlittenkonstruktionen angibt. Die Verbreitungskarte dürfte eine hinreichende Demonstration für die Auffassung liefern, dass der osteuropäische Schlitten eine westliche Schlittenkonstruktion überflügelt haben muss, wodurch auch die behandelten Kontaminationsformen östlich von der auf der Karte verzeichneten Grenzlinie erklärt werden können.

Zwei ron den Kontaminationsformen dringen aber zur gleichen Zeit über die genannte Grenze tief nach Westen vor. Es ist, wie wir beobachtet haben, die geschwungene Querverbindung östlicher Herkunft gewesen, die bei allen diesen Schlitten eine Rolle spielt. Dieser Bestandteil hat bei dem eigentlichen Bindeständerschlitten, der innerhalb eines zerspalteten Verbreitungsgebietes in der westlichen Peripherie des Landes belegt wurde, nicht rorgefunden werden können. Nun fällt es aber auf, dass dem Verbreitungsgebiet des eigentlichen Bindeständerschlittens teilweise noch eine weitere Schlittenkonstruktion gleichwie vorgelagert ist, die gleichfalls keine Spur von einer östlichen Penetration aufzuweisen scheint, die aber mit jenem Schlitten auch nicht zusammenfällt. Diese Konstruktion, die zugleich die letzte aus Finnland kartierte Schlittenvariante darstellt, soll nun im folgenden betrachtet werden.

Die Verbreitungskarte, Fig. 1: 10-11, gibt an, dass diese Variante mit höchster Frequenz westlich von einer Linie, die ungefähr zwischen der Stadt Kokkola und der Landzunge Hango gezogen werden könnte, vorkommt. Östlich von dieser Linie sind nur einige sporadische Belege, die sich in einer von andersartigen Konstruktionen ganz dominierten Umgebung beinahe verlieren, wahrzunehmen. Aber nicht einmal innerhalb ihres Kerngebietes im Westen tritt die in Frage stehende Schlittenvariante alleinherrschend auf. Ein einheitliches Gepräge kann dem Verbreitungsgebiet nur im äussersten Südwesten des Landes, namentlich auf den östlichen Ålandsinseln und in den Küstenstrichen des Eigentlichen Finnlands nebst im südwestlichen Satakunta, zugemessen werden. Sonst ist das Bild überall mit denjenigen Schlittenvarianten, die schon von den obenbe- 
handelten Verbreitungsgebieten bekannt sind, gemischt. Wie die Verbreitungskarte aufweist, ist die Variante durch ein paar sporadische Belege auch in dem nordwestlichen Randgebiet Estlands beweisbar. Die Konstruktion, die hinter diesem uneinheitlichen Verbreitungsgebiet steckt, soll nun zuerst durch eine Abbildung aus dem Inselkirchspiel Korpo im äussersten Südwesten des Eigentlichen Finnlands, Fig. 14, veranschaulicht werden.

Die Abbildung stellt einen flachen, typisch westlichen Schlitten mit langen, bis zu den kaum merklich gekrümmten Kufenenden hinreichenden Seitenstängen dar. Das Ständersystem ist einheitlich. Es wird nur aus drei Paar Ständer derjenigen Art, die wir oben Tragständer genannt haben, zusammengesetzt. Die sämtlichen Ständerpaare sind dazu in der ebenso aus dem Vorhergehenden bekannten, primitiven Astständertechnik hergestellt, d.h. die Ständer werden aus natürlichen, an den Querhölzern festgewachsenen Aststümpfen gebildet. Diese Technik kann hauptsächlich im südwestlichen Teil des Verbreitungsgebietes belegt werden. Irgendwelche Bindeständer, die man bei einer Konstruktion wie diese erwartet hätte, sind bei dem Schlitten also nicht vorhanden. Die Seitenstänge werden hier anstatt der Bindeständer auf eine ganz andere Weise mit dem Schlitten verbunden. Sie sind an den Querhölzern einfach festgenagelt worden. Der abgebildete Schlitten weist zwei, mit aufrecht stehenden Aststümpfen versehene Querblöcke auf, die dem dichten Schlittenboden daraufliegen und eigentlich dem Oberbau des Schlittens zugehören. Diese Querblöcke sind mit der Hilfe von Holzpflöckchen, die sowohl die Bodenbretter als auch die Seitenstänge durchbohren, an den Querhölzern festgesetzt. Die Seitenstänge werden also von oben her fixiert. Dieselbe Methode, d.h. das Festnageln der Seitenstänge, kann aus mehreren Stellen innerhalb des südwestlichen Teils des Verbreitungsgebietes bewiesen werden, ${ }^{1}$ und sie scheint bei denjenigen Exemplaren der Variante, die durch die Astständerkonstruktion charakterisiert werden, die übliche zu sein. Sie ist

1 Z.B. Uusikirkko, Huit tinen, Punkalaidun, SS 109. 


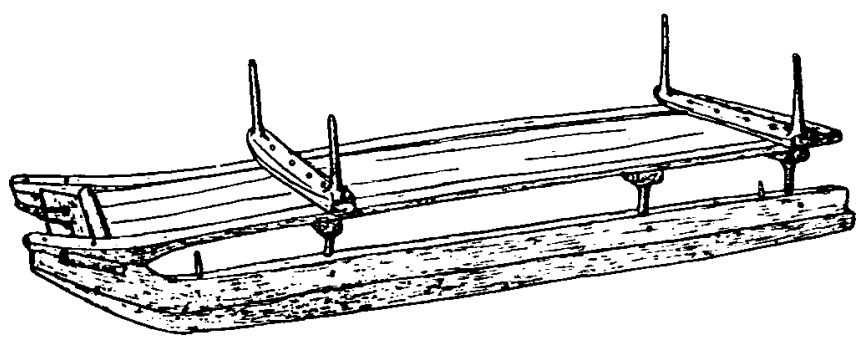

Fig. 1'. Arbeitsschlitten aus Korpo, Finnland. SLS 489. Nach dem Photo gez. Wargret Bengtsson.

jedoch nicht die einzig vorhandene. Wie es aus der Verbreitungskarte hervorgeht, kommt die behandelte Schlittenvariante in zweierlei Abarten vor. An die Seite des aus Korpo abgebildeten, in der Astständerkonstruktion gebauten Schlittens, stellt sich eine Konstruktion mit einer hauptsächlich östlichen und nördlichen Verbreitung, bei welcher die Ständer aus besonderen Stücken in die klotzartigen Querverbindungen eingelassen sind. Es kann nun beobachtet werden, dass die Ständerenden hier ausser den Querhölzern oft auch durch die Seitenstänge des Schlittens hindurchreichen, womit die letztgenannten ohne weitere Massnahmen fixiert werden. ${ }^{1}$ Die Befestigung der Seitenstänge, die in beiden Fällen also ohne die westlichen Bindeständer oder die aus dem osteuropäischen Schlitten überführten Ständer mit der doppelseitigen Funktion erfolgt, stellt in dem finnländischen Schlittenbau einen Zug dar, dem wir bisher noch nicht begegnet sind. Wie stellt sich nun diese Konstruktion kulturhistorisch zu den übrigen, früher behandelten schlittenvarianten im Lande?

Wir werden unsere Anfmerksamkeit zuerst kurz auf die Abart mit der Astständerkonstruktion und den von oben her festgenagelten Seitenstängen richten, die im südwestlichen Teil des Verbreitungsgebietes vorkommt. Im Kirchspiel Uusikirkko, im südwestlichen Eigentlichen Finnland, wo die Konstruktion

I Z.B. Teuva, J a las järvi, Kuort ane, Vi it as a a ri, Perniö, SS 109. 
bezengt ist, ${ }^{1}$ tritt für das mittlere Querholz des Schlittens die Benennung kailusorsi auf. ${ }^{2}$ Dasselbe Wort kann weiter östlich in derselben Landschaft sowie in den angrenzenden Teilen von Häme und Satakunta bei dem daselbst verbreiteten Bindeständerschlitten als Benennung für die obenbehandelte schmale Querleiste zwischen den Bindeständern ${ }^{3}$ oder auch für die Bindeständer selbst, ${ }^{4}$ belegt werden. Ohne auf die Ethymologie des kailus- (nebst mehreren Abarten sowie kaidus-, kainus-, kairus-) hier näher einzugehen, soll nur konstatiert werden, dass das Wort eine alte Benennung für die Bindeständer des Schlittens darstellt. ${ }^{5}$ Es kann deshalb angenommen werden, dass die Bezeichnung kailusorsi im Kirchspiel Uusikirkko eine terminologische Reminiszenz ist, die eine frühere Existenz des Bindeständerschlittens daselbst wahrscheinlich macht. Der Bindeständerschlitten - höchst wahrscheinlich in derselben Ausführung wie er in der östlichen Nachbarschaft des Kirchspiels Uusikirkko noch heute vorkommt - scheint demnach von den westlichen Küstenstrichen des Gebietes entwichen zu sein, oder, mit anderen Worten, die ehemaligen Bindeständer scheinen weggefallen zu sein, wodurch der Schlitten eine einfachere Konstruktion angenommen hat. Wir haben hier aller Wahrscheinlichkeit nach mit einer vereinfachten Schlittenkonstruktion zu tun, die ihre Verbreitung auf Kosten einer älteren Variante gegen Osten und wohl auch gegen Norden angetreten hat.

Dieser Schluss erfährt eine Bekräftigung, wenn wir uns nun eben den nördlichen und östlichen Teilen des gegenwärtigen Verbreitungsgebietes zuwenden. Als eine Illustration für die hier auftretende Abart der Konstruktion wird ein Schlitten aus

1 SS 109.

2 SS 109.

3 Siehe S. 202. - Belege für dje Benennung: kairuksen orsi, L o i m a a, SS 109; kairustin, U r j a la, ebenda.

4 kaidukset, kairukset, kainukset, M y n ä m äk i, KustaA Vilkuna, Varsinaissuomalaisten kansanomaisesta taloudesta ja kulkuneuvoista. Varsinaissuomen historia III, 2. Porvoo-Helsinki 1935, S. 215; kairustin, L i e t o, SS 109; (nuppu)kairustimet, K o i jä r vi, ebenda.

5 Vortrag von Prof. Kustaa Vilk una, "Vad betyder Kainu (Kainut)", an der Stockholmer Hochschule. - Vgl. auch ders., Kainuu - Kvenland. Missä ja mikä? Helsinki 1957, S. 112-116. 


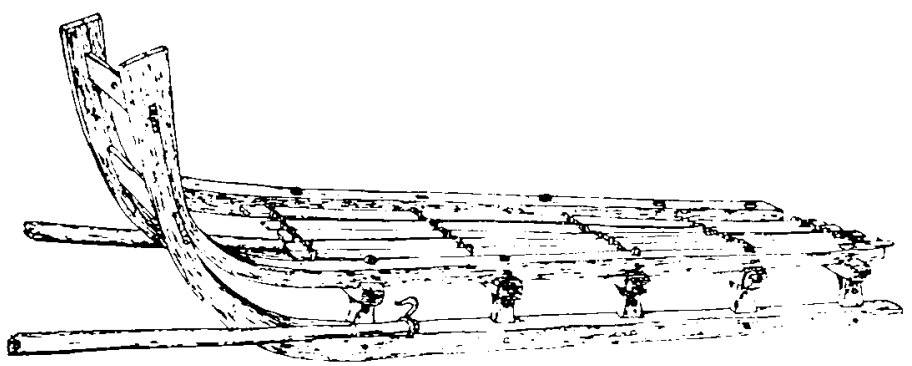

Fig. 15. Arbeitsschlitten aus Toivakka, Finnland. KM Kk 2453: 41. Nach dem Photo gez. Margret Bengtsson.

dem Kirchspiel Toivakka in Ost-Häme, dem am weitesten nach Osten vorgeschobenen Vorposten des Verbreitungsgebietes, Fig. 15, gebracht. Das Ständersystem dieses Schlittens besteht aus fünf Paar kräftigen, einheitlichen Ständern, die alle in die klotzartigen Querhölzer eingelassen sind. Da die Enden der Ständer nicht nur die Querhölzer, sodern auch die Seitenstänge des Schlittens durchbohren, können die letztgenannten - zumal sie durch Querpflöckchen an den Ständerenden fixiert sind - ohne weitere Massnahmen in ihrer Lage zurückgehalten und mit dem Schlitten verbunden werden. Aber nur bei dem ersten und mittleren Ständerpaar reichen die Enden der Ständer ein Stückchen durch die Seitenstänge empor, während man bei den übrigen nichts davon verspürt. Der Schlitten macht in dieser Hinsicht den Eindruck eines Bindeständerschlittens. Darf man daraus schliessen, dass hier etwa eine konstruktive Reminiszenz von jenem Schlitten vorliegt? Das scheint tatsächlich der Fall zu sein. Man denkt dann vorzugsweise auf diejenige der obenbehandelten Kontaminationsformen, Fig. 10, deren Ständersystem, wie oben ausgeführt worden, teils aus den westlichen Tragständern, deils aus den, vom osteuropäischen Schlitten beeinflussten, mit den geschwungenen Querverbindungen ausgerüsteten Bindeständern zusammengesetzt wird. Der Schlitten aus Toivakka schliesst sich dicht der nordöstlichen Peripherie des Verbreitungsgebietes dieser Kontaminationsform mit ihrem halbierten Ständersystem an. Ähnliche Beispiele können aus den anderen Grenzzonen desselben 
Verbreitungsgebietes vorgeführt werden. Auch im Kirchspiel Teuva in Süd-Ostbottnien, wo die hier in Frage stehende Schlittenvariante mit drei bis vier Ständerpalare ausgerüstet auftritt. reichen nur die mittleren Ständerenden durch die Seitenstänge empor. ${ }^{1}$ Aus dem Kirchspiel Kankaanpää im nördlichen Satakunta wird berichtet, dass die mittleren Ständer bei derselben Schlittenvariante konstruktionsmässior die schwächsten unter den Ständern seien, und dass man für die die Benennung lasta. anwende. ${ }^{2}$ Die Benennung lasta ist aber eine typische Bezeichnung für die, mit den geschwungenen Querverbindungen ausgerüsteten Bindeständer, die innerhalb des Verbreitungsgebietes der soeben berührten Kontaminationsform mit dem halbierten Ständersystem allgemein vorkommt. ${ }^{3}$ Aus demselben Kirchspiel liegen weiter Mitteilungen vor, aus welchen entnommen werden kann dass die in Frage stehende Schlittenvariante eine neuere Konstruktion ist, die auf Kosten des älteren. östlich gefärbten Bindeständerschlittens vordringt. ${ }^{\ddagger}$ In ein ganz klares Licht gerückt wird schliesslich das Verhältnis durch einen Bericht aus Tuusula in Mittel-Uusimaa, laut welchem die Variante einfach eine neuere Abart des obenberührten Bindeständerschlittens sei, bei welchem die mit den östlichen, geschwungenen Querverbindungen ausgerüsteten Bindeständer (lastat) einfach weggefallen seien, oder, wie es scheint, zum Teil durch die gewöhnlichen Tragständer ersetzt worden sind. ${ }^{5}$ Das Resultat ist also das gleiche wie im Südwesten des Landes. Die in Frage stehende Schlittenkonstruktion ist, was ihr Ständersystem betrifft, auch im Verhältnis zu der in den zentralen Teilen von Häme und Satakunta, sowie in Süd-Ostbottnien verbreiteten Kontaminationsform, sekundär. Es erübrigt sich noch, einen Blick auf den nördlichsten 'Teil ihres Verbreitungsgebietes zu werfen, wo sie - wie die Verbreitungskarte aufweist - mit einer weiteren west-östlichen Kontaminationsform, Fig. 13, sowie zuletzt mit dem eigentlichen Bindeständer-

1 SS 109.

2 SS 109.

3 SS 109.

4 SS 109.

5 SS 109. 
schlitten in Süd-Ostbottnien in Berührung kommt. Was nun das Verhältnis der uns beschäftigenden Konstruktion zu der zuerstgenannten Variante, einem Schlitten mit dem westlichen Seitenstangenbau und östlichen Ständersystem, betrifft, ist es leicht zu erweisen, dass sie auch in diesem Fall eine vordringende, und der letztgenannte Schlitten eine zurückweichende Erscheinung ist. Entsprechende Berichte, die das Besagte direkt beweisen, können aus verschiedenen ostbottnischen Kirchspielen angeführt werden. ${ }^{1}$ Dieselbe Agressivität wird schliesslich von der für uns aktuellen Konstruktion zu Tage gelegt, wenn es den Kontakt zwischen derselben und dem ostbottnischen Bindeständerschlitten, welcher nur noch in einigen Küstenkirchspielen südlich von der Stadt Vasa verbreitet ist, gilt. In diesem Gebiet liegt ein Bericht aus dem Kirchspiel Isokyrö vor, welcher meldet, dass der lokale Arbeitsschlitten drei Paar in die klotzartigen Querhölzer eingelassene Ständer besitze (früher manchmal Astständerkonstruktion), dass dieselben aber in einer früheren Zeit noch mit zwei Paar Bindestäbchen komplektiert gewesen seien. ${ }^{2}$ Der Bericht soll dermassen ausgedeutet werden, dass die hier verfolgte Schlittenvariante im Begriffe ist, in das ganz unbedeutliche, noch übrig gebliebene Verbreitungsgebiet des eigentlichen Bindeständerschlittens in Ostbottnien überzugreifen, und dass sie, wie die Verbreitungskarte bezeugt, das Gebiet teilweise auch schon penetriert hat. Dasselbe kann, wie es aus den oben angestellten Betrachtungen hervorgegangen ist, von den Verbreitungsgebieten aller Schlittenvarianten, mit welchen die in Frage stehende Konstruktion in Berührung tritt, behauptet werden. Wir stellen also fest, dass es hier offensichtlich von einer neueren, ganz expansiven Schlittenform die Frage ist, welche zur Zeit im Begriffe steht, die älteren, oben kommentierten Verbreitungsgebiete in westlichen Teilen des Landes nach und nach auszugleichen, und welche also, was ihr Ständersystem betrifft, nicht zu der Grundschicht des finnländischen Schlittenbestandes gerechnet werden kann.

I Z.B. Ja lasjärvi, Korteis järvi, Alavus, Alahärm ä, L a p p a jär vi, SS 109 .

2 SS 109. 
Wir können jetzt, bevor wir uns Estland zuwenden, die Ergebnisse der Kartenanalyse über Finnland kurz zusammenfassen. Das Land wird, was die Schlittenkonstruktionen betrifft, in mehrere Verbreitungsgebiete aufgeteilt. Es sind indessen von diesen Konstruktionen nur zwei, die auf eine vollständige typologische Selbständigkeit Anspruch machen können: der eigentliche Bindeständerschlitten im Westen und der osteuropäische Schlitten im Osten. Diese von einander schroff abweichenden Schlittenformen stehen heutzutage miteinander in keinerlei unmittelbarem Kontakt. Es steht aber ausser Zweifel, dass sich zwischen Ihnen ein Prozess gegenseitiger Wechselwirkung abgespielt hat. Dieser Prozess wird von einer Anzahl von Kontaminationsformen angedeutet, die zwischen den genannten, gegensätzlichen Ausgangskonstruktionen gleichwie eine vermittelnde Brücke schlagen. An Hand dieser Kontaminationsformen kann verfolgt werden, wie der konstruktive Einfluss des osteuropäischen Schlittens sich weit westlich der Westgrenze desselben Schlittens geltend macht. Zwei von den Kontaminationsformen stiessen bis zum Bottnischen Meerbusen vor, zerspalten das Verbreitungsgebiet des eigentlichen Bindeständerschlittens, und lassen dasselbe nur noch als ein typisches Reliktgebiet zurück. Auf der anderen Seite sind deutliche Spuren des Bindeständerschlittens östlich von der Westgrenze des osteuropäischen Schlittens anzutreffen. Aus einem solchen Verbreitungsbilde kann nur der Schluss gezogen werden, dass dem eigentlichen Bindeständerschlitten einmal ein umfangsreicheres Verbreitungsgebiet, welches sich östlich von der gegenwärtigen Westgrenze des osteuropäischen Schlittens erstreckt hat, zugekommen haben muss, und dass also der osteuropäische Schlitten, und nicht etwa sein nach dem äussersten Westen zurückgeträngter Antipode, eine sekundäre Schlittenform im Lande ist. Diesem Schlusse widerspricht nicht die nach Osten gerichtete Bewegung derjenigen westlichen Schlittenvariante, deren fortwährend sich verbreitende Verbreitung wir oben zuletzt haben betrachten können. Denn es hat sich ja erwiesen, dass die genannte Konstruktion eben auf Kosten der schon früher ausgebildeten Verbreitungsgebiete vordringt. Sie ist, trotz einiger alten Züge die ihr anhaften (Seitenstangenbau 
z.T. Astständerkonstruktion), als eine Komplexerscheinung betrachtet, neu. Wir haben hier mit anderen Worten mit einer Novation westlichen Ursprungs zu tun, die im Begriffe ist, ein älteres Verbreitungsbild zu überschwemmen - ganz wie der osteuropäische Schlitten es augenscheinlich einmal früher mit Ausgangspunkt von der entgegengesetzten Richtung getan haben muss. Es wird auf diese Doppelbewegungen noch später in den Schlussbetrachtungen zurückzukommen sein.

Wenn wir uns nun wieder dem südlichen Teil der Verbreitungskarte, namentlich Estland, zuwenden, fällt zuerst eine Konstruktion auf, die in Finnland nicht beobachtet werden konnte. Das Verbreitungsgebiet derselben, Fig. 1: 12, umfasst im grossen und ganzen die westlichen, zwischen der Westgrenze des osteuropäischen Schlittens und dem Verbreitungsgebiet des eigentlichen Bindeständerschlittens liegenden Teile des Landes. Es ist jedoch zur gleichen Zeit wahrzunehmen, dass weder die Westgrenze des osteuropäischen Schlittens, noch der Ostrand des Verbreitungsgebietes des eigentlichen Bindeständerschlittens im äussersten Westen das Verbreitungsgebiet der in Frage stehenden Schlittenkonstruktion vollständig abgrenzt. Die erstgenannte Grenze wird nämlich nach Osten hin überschritten, und das Verbreitungsgebiet des eigentlichen Bindeständerschlittens scheint von der Konstruktion, die sogar noch auf den kleinen peripherischen, estlandschwedischen Inseln belegt werden kann, teilweise penetriert zu sein. Die aktuelle Schlittenvariante wird hier eben aus der einen von den genannten Inseln im Nordwesten, Rågö, und dann weiter aus einem Festlandskirchspiel, namentlich Martna, abgebildet. Die erstgenannte Abbildung, Fig. 16, stellt einen ziemlich niedrigen Schlitten mit langen Seitenstängen, die vorne unmittelbar mit den Kufenenden verbunden sind, dar. Das Ständersystem des Schlittens wird durch eine Zweiteilung charakterisiert. Man unterscheidet zuerst eine Gruppe von kräftigen Stollen, die dazu bestimmt sind, den Schlittenboden aufzutragen, und die daher als eine Art Tragständer bezeichnet werden können. Irgendwelche klotzartige Querhölzer, die wir bei dieser Ständergruppe in Finnland vorgefunden haben und die ja auch in Estland für den eigentlichen Bindeständerschlitten in der west- 


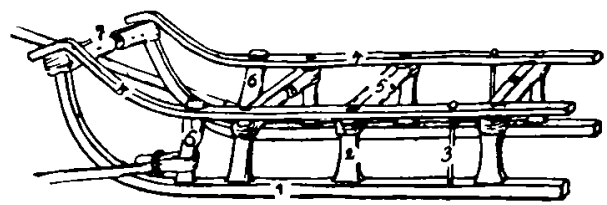

Fig. 16. Arbeitsschlitten aus Rảgö (Pakri), Estland. Nach Per Söderbäck.

lichen Peripherie des Landes eigen sind, können hier jedoch nicht wahrgenommen werden. Anstatt derselben sind die Tragständer, die bei dem abgebildeten Schlitten in einer Anzahl von drei Paar auftreten, mit den geschwungenen Querverbindungen östlicher Technik ausgerüstet. In voller Konsequenz damit sind die oberen Enden der Ständer auch in die Seitenstänge eingelassen, womit eine vollständige Gleichheit dieser Ständergruppe mit der aus dem osteuropäischen Schlitten bekannten Ständerkonstruktion erzielt wird. Ungeachtet der doppelseitigen Funktion der Ständer, die durch diese Technik ermöglicht wird, findet man aber bei dem Schlitten noch besondere Bindeständer ohne Querverbindungen vor, von welchen ein Paar flache ganz vorne, und das andere, welche von einer schmalen, runden Form sind und daher Bindestäbchen genannt werden müssen, ummittelbar vor den letzten Tragständern erblickt werden kanm. Es ist oben angedeutet worden, dass eben dieselbe Kombination von Bindeständern verschiedener Form auch für den eigentlichen Bindeständerschlitten in Estland bezeichnend ist. Der Schlitten aus Rảgö schliesst sich also, was den Bestand von Bindeständern betrifft, direkt dem eigentlichen Bindeständerschlitten in derjenigen Gestalt an, wie derselbe in dem äussersten Westen Estlands auftritt. Dasselbe kann ron dem anderen, aus dem Kirchspiel Martna abgebildeten Schlittenexemplar, Fig. 17, behauptet werden. Die einzige Abweichung von dem Vorhergehenden kann nur darin erblickt werden, dass die für die Femerstänge bestimmten, flachen Bindeständer weggefallen sind, und der Schlitten bloss mit zwei Paar runden Bindestäbchen ausgerüstet ist. Die beiden Abarten der Schlittenvariante können miteinander abwechselnd 


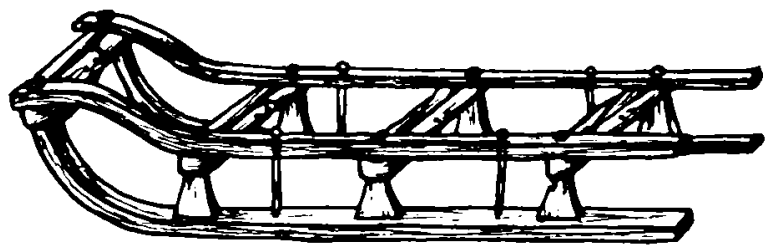

Fig. 17. Arbeitsschlitten aus Martna, Estland. Samml. von A. Saareste.

vorgefunden werden. Die flachen Bindeständer können ausser der nordwestlichen Insel Rågö z.B. auch im Kirchspiel Mihkli im südwestlichen Teil des Verbreitungsgebietes bewiesen werden. ${ }^{1}$ Die Anzahl, Form, sowie auch die Verteilung der Bindeständer variiert von Ort zu Ort. Die Konstruktion der mit den Querverbindungen östlicher Technik ausgerüsteten Tragständer ist aber über dem ganzen Gebiet gleich. Sie gehört ursprünglich dem osteuropäischen Schlitten zu. Ganz wie in Finnland ist also die östliche Querverbindung auch in Estland tief über die Westgrenze des osteuropäischen Schlittens vorgestossen und hat eine eigene Kontaminationsform hervorgerufen, die direkt auf den eigentlichen Bindeständerschlitten im Lande zurückgeführt werden kann. Der unmittelbare Schluss der sich daraus ergibt, ist, dass das Verbreitungsgebiet der letztgenannten Konstruktion, welches heute nur auf die Westinseln und die westlichen Küstenstriche beschränkt ist, sich früher über ein weit grösseres Gebiet des Festlandes erstreckt haben muss. Wir haben aber schon oben darauf hingewiesen, dass die soeben behandelte Kontaminationsform vor der Crenze des osteuropäichen Schlittens nicht halt macht, sondern durch sporadische Belege noch östlich davon verspürt werden kann. Die Westgrenze des osteuropäischen Schlittens kann also mit anderen Worten auch in Estland nicht mit der historischen Ostgrenze für das Verbreitungsgebiet des westlichen Bindeständerschlittens gleichgestellt werden. Wir finden hier somit eine Parallele mit den Verbreitungsverhältuissen in Finnland vor, obschon

1 AES I. 
die in Frage stehende Schlittenvariante selbst in identischer Form dort nicht anzutreffen ist.

Derselbe Parallelismus zwischen den beiden Ländern wiederholt sich, wenn wir nun diejenige Schlittenvariante in Estland ins Auge fassen, die schon oben, bei der Analyse der finnischen Schlittenvarianten, eine nähere Behandlung gefunden hat. Es ist von der Konstruktion die Rede, die einen westlichen Seitenstangenbau nebst einem, von dem osteuropäischen Schlitten überführten, einheitlichen Ständersystem mit den geschwungenen Querverbindungen aufwies. Die Kontaminationsform kann aus Estland hier leider nicht abgebildet werden. Die vorliegenden Berichte legen jedoch dar, dass man mit einer Konstruktion zu tun hat, welche, was eben den Seitenstangenbau und das Ständersystem betrifft, mit dem aus Finnland vorgeführten Typbeispiel, Fig. 13, übereinstimmt. ${ }^{1}$ Es ist nun oben dargetan worden, dass die Belege über diese Schlittenvariante sich in Finnland vorzugsweise in den Regionen der Westgrenze des osteuropäischen Schlittens anhäufen, und dass sie die genannte Grenze an einigen Stellen auch nach Osten hin überschreiten. Dasselbe kann in Estland wahrgenommen werden. Die Verbreitungskarte, Fig. 1: 9, weist auf, dass die entsprechenden Belege sich auch hier an die Grenzzone anschliessen, und dass sie eben noch östlicherseits der Westgrenze des osteuropäischen Schlittens angetroffen werden können. In der Landschaft Harjumaa im nördlichen Teil des Territoriums, stiesst der Schlitten ganz weit nach Osten vor. Man ist nun kaum grezwungen, die von einander isolierten Verbreitungsgebiete dieser Schlittenvariante in Finnland und Estland dermassen auszudeuten, als ob sie etwa in einer direkten kulturhistorischen Beziehung zueinander stünden. Die Konstruktion kann vieImehr ohne Schwierigkeiten als eine Kontaminationsform erklärt werden, die auf beiden Seiten des Finnischen Meerbusens selbständig aus gleichartigen Voraussetzungen entstanden ist. Dafür

1 A u d ru, briefl. Mitteil. vom Herrn M. Metgaits, den 31. 1. 55 und von Frau A. Bavgus, den 6. 2. 54, Schweden; T ori, Mitteil. von Prof. E. Blumfecdt, Schweden; Lmgeb. von der Stadt P e r a u und Kirchsp. J u u r u, Aufzeichen. des Verf. im J. 1942-. Vgl, auch HAGAR, op.cit., S. 121 . 
spricht nicht nur die Konstruktionsanalyse und die Stellung der Schlittenvariante die sie in dem lokalen Verbreitungsbilde in Estland bzw. in Finnland einnimmt, sondern auch die Tatsache, dass dieselbe Konstruktion - wie wir noch später sehen werden - auch anderswo in den Randgebieten des Verbreitungsgebietes des osteuropäischen Schlittens, wo die gleichen Voraussetzungen rorhanden sind, wieder auftaucht. Unter solchen Umständen bezeugt aber ihr Auftreten östlich der Westgrenze des osteuropäischen Schlittens in Estland zweifelsohne von einer ehemaligen weiteren Ausdehnung des Verbreitungsgebietes einer westlichen Schlittenkonstruktion, welche also eben ganz wie in Finnland - von dem osteuropäischen Schlitten überflügelt worden sein muss. Reste der westlichen Konstruktion können in dem Schlitteninventar in Estland tatsächlich noch weit östlicher festgestellt werden als die Verbreitungskarte es darzutun vermag. Ein diesbezüglicher Bericht liegt z.B. aus dem Kirchspiel Koeru in Ost-Järvamaa (Jerwen) im östlichen Teil Mittelestlands, vor. ${ }^{1}$ All das besagt, dass man in Estland ein Verbreitungsbild vor sich hat, das im Prinzip mit demjenigen in Finnland verglichen werden kann. Denn auch Estland wird durch mehrere Verbreitungsgebiete verschiedener Schlittenkonstruktionen gekennzeichnet, von welchen indes nur diejenigen Hauptkonstrultionen wie in Finnland, nämlich der eigentliche Bindeständerschlitten im Westen und der osteuropäische Schlitten im Osten und Süden des Landes eine typologische Selbständigkeit aufweisen. Ein ganz umfassendes Gebiet zwischen den einander gegenübergestellten Verbreitungsgebieten der genannten Konstruktionen wird sodann von den Kontaminationsformen ausgefüllt, welche einerseits den konstruktiven Einfluss des osteuropäischen Schlittens bis zu der Ostsee erweitern, indem sie einen beträchtlichen Teil des Verbreitungsgebietes des eigentlichen Bindeständerschlittens penetriert haben, andererseits aber deutliche Spuren der westlichen Grundkonstruktion noch östlich der Westgrenze des osteuropäischen Schlittens wahrnehmen lassen. Wie in Finnland, soll

1 ERM Kv 54: 447. - Vgl. HaGar, op.cit., S. 116. - Aus Grund der unzulänglichen Kenntnis der Konstruktionsdetails hat der Schlitten nicht kartiert werden können. 
also das Verbreitungsgebiet des eigentlichen Bindeständerschlittens auch in Estland als ein nach dem Westen zurückgedrängtes Reliktgrebiet, und der osteuropäische Schlitten folglich als eine sekundäre, expansive Konstruktion bewertet werden. Die nach dem Westen gerichtete Bewegung des osteuropäischen Schlittens kamn in Estland an Hand einer etwas modernisierter Variante desselben tatsächlich noch in der Gegenwart verfolgt werden. Die krïftigen Ausbauchungen, welche von der Westgrenze des genannten Schlittens in sowohl Ost-Harjumaa. als auch besonders im nordwestlichen Pärnumaa gebildet werden, grenzen nämlich an und für sich diejenigen peripherischen Regrionen des Verbreitungsgebietes ab, wo der osteuropäische Schlitten laut Traditionsaufzeichmungen erst neuerdings vorgedrungen ist. ${ }^{1}$ Die iltere Grenze ist auf der Verbreitungskarte dagegen durch eine Punktiere, Fig. 1: 14, östlich der betreffenden Zonen angedeutet worden. Wir können also bezeugen, dass die Westarrenze des osteuropäischen Schlittens in Estland fortwährend im Vordringren begriffen ist. Es gribt kaum einen Anlass anzunehmen, dass dieses späte Vorrücken der Grenze nur etwa als cine historisch isolierte Erscheinung in der Schlittengeschichte des Landes aufgefasst werden soll. Das ganze Verbreitungsbild zwingt vielmehr zu der Annahme, dass man hier die letzte Etappe eines lange fortgedauerten Expansionsworganges vor sich hat. Irgendeine Gegenbewegung nach dem Osten hin, wie wir sie an Hand einer westlichen Schlittenvariante in Finnland haben bezeugen können, kann in Estland nicht registriert. werden - obschon dieselbe Variante durch ein paar Belege auch in der westlichen Peripherie Estlands wieder zum Vorschein kommt. Die Konstruktion ist übrigens auch hier späteUrsprungs, sie stellt bloss eine Vereinfachung des alten Binden. ständerschlittens dar. ${ }^{2}$

$1 \mathrm{Nissi}$. ERM Kv 54: 169; Viga I a, ERM EA 5: 413-415= Ethnographisches Archiv im Estnischen Nationalmuseum; U ih k li, AES I; A u d r u, brietl. Mitteil. vom Herrn M. Mergaits, den 31. 1. 55.

2 Wo r m s ö. Aufzeichn. des Verf. im J. 194: auf der Insels Ramsö, Schweden, nach Herrn J. Appelalox aus Wormsö; Ode n s h o l m (Osmussaar), Aufzeichn. des Verf. im J. 1949 auf der Insel Ormö, Schweden, nach Herrn J. Erkas aus Odensholm. 


\section{II}

Wir sind also zum Resultat gekommen, dass die Schlittengeschichte, wie sie sich im Lichte einer rezenten Verbreitungskarte ausnimmt, in ihren Hauptzügen einen gleichartigen Verlauf in den beiden Ländern gehabt zu haben scheint. Deun im äussersten Westen sowohl Finnlands als Estlands liegt ein zersplittertes Verbreitungsgebiet des sog. eigentlichen Bindeständerschlittens vor, das sich als ein typisches, durch das Vordringen des osteuropäischen Schlitten entstandenes Rückzugsgebiet hinstellen lässt. Der Schluss, unter solchen L'mständen in dem osteuropäischen Schlitten eine Konstruktion zu erblicken, die innerhalb des behandelten Gebietes sekundär sein muss, liegt auf der Hand. Es ist aber damit noch nichts näheres über die Frühgeschichte und die frühen Verbreitungsrichtungen desselben Schlittens ausgesagt worden. Dessen Verbreitungsgebiet in den weiten östlichen Regionen des abgegrenzten (iebietes liegt als eine homogene Masse da, die bisher kulturhistorisch noch nicht gegliedert werden konnte. Bevor man diese Fragen näher angreifen kann, soll jedoch unser bisheriges Ergebnis, das sich ja fast ausschliesslich auf das lokale Material stützt, aus einem weiteren Ausgangspunkt überprüft werden. Inwieweit kann die kulturhistorische Prioritätsstellung des eigentlichen Bindeständerschlittens im Lichte eines vergleichenden Materials aufrecht erhalten werden? Wir haben schon oben das gesamte Verbreitungsgebiet des osteuropäischen Schlittens umrissen. Wie nimmt sich nun das gesamte Verbreitungsgebiet des eigentlichen Bindeständerschlittens aus?

Die Geschichte des eigentlichen Bindeständerschlittens ist in ihren Hauptzügen von dem schwedischen Ethnologen Gös' $\mathrm{A}$ BERG untersucht worden. Das von ihm zusammengestellte Belegmaterial lässt, was zuerst die rezenten Verbreitungsverhältnisse des Schlittens betrifft, die Konturen eines weitumfassenden, von Skandinavien bis zu den südeuropäischen Alplandschaften hinreichenden, zur gleichen Zeit aber eines vollständig zersplitterten Verbreitungsgebietes wahrnehmen. In Skandinavien ist die Konstruktion von BERG aus fast ganz Norwegen (nur die Landschaft Hedmark ausgenommen) und aus einigen 
Landschaften Westschwedens, namentlich Härjedalen, Värmland, Dalsland und Bohuslän belegt worden. ${ }^{1}$ Irgendeine einheitliche Verbreitung hat die Konstruktion in Skandinavien also nicht aufzuweisen - obschon das Gebiet wo sie rorkommt, innerhalb Schwedens laut später hinzugekommenen Materials auch einigermassen erweitert werden kann. ${ }^{2}$ Von einem besonderen Interesse ist es, dabei zu bemerken, dass die Konstruktion noch weit östlich und nördlich von den oben aufgezählten Landschaften Westschwedens, namentlich aus den Kirchspielen Alfta und Ovanåker in Hälsingland, ${ }^{3}$ sowie aus dem Kirchspiel Bjurholm in Nordost-Ångermanland ${ }^{4}$ belegt werden kann. Diese Belege stehen von den westschwedischen Belegstellen ganz isoliert da. Wenn man die sämtlichen Schlittenkonstruktionen in Skandinavien kartieren möchte, würde das Verbreitungsgebiet des eigentlichen Bindeständerschlittens sich als eine westliche Randerscheinung erweisen, welches in der Höhe von den Landschaften Dalarna-Hedmark nahezu abgebrochen ist, und welchem im Osten und Nordosten dazu noch einige abgesonderten Verbreitungsenklaven vorgelagert sind. Es ist mit anderen Worten ein Verbreitungsgebiet, das von andersartigen Schlittenkonstruktionen überschwemmt, zurückgedrängt und zersplittert worden ist. Weit von Skandinavien entfernt fällt ein weiteres Bruchstück des Verbreitungsgebietes sodann eben in den Alplandschaften auf, wo der eigentliche Bindeständerschlitten zuerst von BERG in den Kantonen Graubünden und Tessin in der Schweiz nachgewiesen ${ }^{5}$ wird. Die Konstruktion, welche ersichtlich in der ganzen Schweiz nach-

1 Berg, op.cit., S. 56-57.

2 Die Konstruktion kann in den, sich der Landschaft Härjedalen direkt anschliessenden Kirchspielen $\mathrm{Kl}$ ö v s jö in Süd-Jämtland und I $\mathrm{d} r \mathrm{e}$ in Nordwest-Dalarna bewiesen werden. Aufzeichn. des Verf. im J. 1956.

3 Aufzeichn. des Verf. im J. 1954; der Schlitten mit den runden Bindestäbchen in dem Provinzialmuseum in Edsbyn, Kirchsp. O v a n å k e r, repräsentiert.

4 EU 11011; der Schlitten hier mit den flachen Bindeständern ausgerüstet.

5 Beng, op.cit., S. 58. 
gespürt werden kann, ${ }^{1}$ taucht aber gemäss erst neulich bekanntgewordenem Material dazu noch in Tirol nördlich des Brenners wieder auf, wodurch ihr Verbreitungsgebiet hier die Form eines ziemlich langen, nördlich von den Alpen hingezogenen Gürtels annimmt. ${ }^{2}$ Es ist cinleuclitend, dass man auch in diesem Falle ein ebensolches Randrelikt vor sich hat wie in Skandinavien, denn der Nachweis ist möglich, dass der Mitteleuropäische Raum nördlich der Alpen, der ganze Westeuropäische Kontinent, der Balkan und die Donauländer heutzutage von einer Schlittenkonstruktion beherrscht werden, die ron dem eigentlichen Bindeständerschlitten vollständig abweicht. ${ }^{3}$ Das Verbreitungsgebiet derselben Konstruktion - es handelt sich um einen Schlittentypus, der ganz ohne Seitenstänge gebaut ist - greift dann auch nach Schweden hinüber, wo es sich bis zu den nördlichen Regionen des Landes erstreckt und wahrscheinlich auch hier beim Entweichen des eigentlichen Bindeständerschlittens eine Rolle mitgespielt hat. ${ }^{4} \mathrm{Zu}$ diesen, ron einander weit entfernten Randgebieten gesellen sich dann schliesslich das Baltikum und Finnland. Die beiden Gebiete sind schon seit BERG in das Verbreitungsgebiet des eigentlichen Bindeständerschlittens einbezogen gewesen, obschon der genannte Verfasser aus dem zuerstgenannten Gebiet nur einige auf den Westinseh Estlands lokalisierte Belege kennt und betreffs Finnlands bloss auf eine Kontaminationsform aus Ostbottnien hingewiesen hat. ${ }^{5}$

1 So auch in $\mathrm{St}$. G a 11 e $\mathrm{n}$, Anvi Walmeier-Brockuan, Sammelwirtschaft in ren Schweizer Alpen, eine ethnographische Studie. Schweizerisches Archiv für Volkskunde 38, S. 256, Abb. 15. - H. BrockмaxxJевоsсн, Schweizer Volksleben I. Erlenberg-Zürich 1931, Abb. 59.

2 Urika Hubatscheк, Zur bäuerlichen Arbeits- und Gerätekunde des inneren Stubaitales. Volk und Heimat. Festschrift für Viktor von Geramb. Graz 1949, Abb. 6 und Taf. III.

3 Eine diesbezügliche Belegzusammenstellung Hagar, op.cit,, s. 906. - Vgl. hierzu noch Sza bó KÁ Mán, Kecskeméti Múseum kalászati gyüjteménye. A Néprajzi Múseum Országos Magyar Történeti Múseum Néprajzi Tára Értesítoje X. Budapest 1937, Abb. 87 (Ungarn.)

- Vgl. die von BERG, op.cit., S. 61-62, gebrachten Belege; weiter im Kirchsp. G r a n i n g e, Angermanland, EU 11526; dazu Aufzeichn. des Verf. im J. 1954 und 1956 aus Mittel- und Nordschweden.

5 Berg, op.cit., S. 57-58.

15 - Finnisch-ugrische Forschungen 
Ein einigermassen erschöpfendes Material ans Estland unıl Finnland ist num oben kartographisch dargeboten worden. Es dürfte nicht bestritten werden kümmen, dass diejenigen peripherischen und zersplitterten Verbreitungsgebiete des eigentlichen Bindeständerschlittens, welche auf der Karte hervortreten, ausgezeichnet mit dem gesamten Verbreitungsbilde des genannten Schlittens übereinstimmen. Der eigentliche Bindeständerschlitten ist nicht nur in Estland und Finnland, sondern überall in Europa wo er heutzutage vorkommt, als eine Relikterscheinung aufzufassen. Die peripherischen Brurhstücke, aus welchen sein Vejbreitungsgebiet sich zusammensetzt, fallen mit einigen von den meist typischen Rückzugsgebieten Europas zusammen und sind zweifelsohne als die letzten Reste eines früher zusammenhängenden Verbreitungsgebietes auszudeuten. Es ist deutlich, dass solche Verbreitungsverhältnisse stark für ein hohes Alter der in Frage stehenden Sehlittenkonstruktion sprechen müssen. Ein direkter Beweis dafür lässt sich auch tatsächlich an Hand des vorhistorischen Fundmaterials erbringen. Der eine von den drei Schlitten welche in dem berühmten Osebergsfunde aus der Vikingerzeit enthalten sind, sowip auch der Schlitten im Gokstadsfunde aus derselben Periode, erweisen sich als Bindeständerkonstruktionen. Peide sind von BERG in der obengenannten Untersuchung angefüht und mit dem rezenten Material verglichen worden. ${ }^{3}$ Ausser den genannten vikingerzeitlichen Fünden ans Norwegen hat aber derselbr Verfasser auch einen vorhistorischen Kufenfund aus Vilhelmina in Süd-Lappland in Schweden hervorgehoben, welcher von ihm! ebenfalls mit einer Bindeständerkonstruktion in Verbindung gebracht wird. Die Kufe, welche mit zwei rechteckigen Vertiefungen für die Tragständer versehen ist, weist dicht an der einen Seite von denselben je ein kleines, rundes Joch auf, welche die Kufe penetrieren. Ein gleiches Loch nimmt man weiter ganz hinten an der Kufe wahr. Die Löcher sind von Berg als Befestigungspunkte für die unteren Enden der runden Bindestäbchen interpretiert worden. ${ }^{2}$ I)as Alter des Fundes ist nicht näher bekannt. Die Kufe schliesst sich indes formkritisch einfr tranzen

1 op.cit., S. $5 \%$.

2 up.cil., N. 56 , Abb. 24. 
truppe: von vorhistorischen Kufenfünden alls Nordschweden und Finnland an, welche anf Grund einiger pollenanalytisch untersuchten Exemplare etwa zum Beginn unserer Zeitrechnung datiert werden kann. Alle diese Fünde repräsentieren einen Schlittentypus, bei welchem man mit den langen, bis zu den Kufenenden emporreichenden und daselbst fixierten Seitenstängen rechnen darf. Ausser der oben angeführten Kufe mit den runden, senkrechten Iöchern für die Bindestäbchen, weisen verschiedene andere Exemplare derselben tiruppe wagerecht" Iöcher auf, welche sich in einem dickeren oder erhöhten Mittelteil der Kufe befinden und nhme Zweifel zur Fixierung irgendwelcher zusammenschliessenden Bänder zwischen der Kufe und der Seitenstange gedient haben. ${ }^{1}$ Zwei Kufen dieser Art sind später in Ostfinnland, namentlich in den Kirchspielen I'ielavesi in Savo und Funsamo an der Reichsorenze im östlichen Ostbottnien, aus der Erde gehoben worden. ${ }^{2}$ Es scheint umbestrittlich zu sein, dass man also auch bei denjenigen Schlitten, von welchen die angeführten Kufen herstammen, mit einer Bindekonstruktion rechnen darf, obschon das Bindeelement zwischen den Kufen und Seitenstängen hier nicht durch spezielle Ständer, sondern durch elastische Bänder erzweckt worden ist. Es braucht kaum bemerkt zu werden, diss gerade den ostfinnischen Fünden dieser Art eine besondere Bedeutung zukommt, weil sie in einem ausgezeichneten Zusammenklange mit den ubengebrachten Kartenamalyse stehen. Wir werden gleich unten die Gelegenheit haben, die ingroleutete Lïsung des Bindeproblems noch näher an IIand eines jüngreren Bodenfundes zu heleuchten.

Die angebrachte kurze I'bersicht hat ergeben, dass der eigentliche Bindeständerschlitten eine uralte Konstruktion ist, die im Nordischen Raume bis zur älteren Eisenzeit zurückgefolgt werden kann. Das rezente, zersplitterte und nach den Randgebieten zurückgedrängtc Verbreitungsgehiet desselben Schlittens hat sich also beweiskräftig erwiesen. Bei der Abgrenzung dicses Verbreitungsgebietes oben ist nicht nälıer auf das Vergleich der

1 op.cit., s. $44-50$.

2 'T. I. Itkonen, Muinaissuksia ja -jalaksia IV. Suomen Museo 1936, s. $77-79$. 


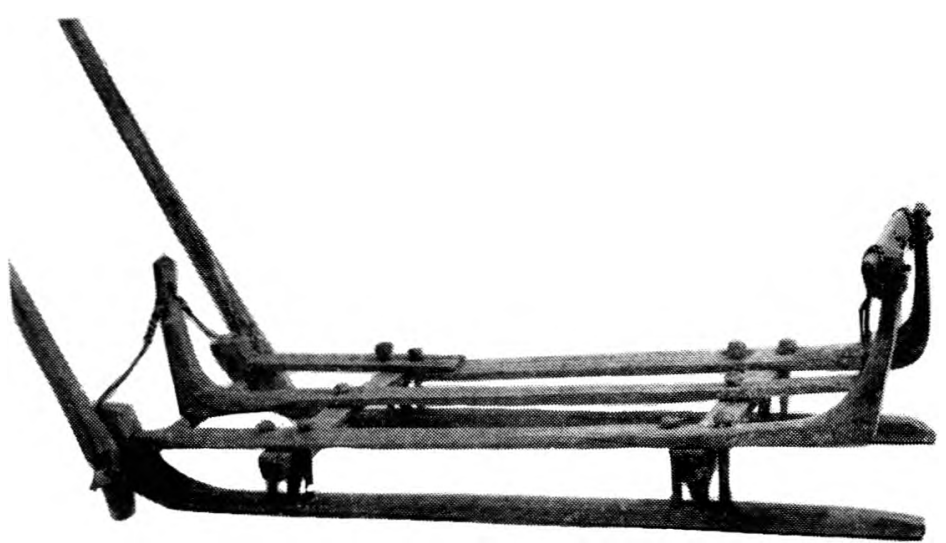

Fig. 18. Arbeitsschlitten aus Korgen, Nordland, Norwegen. Norsk Folkemuseum NFL 6321.

Konstruktionsdetails eingegangen worden. Es sei hier nur kurz bemerkt, dass die Lösung des Bindeproblems sowohl in den Alplandschaften als in der Regel auch in Skandinavien, durch de runden Bindeständer erfolgt, welche, besonders in Anbetracht der vorhistorischen Belege, im Vergleich mit den flachen Bindeständern als die primären angesehen werden müssen. Es gibt indes Anlass, in diesem Zusammenhange besonders auf die sog. Astständerkonstruktion, die aus Estland und Finnland beschrieben wurde, zurückzukommen. Wir haben oben dieser Tragständerkonstruktion eine bedeutungsvolle Rolle im Schlittenbau beigemessen und zugleich angedeutet, dass die Erscheinung in sowohl Estland als Finnland alt sein muss. Diese Annahme stützt sich ausser den lokalen Verbreitungsverhältnissen im finnisch-baltischen Raume darauf, dass dieselbe Konstruktion auch in allen übrigen Verbreitungsgebieten des eigentlichen Bindeständerschlittens vorkommt, so in der Schweiz, ${ }^{1}$ in Schweden, ${ }^{2}$ und in Norwegen. ${ }^{3}$ Aus dem letzterwähnten Lande wird

3 Brock.4an-Jerosch, op.cit., Abb. 264, 267.

2 Entsprechende Belege liegen aus folgenden Kirchsp. vor: B j u r$\mathrm{h}$ o $\mathrm{Im}$ in Angermanland, EU 11011; Vem ale $\mathrm{n}$ und $\mathrm{Sveg}$ in HärJedaten. KIövs jö in Jämtland, Aufzeichn, des Verl', im J. 1956.

s Nesheim, opreit., S. 50 , Abb. 6. - Svein Steinses, Gamle køyre- 

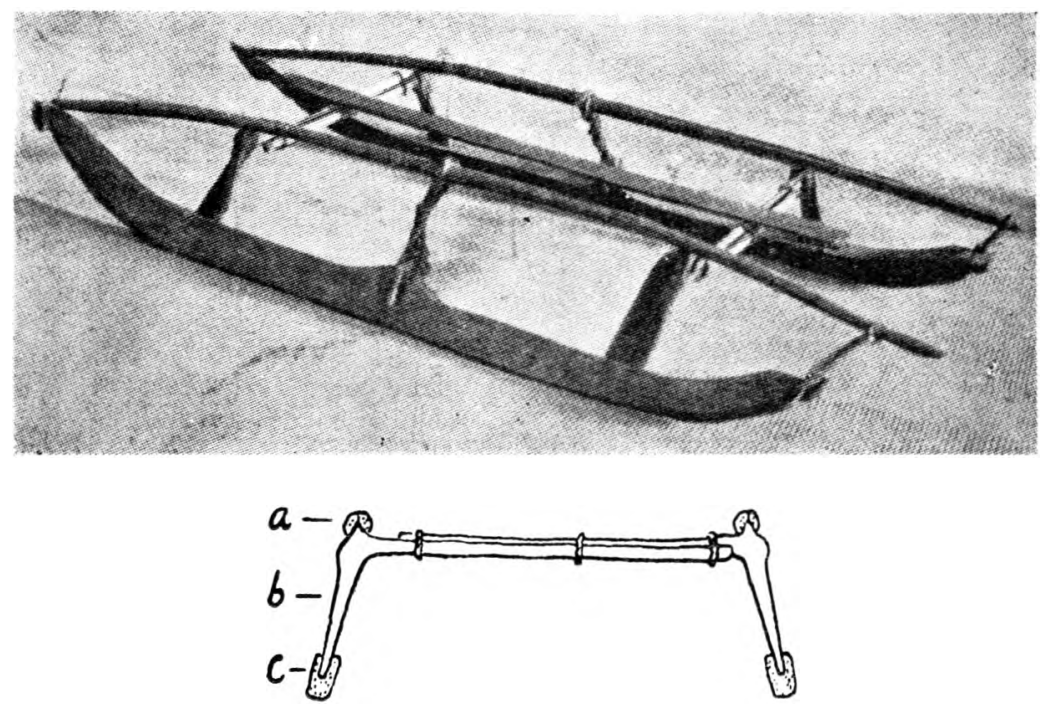

Fig. 19. Schlitten aus Parkano, Finnland. Nach T. I. Itkonen.

hier ein in der Astständerkonstruktion gebauter Schlitten, Fig. 18, abgebildet, ${ }^{1}$ der indessen, was die Ausformıng der genannten Konstruktion betrifft, eine Technik aufweist, welche bisher noch nicht besprochen wurde. Es kann nämlich festgestellt werden, dass die Querverbindungen des Schlittens hiel nicht aus einheitlichen Holzklötzen bestehen, sondern ans zwei, übereinander liegenden ungleichen Hälften, welche je mit einem natürlichen Astständer versehen ist, zusammengesetzt sind. Diese Technik, die auch in Nordschweden zu notier'n ist. ${ }^{2}$ erbietet ein besonderes Interesse, weil sie mit einer verwandte.. Technik der Tragständerkonstruktion bei einem Bodenfunde aus Finnland verglichen werden kann. Der Fund, welcher dus dem Kirchspiel Parkano in Satakunta herstammt, wird hier in einer teilweise rekonstruierten Gestalt, Fig. 19, nach T. I. IткоNEN abgebildet, und stellt einen Handschlitten dar, dessen

greidor i Karmsund. Museel i llaugesund. 10 ărs melding 1925-1935 og Avhandlinger om Vest-Norsk kultur. Haugesund 1935, S. 88.

1 Für die Photographie bin ich Herrn Konservator Hilmar Stigua. Oslo, zu Dank verpflichtet.

2 B jurholm, EU 11011. 
Kuffuenden suwohl vorue als auch hinten gekrümmt sind." Das Thagsystem des schlittens ist ohne Zweifel als eine Art Astständerkonstruktion zu bezeichnen. .Jedes von den beiden Tragständerpaaren mit welchen der Schlitten ansgerüstet ist, wird aus zwei rechtwinkligen Hälften zusammengesetzt, deren wagerechte, in der Mitte des Schlittens übereinander liegenden und umbundenen Teile als Querverbindungen fungieren. Wie es aus der Abbildung zu entnehmen ist, liegt der Unterschied von dem oben rorgeführten norwegischen Schlitten hauptsächlich darin, dass den Ïsten hier die Rolle von Querverbindungen zukommit, während sie dort als Ständer dienten. Die ganze Konstruktion tritt sozusagen in einer mmgekehrten restalt auf. Ein weiterer Unterschied ist sodann dirin zu erblicken, dass die Querverbindungen, welche ja hier nur aus ganz schwachen Ästen bestehen, um ein bedeutendes schwächer sind als bei lem vorhergehenden Schlitten. Es ist offenbar, dass die Tragkraft eines Schlittens, der mit Querverbindungen vorliegender Art ausgerüstet ist, mit der Tragkraft derjenigen schweren I astschlitten, mit welchen wir ms bisher beschäftigt haben, nicht verglichen werden kann. Die Vermutung liegt deshall, nahe, dass wir hier einer anderen Tradition des Schlittenbaues begegnen, die jenseits der schweren landwirtschaftlichen Transporte liegt. Das Alter des Parkanoschlittens hat man nicht hestimmen können. ITKosex, der den Fund publiziert hat, scheint denselben in eine historischr /eit verlegen zu wollen. Es ist immerhin merkwürdig, dass bei dem schlitten ein Bindesystem anftritt, dem man bei dem rezenten Material nicht mehr hegegnet. I)ie Seitenstänge des Schlittens, welche sich auf die sujtzen Enden der 'Tragständer stützen, werlen nämlich mit Hilfe von den durch die entsprechenden, in den Kufen befindlichen Löchern hindurchgezogenen Rutenbändern in ihrer Lage zurückgehalten. Wir haben mit anderen Worten eben dieselbe Konstruktion vor uns, die oben, bei der Besprechung einer der Teilgruppen von den rorhistorischen Kufenfünden aus der älteren Eisenzeit als wahrscheinlich angenommen wurde. Obschon die Kufe aus Parkano sonst nicht, was nämlich den

1 T. I. ITKONES, op.cit., S. 81. 
Unriss derselben betrifft, formkritisch mit denjenigen eisenzeitlichen Fünden gleichgestellt werden darf, erscheint es wenigstens sicher, dass man hier mit einem Fall zu tun hat, der weit jenseits des gegenwärtigen Schlittenbestandes liegt.

Im Gegensatz zu der vorhistorisch anmutenden Bindekonstruktion kann aber die Astständerkonstruktion derselben Ausführung wie sie bei dem Schlittenfunde aus Parkano auftritt, auch in dem rezenten Schlittenmaterial angetroffen werden. Aus Enontekiö-Lappmark an der Nordgrenze Finnlands hat 'T. I. IткоNen einen Renntierschlitten beschrieben, welcher eine vollständig identische Ständerkonstruktion aufweist. Auch hier werden die Querverbindungen des Schlittens aus den natürlichen, an den Ständern angewachsenen Ästen gebildet und mit Hilfe von Rutenringen zusammengehalten. Irgendein Bindesystem ist nicht vorhanden, der Schlitten wird aber sonst durch langen, bis zu den Kufenenden hinlaufenden Seitenstänge und eine sehr flache Form gekennzeichnet. ${ }^{1}$ Wie kann nun der lange Abstand zwischen den beiden Belegorten, Parkano einerseits und Enontekiö andererseits, erklärt werden? Ist das Auftreten der in Frage stehenden Astständerkonstruktion in Enontekiö etwa als eine zurückgedrängte Randerscheinung aufzufassen, die südlicherwärts nur noch durch einen Bodenfund zu Tage gelegt werden konnte? Das scheint tatsächlich der Fall zu sein. Aus dem Kirchspiel Nivala, der weit nördlich von Parkano im mittleren Ostbottnien liegt, wird hier ein (Querschnitt eines Schlittens gebracht, welche das mittlere ständerpaar nebst der dazugehörenden (querverbindung darstellt, Fig $20{ }^{2}$ Das Detail rührt von einem typischen osteuropäischen schlitten her. Die geschwungene Querverbindung, welche zwischen den oberen Enden der Ständer beobachtet werden kann, ist deshalb auch als vollständig erwartungsgemäss zu bezeichnen. Unter dieser Querverbindung östlicher Technik fällt aber noch ein weiteres Detail auf, das gleichwie eine Unterlage für sie

1 'T'. 1. It konen, Suomen lappalaiset vuoten 1945 I. Porroo-Helsinki 1948, S. 410.

2 KustaA Vilkuna, Vanhat veto- ja ajoneuvot. I. Sanastonkerääjän apuneuvoja 10. Helsinki 1930, S. 28, Fig. 13. 


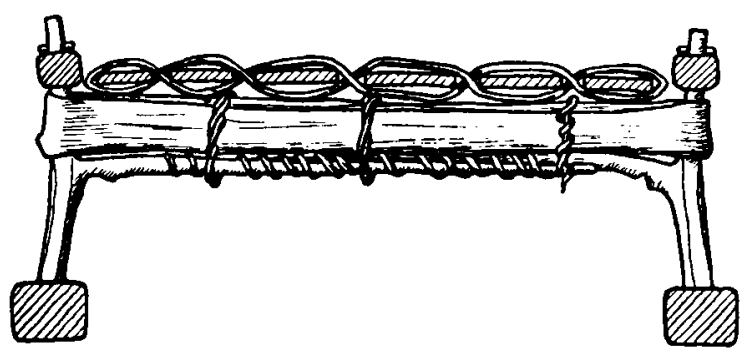

Fig. 20. Querverbindung des Schlittens aus Nivala, Finnland. Nach Kustaa Vilkuna.

bildet: die Astständerkonstruktion derselben Beschaffenheit, wie wir sie aus Parkano und dann aus Enontekiö kennen gelernt haben. Die Konstruktion kann auf der Abbildung deutlich unterschieden werden: von den beiden Ständern springen rechtwinklige Äste hervor welche quer über den Schlitten hervorragen und aneinander festgebunden sind. Die Astunterlage ist dann mit den oberen, geschwungenen Querverbindung mit Hilfe von Rutenbändern zusammengebunden worden. Das Resultat ist also eine Art verdoppelte Querverbindung, oder, anders ausgedrückt, zwei Querverbindungen in ein und demselben Schlitten, die aber kulturhistorisch auseinanderzuhalten sind. Denn es dürfte kaum bezweifelt werden können, dass hier tatsächlich zwei grundverschiedene Querverbindungskonstruktionen zusammentreffen, welche ursprünglich auch ganz verschiedenen Schlittentypen angehört haben.

Der Kirchspiel Nivala, aus welchem die vorgeführte Doppelkoustruktion herstammt, liegt in der nordwestlichen Randzone des Verbreitungsgebietes des osteuropäischen Schlittens in Finnland. Deutliche Spuren nach derselben Konstruktion könnell nun aber auch in den anderen Teilen des genannten Verbreitungsgebietes angetroffen werden. Aus cinem der östlichen Grenzkirchspiele des Landes, namentlich Ilomantsi, meldet z.B. Kustaa Vilkuna, dass man die Ständer des Schlittens womöglich immer derart herstellt, dass an den Innenseiten derselben je ein Ast zurückbleibt, welche dann in der Querrichtung des Schlittens himragen und zwischen den beiden zusammengefalte- 
ten Hälften der Querverbindung liegen kommen. ${ }^{1}$ Dieselb" 'T'echnik kann so gut wie aus allen Teilen des Verhreitungsgrehietes des osteuropäischen Schlittens in Finnland bewiesen werden, obschon sie auch nur sporadisch auftritt und heutzutage im Verschwinden begriffen zu sein scheint. ${ }^{2}$ Zum Unterschied von dem obenzitierten Bericht, laut welchem die Enden der Äste zwischen den übereinanderliegenden Hälften von der geschwungenen Querverbindung festgehalten werden, kanı man manchmal feststellen, dass die Äste - also ganz wie in Nivala - durch Umbinden an die Querverbindung fixiert werden. ${ }^{3}$ Die Aststümpfe, welche dermassen eine Unterlage für die geschwungene Querverbindung bilden, sind bisher gewöhnlich als erstärkende Stützen für Querverbindungen und zugleich als eine Massnahme, dem Wälzen des Schlittens Vorschub zu leisten, erklärt worden. ${ }^{4}$ Diese Erklärung trifft, was die Ausdeutung der funktionellen Seite der Erscheinung in der gegenwärtigen Schlittenkonstruktion angeht, unzweifelhaft zu. Sie schliesst aber eine historische Erklärung nicht aus. Eine solche wird sich darbieten, wenn man annimmt, dass die Astständerkonstruktion derjenigen Beschaffenheit, wie wir sie an Hand des Parkanofundes sowie auch des Renntierschlittens aus Enontekiö beleuchtet haben, einmal über das ganze nördliche und östliche Finnland verbreitet gewesen ist, dass sie aber dort in einer späteren Periode von der geschwungenen Querverbindung überschwemmt worden ist und jetzt nur noch als eine Kontaminationsform auftritt. Das besagt aber mit anderen Worten, dass wir hier höchst wahrscheinlich konstruktive Überbleibsel einer älteren Schlittenkonstruktion vor uns haben die aus einer Zeit herrühren, wenn der osteuropäische Schlitten sich in den betrachteten Gebieten noch nicht eingebürgert hatte.

1 Kustaa Vilkuna, Hevonen ja reki. Kansatieteellisiä muistiinpanoja Ilomantsin itäkylistä. Kansatieteellinen Arkisto III, S. 167168.

2 SS 109.

${ }^{3} \mathrm{Pihtipudas}$ in Nord-Häme, Kuhmoniemi in NordKarelien, SS 109.

4 Vgl. z.B. VILKunA, Hevonen ja reki, S. 168. 
Doch welchenı Schlittentypus mag diejenige Astständerkonstruktion, die wir nunmehr hauptsächlich noch als eine Kontaminationsform wahrnehmen können, ursprünglich angehört haben?

Es ist schon oben angedeutet worden, dass die Konstruktion, wie sie durch den Schlittenfund aus Parkano und den Renntierschlitten aus dem hohen Norden bezeugt wurde, schon angesichts ihrer herabgesetzten Tragkraft einer Schlittenform zugemutet werden muss, die mit den schweren landwirtschaftlichen Lastschlitten nicht gleichzustellen ist. Der Schlittenfund aus Parkano stellt, aus den Massverhältnissen zu schliessen, einen Handschlitten dar. Der Renntierschlitten aus Enontekiö ist, ganz abgesehen davon, wann derselbe bei den Lappen in Gebrauch gekommen ist, als ein Transportmittel eines hochnordischen Randgebietes aufzufassen, zu welchem keine, mit den schweren landwirtschaftlichen Transportbedürfnissen vergleichbaren Ansprachen gestellt werden. Insofern die oben darzelegte Annahme von einer ehemaligen Verbreitung der aus beiden diesen Schlitten bekannten Querverbindungs- bzw. Astständerkonstruktion über ganz Nord- und Ostfinnland zutrifft, soll also derjenige Schlitten, welcher hier als ein Vorläufer des osteuropäischen Schlittens gilt, aus einer Periode gesucht werden, die jenseits des eigentlichen landwirtschaftlichen Zeitalters in den genannten Gebieten des Landes liegr. Ein solcher Schlitten wird nun wahrscheinlich von derjenigen liruppe vorhistorischer Kufenfündle aus dem nördlichen Fennoskandien repräsentiert, von welcher wir schon ohen Erwähnung getan, und einige Exemplare anch etwas näher ins Auge gefasst haben. (Gösta BERG, der das Material einer näheren Behandlung unterzogen hat, nimmt an, dass der in Frage stehende Schlitten ein handgezogenes Transportmittel für die frühen, im Norden zirkulierenden Kaufleute darstellt. ${ }^{1}$ Die Konstruktionsdetails, welche sich aus den beabsichtigten Kufenfünden abstrahieren lassen, sind von einer etwas heterogenen Konsistenz. Die Uneinheitlichkeit mag wahrscheinlich teilweise aus dem Umstande erklärt werden können, dass die

1 BERG, op.cit., S. 52 . 
Fünde durchans nicht syuchronistisch sind, sondern sich über rine längere Zeitspanne erstrecken dürften. Eine Rekonstruktion, welche für die ganze Fundgruppe in allen Einzelheiten repräsentativ sein würde, ist demnach bisher noch nicht möglich gewesen. Von den Ständern, bzw. Querverbindungen liegen überhaupt keine Funddetails vor. Auf Grund des oben angeführten rezenten Materials wagt der Verfasser des vorliegenden Aufsatzes anzunehmen, dass die Astständerkonstruktion zuletztbesprochener Art aus derjenigen Zeit herstammt, wo der leichte Schlitten, von welchem die berülırten Kufenfünde Zeugnis ablegen, in den nördlichen und üstlichen Teilen von Fennoskandien noch im Gebrauch war, und dass sie demnach als ein integrierender Teil dieses schlittens oder wenigstens gewisser Varianten desselben gelten dürfte. Die Wahrscheinlichkeit spricht also dafür, dass man der uns hier beschäftigenden Astständerkonstruktion ein vorhistorisches Alter zusprechen kann. Wir haben schon oben darauf aufmerksam gemacht, dass eine verwandte Technik auch bei einigen späten Lastschlitten in Nordnorwegen nnd Nordschweden zum Vorschein kommt. Wir haben also damit gerechnct, dass diejenige Technik, die Querverbindungen aus zwei kräftigen, übereinander liegenden Holzklötzen mit je einem Astständer zusammenzusetzen, auf die leichte, aus dem Parkanofunde bekannte Konstruktion zurückweist. Zu den oben angeführten Beispielen dieser Art kamn noch ein Iastschlitten ans dem Kirchspiel Östmark in Värmland gefü̈gt werden, bei welchem die (2uerverbindungen aus unbearbeiteten, aber schr kräftigen Ästen bestehen, wodurch die Konstruktion gleichwie eine l'bergingsform zwischen den beiden berülirten Arten darstellt." I)ass man mit einem Substrat gleicher Technik in ganz Nord-Skandinavien zu rechnen hat, wird noch durch eine Abbildung eines Handschlittens aus Stordalen in Norwegen bestätigt, die neulich von AsbJörn Nesheim publiziert worden ist. Der Schlitten ist in einer regelmässigen Bindeständerkonstruktion aufgebaut. Die Querverbindungen bestehen aus dünnen, einheitlichen Holzblöcken, die sich aber auf zwei lange, von den Ständern hervorspringende 
Ïste stützen, welche - ganz, wie bei dem osteuropäischen Schlitten in Finnland - eine Unterlage für die wirkliche Querrerbindung bilden. ${ }^{1}$ Was diese Tatsachen für die Beleuchtung der Teschichte des osteuropäischen Schlittens in Finnland ausmachen, braucht hier nicht mehr näher erklärt zu werden. Wir haben eine weitbelegte und zugleich chronologisch tiefgreifende Astständerkonstruktion vorgefunden, die dem osteuropäischen Schlitten wesensfremd ist, die aber doch in der Konstruktion desselben rudimentär bewiesen werden kann. Wir sind mit anderen Worten bis zu der Grundschicht des modernen osteuropäischen Schlittens in Finnland vorgedrungen, welche einen direkten Beweis dafür ablegt, dass der genannte Schlitten daselbst keine bodenständige -Erscheinung darstellt, sondern einmal ins Land eingewandert ist und eine ältere Schlittenkonstruktion überschichtet hat. Estland mit seinen Reliktgebieten kann aus diesem Bilde nicht ausgeschlossen werden, obschon irgendwelche vorhistorischen Kufenfünde aus dem Baltikum überhaupt nicht bekannt sind, und die zuletztbehandelte, in die vorhistorische Zeit zurückgreifende Astständerkonstruktion dort bei dem osteuropäischen Schlitten nicht zu spüren ist. Für die alte Provenienz des eigentlichen Bindeständerschlittens in Estland verbürgt hinreichend das Ergebnis der Kartenanalyse und die Stellung, welche das Land in dem gesamten Verbreitungsbilde des genannten Schlittens einnimmt. Erweitert man dazu den Blick über die Grenzen des hier direkt behandelten Teils im Verbreitungsgebiet des osteuropäischen Schlittens, nimmt man wahr, dass auch in den Randzonen ausserhalb desselben gewisse Kontaminationsformen auftreten, die auf ein älteres Substrat zurückgeführt werden müssen. Es verwundert kaum solche in Nordschweden vorzufinden, da ja die Verbreitung des osteuropäischen Schlittens in diesem Teil von Fennoskandien eine verhältnismässig späte Erscheinung sein dürfte. Die übliche diesbezügliche Konstruktion, die hier vorkommt, weist einen westlichen Seitenstangenbau nebst den östlichen Querverbindungen auf, ${ }^{2}$ und fält somit mit einer von

1 Nesheis, op.cit., S. 50, Fig. 5.

2 J ukkas järvi, EU 10342; V il hel m in a, Er 911; L ö- 
den Kontaminationsformen, die schon aus Estland und Finnland bekannt sind, zusammen. Eine in allen Hauptstücken identische Konstruktion kann aber auch von der Halbinsel Kola belegt werden ${ }^{1}$ - also aus einem Gebiet, wo irgendein späterer westlicher Einfluss ausgeschlossen erscheint. Dieselbe Kontaminationsform ist weiter südwestlich ron Estland, aus dem Livischen Besidlungsgebiet in Nord-Kurland bezeugt, wo sie übrigens auf der Verbreitungskarte, Fig. 1: 9, verzeichnet ist. $^{2}$ Wir finden also nicht nur in den westlichen Teilen ron Estland und Finnland eine Randzone von Kontaminationsformen vor, sondern konstatieren einen Gürtel von denselben auch in einem weiteren Umkreis, der das Verbreitungsgebiet des osteuropäischen Schlittens in Finnland und Baltikum gleichwie umschliesst. Es dürfte deshalb nach der Auswertung des sowohl rezenten als auch vorhistorischen Materials keinen Zweifel mehr darüber geben, dass der osteuropäische Schlitten in Finnland und Estland als eine sekundäre Konstruktion zu bewerten ist, und dass die Theorie von seiner Prioritätsstellung im Vergleich mit der sog. westlichen Konstruktion in diesen Ländern also endgültig abgewiesen werden kann.

\section{III}

Dies besagt jedoch nicht, dass der osteuropäische Schlitten an und für sich innerhalb des kartierten Gebietes etwa eine ganz späte Erscheinung wäre, und selbstverständlich nicht, dass man ihm ein gleiches Alter in allen Teilen desselben Gebietes zusprechen könnte. Ein tieferer Einblick in die Chronologie des genannten Schlittens sowie eine weitere Beleuchtung der Schlittengeschichte innerhalb des behandelten Gebietes überhaupt erscheint nun durch Heranziehen der terminologischen Seite des Materials möglich.

vång e r, RAGxar JıRLow, Livet i Lövånger under senare hälften av 1800-talet. Västerbotten 1943. Västerbottens läns Hembygdsförenings ársbok. Umeå 1943, S. 101-104.

I Berg, op.cit., Taf. V: 1.

2 F. Lın us, Liivi etnograafia. Handschrift im Estnischen Nationalmuseum in Tartu. 
In seinem fimnischen Idialektatlas hat IaUR I KETTunen eint Karte über die Benennungren von Schlittenständer vorgelegt, welche hier zunächst als ein Beispiel für die existierenden terminologischen Gegensätze herangezogen sei. ${ }^{1}$ In der Beleuchtung der Karte zerfällt das Territorium Finnlands in grossen Zügen in drei Gebiete. Das überaus grösste ron ihnen, das den ganzen Osten des Landes umfasst, wird rom Worte kaplas beherrscht. Im Südwesten schliesst sich diesem grossen Verbreitungsgebiet ein kleineres an, wo die schwache Stufe desselben Wortes, namentlich kaulas oder kaulain, belegt ist. Wenn man die beiden Verbreitungsgebiete summiert, erhält man eine Westorrenze, die am Bottnischen Meerbusen etwas nördlich von der Stadt Kokkola beginnt, und dann durch Mittel()stbottnien, Nord-Satakunta, Mittel-Häme und Ost-Uusimaa dem Finnischen Meerbusen im süden, etwas westlich von der Mündung des Flusses Kymi, zuläuft. Nordöstlich von dieser Grenze dringt das Verbreitungsgebiet ron kaplas also auf einer breiten Front zum Bottnischen Meerbusen vor. Das Gebiet südwestlich von der Grenze wird dann von anderen Benennungen, wie ketara, käpälä, pii u.s.w. beherrscht, unter welchen das erstgenamnte Wort, namentlich ketara, eine dominierende stellung eimnimmt.2 Dieselbe Benennung taucht aber dann ganz isoliert von ihrem südwestlichen Verbreitungsgebiet im Sorden wieder auf wo es das nördlichste Ostbottnien und südliche Lappland umfasst. Die Südgrenze für ihre Verbreitung kann hier etwa längs der Nordgrenze von den Kirchspielen Kuivaniemi, Ranua und Kuusamo gezogen werden. Das Verbreitungsgebiet setzt dann über ein kleineres Gebiet in der Gegend der Reichsgrenze Schwedens, wo kaulas belegt ist, im finnischen Norrbotten jenseits der Reichsgrenze fort. - Es ist also leicht zu ersehen, dass wir ein typisches abgebrochenes Verbreitungsgebiet von ketara vor uns haben. Denn die Verteilung der hier abgerissenen Verbreitungsgebiete kann nicht anders erklärt werden, als dass die kaplas kaulas Crruppe rinen expansiven Terminus darstellt, der von Osten her nach

I Lauri kettunen, Summen murtert. III. Helsinki 1940, Karte Nr 24.

2 SS. 
dem Westen eimgefallen ist und rin ehemaliges Verbreitungsgobiet von ketara zersprengrt hat.

Diese Feststellung kann bekrältixt werden, wenn man die Zusammensetzung der vorliegenden terminologischen Verbreitungsgebiete einer etwas näheren Betrachtung unterzieht. Die scharfe (trenzlinie in Westen, die wir oben aus der Atlaskarte abstrahiert haben, ist, weil die Karte nur ganz summarisch gezeichnet ist, in gewissem Sinne irreführend. Es stimmt, wi! eben die Karte ausweist, dass der Terminus kaplas - kaulas rine durchaus dominierende Ständerbenennung in den üstlichen und mittleren Teilen des Landes ist, es stimmt aber dagegen nicht, wie das Kartbild ebenso vorgeben will, dass die Westgrenz seiner Verbreitung zur gleichen Zeit eine ()stgrenze für die westlichen Benenmungen bildet. Zwri von ihnen, namentlich liäpälä, welche auf einem begrenzten (rebiet in Sücl-Häme und linsimaa vorgefunden werden kann, hesonders aber ketara, welche überall im Westen verbreitet ist, können allch istlich der trrenze, also innerhalb des Varbreitungsgebietes von kaplas $\sim$ kaulas (truppe, belegt werden. Kä̈älä kommt z.B. in den Kirchspielen Iitti und Jaala in südost-Häme, ${ }^{1}$ letara an mehreren Stellen tief innerhalb des Verbreitungsgebietes von kaplas $\sim$ kaulas Gruppe in Nord-Satakunta und Mittel-Häme, ${ }^{2}$ sporadisch aber sogar in nördlichenı Ostbottnien und Karelien ${ }^{3}$ als Ständerbenennung vor. Andererseits kann festgestellt werden, dass die östliche Benennung sporadlisch westlich von derjenigen Westgrenze ihrer Verbreitung, die von der Atlaskarte angegeben wird, vorkommt. Wenn man nun die genannte terminologische Grenze mit der West rrenze des osteuropäischen Schlittens vergleicht das auf der Verbreitungskarte Fig. 1: 13 verzeichnet worden ist, erfährt man, dass die beiden (Grenzlinien im Jorden ziemlich nahe miteinander zusammenfallen, dass aber die terminologische Grenze im nördlichsten Teil der Landschaft Satakunta plötzlich ron der Schlittengrenzr abweicht

1 i l t i, Sis 109; I a a la, sis.

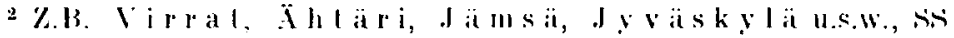
109.

s saloinen, Polvijärvi, Parikkala, Sts 109.

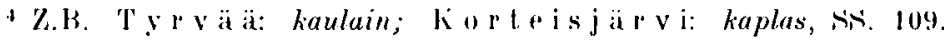


und dann auf einem beträchtlichen Abstand westlich von derjenigen dem Finnischen Meerbusen zustrebt. Man stellt also von der einen Seite fest, dass die östliche Ständerbenennung ziemlich tief in dasjenige Gebiet eingedrungen ist, wo der osteuropäische Schlitten nicht mehr vorhanden ist, und dass ihre Frequenz nach dem Westen hin allmählich abnimmt, während man von der anderen Seite konstatiert, dass die westliche Benennung ketara auch innerhalb des Verbreitungsgebietes des genannten Schlittens vorkommt. Im Osten des Landes sowie im nördlichen Ostbottnien können zwar nur einzelne sporadische Fälle davon belegt werden, in Süd-Lappland nebst angrenzenden Teilen von der genannten Landschaft ist aber Letara ganz vorherrschend.

Wenn man nun das Material in jenen westlichen Gebieten ausserhalb des Verbreitungsgebietes des osteuropäischen Schlittens näher untersucht, erweist es sich, dass die östliche Benennung dort stets nur auf diejenigen Ständer appliziert wird, die mit jener geschwungenen Querverbindung, die wir oben als ein spezielles östliches Konstruktionsdetail hingestellt haben, ausgerüstet sind. ${ }^{1}$ Die Beobachtung wird ganz besonders markiert, wenn bei dem Schlitten gleichzeitig ein zweigeteiltes Ständersystem auftritt. In diesem Falle werden nur die mit den östlichen Querverbindungen ausgerüsteten Ständer, welche hier also die Rolle von Bindeständern spielen, mit der östlichen Benennung bezeichnet, während den anderen, also den Tragständern, entweder käpälä (soweit dieser Terminus überhaupt vorkommt), oder, in Regel, ketara zukommt. ${ }^{2}$ Der Schluss, welcher aus diesen Distinktionen gezogen werden kann, besagt also, dass die östliche Ständerbenennung auch wirklich von einer östlichen Konstruktion getragen wird, dass sie mit anderen Worten eine spezielle Benennung des Ständers bei dem osteuropäischen Schlitten in Finnland ist und zur gleichen Zeit denjenigen östlichen Einfluss bei den Schlittenkonstruktionen im Westen des Landes dokumentiert, welcher oben an Hand der Konstruktionsanalyse bewiesen wurde. Zur gleichen Zeit

1 SS 109 .

2 Z.B. Nastola, Ja a la, Jämsä, Ku ru, Ki h n iö, Ty rvä ä u.s.w., SS 109. 
konstatiert man aber, dass die besprochene östliche Benennung nicht das ganze Gebiet im Westen, wo die östlich gefärbten Kontaminationsformen von Schlitten auftreten, deckt. Nur die östlichen Teile vom Verbreitungsgebiet derjenigen Kontaminationsform die sich aus den westlichen Tragständern und östlichen Bindeständern mit den geschwungenen Querverbindungen zusammensetzt, Fig. 1: 6-7, werden von ihr penetriert. Weiter westwärts tritt an ihre Stelle lasta, welche ganz bestimmt eine ältere Lokalbenennung für die Bindeständer in diesem Teil des Landes darstellt, ${ }^{1}$ während die Tragständer nach wie vor hauptsächlich mit ketara bezeichnet werden. ${ }^{2}$ Ebenso wird ein grosser Teil vom Verbreitungsgebiet derjenigen Kontaminationsform, die ein einheitliches, von dem osteuropäischen Schlitten überführten Ständersystem nebst langen, westlichen Seitenstängen aufzeigt, Fig. 1: 9, nicht von dem östlichen Terminus, sondern von der westlichen Benennung ketara beherrscht. ${ }^{3}$ Zuletzt haben wir ein beträchtliches Gebiet im Norden des Landes ausscheiden können, wo ketara sogar innerhalb des Verbreitungsgebietes des osteuropäischen Schlittens so gut wie einsam dominiert. Man konstatiert mit anderen Worten, dass der östliche Terminus nicht ganz mit der Verbreitung des östlichen Konstruktionseinflusses Schritt gehalten hat, dass unter der kaplas $\sim$ kaulas Gruppe eine ältere Schicht von Ständerbenennungen existiert, welche von ihr nur teilweise bedeckt worden ist. Es kann nun kaum einen $Z$ weifel darüber geben, dass diejenige ältere Benennung, worauf es hier vor allem ankommt, ketara ist.

Wir haben oben darauf hinweisen können, dass ketara bei denjenigen Schlitten im Westen, wo eine Zweiteilung des Ständersystems vorkommt, immer nur als Bezeichnung von Tragständern angewandt wird. Dasselbe kann von dem be-

1 Das Verhältnis geht ausgezeichnet von einem Bericht aus dem Kirchsp. N a s t o l a hervor, wo die Tragständer mit käpälä, die mit den geschwungenen Querverbindungen versehenen Bindeständer mit kaulai, das vorderste Paar der letztgenannten, das ganz ohne Querverhindung ist. mit lastikai hezeichnet werden, SS 109

2 si 109 .

3 SS 109 .

16 - Finnisch-ugrische Forschungen 
sprochenen Terminus behauptet werden, wenn er bei den Schlitten mit zweigeteiltem Ständersystem auftritt, die östlich von der Grenze des osteuropäischen Schlittens belegt werden können. ${ }^{1}$ Wenn man sodann den Blick auf das Belegmaterial im Westen des Landes, diesseits der Westgrenze des osteuropäischen Schlittens richtet, findet man, dass ketara daselbt oft den ganzen Tragständerkomplex, d.h. ein ganzes Paar von Tragständern nebst dazugehörender Querverbindung bezeichnet. ${ }^{2}$ Es muss zwar zugegeben werden, dass dieser Komplex oft zur gleichen Zeit wieder terminologisch zerlegt wird, indem man den Ständern pii oder piikki, ${ }^{3}$ der Querverbindung aber eine Menge von speziellen Benennungen, sowie niska, (ketaran)selkä, ketarorsi, (ketaran)penkki oder -lauta, miekklauta, pankka, auch pakka oder pakko, beibringt.* Diese untergeordneten Termini sind zufällig. Ihre Verbreitung'sgebiete sind schwach abgegrenzt, man könnte, etwa mit Ausnahme von pakko, welches unten in einem anderen Zusammenhange zu besprechen sein wird, von einer terminologischen Verwirrung sprechen. Dass ketara als Komplexbenennung hier als primär angesehen werden soll, wird auch dadurch bestätigt, dass dasselbe Wort oft nur auf die klotzartige Querverbindung beschränkt erscheint, während die Ständer selbst dann auf irgendeiner anderen Weise bezeichnet werden. ${ }^{5}$ Und wenn man dann zuletzt der angenommenen Komplexbenennung ketara die entsprechende Komplexkonstruktion, namentlich die schon oben eingehend behandelte Astständerkonstruktion, an die Seite stellt, und dabei findet. dass auch diejenige bloss mit

I Z.B. Polvijärvi; weiter horpila ht i, wo der Tragstiander zum Unterschied von kaulain, womit die mit den geschwungenen Querverbindungen versehenen Bindeständer bezeichnet werden, ketarakaulain genannt wird, SS 109.

z Z.B. Suodenniemi, Lavia, Huittintl, Kangasa 1 a, H a uho, Orivesi, J ä m sä u.s.w., SS 109.

3 La $i a, s u o d e n n i e m i, H u i t t i n e n, P u n k a l a j d u n$ U.s.W., SS $10 y$.

4 SS 109 .

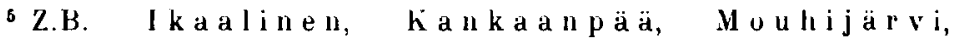
K a rk k, Pirkkala,Padas joki u.s.w., sS 109. 
ketara bezeichnet wird, ${ }^{1}$ muss man die Annahme für möglich halten, dass das Wort als Ständerbenennung ursprünglich eben eine Astständerkonstruktion bezeichnet hat. Eine Konstruktion also, wo die Ständer und Querverbindung entweder aus einem einzigen Stücke hergestellt sind, oder auch das Ganze derart itus zwei Hälften zusammengesetzt ist, dass irgendwelche Grrenze zwischen den Ständern und der Querverbindung technisch nicht zu unterscheiden ist. Eine solche Konstruktion haben wir nun aber nicht nur im Westen, sondern als eine Reminiszenz auch bei dem osteuropäischen Schlitten im Osten des Landes vorgefunden. Die Konstruktion gehört somit einer Periode in der Schlittengeschichte Finnlands an, die älter als der usteuropäische Schlitten im Lande ist. Wenn man nun mit dem terminologischen Verbreitungsbilde rechnet, und zur gleichen Zeit auf die ubengebrachte historische Penetrierung der Ständersysteme Rücksicht nimmt, kommt man zum Schlusse, dass auch ketara als Ständerbenennung ihren Ursprung aus derjenigen Zeit herleiten kann, wo der osteuropäische Schlitten im Lande noch nicht existiert hat. Man wird mit anderen Worten annehmen dürfen, dass die Ständerbenennung ketara einmal auch im Osten des Landes verbreitet gewesen, dass sie später in breiten Gebieten von kaplas kaulas Gruppe verdrängt worden ist, und dass der neue Terminus zur gleichen Zeit auch höchst wahrscheinlich das Vordringen einer neuen Schlittenkonstruktion, den osteuropäischen Schlitten, in weiten (rebieten Finnlands dokumentiert.

Die schlittenhistorische Bedeutung von kaplas liegt nun in einem weiteren Sinne darin, dass das Wort von der linguistischen Seite als ein slavisches Lehnwort angesehen wird. ${ }^{2}$ Es ist in der Bedeutung von Schlittenständer im Grossrussischen und Ruthenischen belegt. ${ }^{3}$ Soll nun diese Tatsache so ausgedeutet werden, als ob der besprochene Terminus zu derjenigen

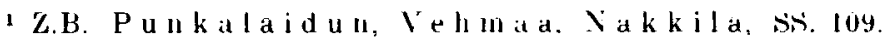

2 JALo KA LIMA, Slaavilaisperäinen sanastomme. Helsinki 1952, s. 5 , 232 .

3 D. Zelenin, Russische (ostslavische) volkskunde. Berlin-Leipzig 1927, S. 135. - Eugen Zelechowsk1, Ruthenisch-deutsches Wörterbuch I. Lemberg 1886, SS. 36't. 
Auffassung beitragen könnte, dass der osteuropäische Schlitten in Finnland oder gar im ganzen Besiedlungsgebiet der Ostseefimnen durch Vermittlung der Grossrussen eingewandert wäre?

Die Frage kann nicht ohne weiteres beantwortet werden. Das Wort kaplas ist ausser dem Finnischen noch im Karelischen, Olonetzischen, Lüdischen und Wepsischen belegt, ${ }^{1}$ dagegen aber nicht im Estnischen, Wotischen und Livischen. In den letztgenannten Sprachen herrschen genaue ethymologische Entsprechungen zum finnischen Wort ketara ror, ${ }^{2}$ während kaplas vollständig unbekannt ist. Dazu soll bemerkt werden, dass sich für ketara eine finnisch-ugrische Ethymologie bringen lässt, ${ }^{3}$ und dass das Wort ausser der oben besprochenen Bedeutung innerhalb des Verbreitungsgebietes des osteuropäischeu Schlittens in Finnland sporadisch auch noch die oberen, gekrümmten Enden, oder auch den ganzen Vorderteil des Schlittens bezeichnet. ${ }^{4}$ Es ist nicht unmöglich, dass es hier um eine Bedentungsverschiebung handelt. Als Schlittenterminus ist das Wort sonst nur auf die ostseefinnischen Sprachen beschränkt. Wenn man unter solchen Umständen den Beweiswert des slavischen Lehnwortes erproben will, liegen drei Alternative vor: entweder bezieht sich seine Beweiskraft nur auf Finnland nebst den übrigen östlichen Gebieten der Ostseefinnen, oder ist der osteuropäischen Schlitten jedoch in das gesamte Besiedlungsgebiet genannter Völker durch Vermittlung von Grossrussen eingewandert, ohne dass das besprochene Lehnwort sich überall eingebürgert hätte, oder aber hat der osteuropäische Schlitten bei den Ostseefinnen schliesslich ursprünglich gar nichts mit dem russischen Kultureinfluss zu tun, wobei das Lehnwort bloss als ein späterer Zusatz in der Schlittenterminologie anzusehen wäre. Welche von diesen Alternativen gebilligt werden soll, kann indes nicht nur an Hand des in Frage ste-

1 Y. H. Torvonen, Suomen kielen etymologinen sanakirja I. Helsinki 1955 , S. 159.

2 Tolvonen, op.cit., S. 187. - Zum Wotischen (Joenperä), Privalsamml. von Prof. G. RÄNK, Stockholm; zum Estn. Ferdinand Wiedemann, Ehstnisch-deutsches Wörterbuch. St. Petersburg 1893, S. 315, und iamml i AEs.

3 'Torvonen, op.cit. S. 187.

ASS 109. - Vgl. auch Torvonen, up.cil. 
henden Wortes entschlossen werden. Eine Behandlung desselben ist nötig gewesen, weil es den einzigen, in die Grundkonstruktion des Schlittens eingreifenden Terminus in den ostseefinnischen sprachen bildet, dessen Ursprung bei den slavischen Nachbarn gesucht, werden muss. Wir wenden uns nun ein paar weiteren Benennungsgruppen zu.

Die Verbreitungskarte Fig. 21 stellt die Benennungen der geschwungenen Querverbindung, ungeachtet dessen, weicher Schlittenkonstruktion sie zugehört, dar. ${ }^{1}$ Obschon die Anzahl ron Benennungen recht gross ist, erscheint das Kartbild trotzdem nicht verworren, sondern zeiclnet sich durch fest abgeyrenzte Verbreitungsgebiete aus. Die Karte wird vor allem durch Hervortreten von zwei verschiedenen Termini geprägt, von welchen der eine in Finnland und der andere in Estland eine zentrale Stellung einnimmt. Den übrigen Benennungen scheint im Vergleich mit denselben nur eine Randposition zuzukommen. Der dominierende Terminus in Finnland ist paju, Fig. 21: 1, welche den Gegenstand aus dem Rohmaterial heraus kennzeichnet und mit dem entsprechenden Baumnamen, namentlich "Weide", der als solcher in allen ostseefinnischen Sprachen rorkommt, identisch ist. Als Benennung der Querverbindung ist das Wort ausser in Finnland sporadisch noch in Ostkarelien und dem olonetzischen Gebiet, besonders aber in den, vom Finnischen überschwemmten ingermanländischen und wotischen Besiedlungsgebieten bezeugt. Im Westen Finnlands ïberflügelt paju eine ältere Benennung, namentlich ketara, Fig. 21:3, welche hier deutlich als ein terminologisches Relikt nach derjenigen Komplexbenennung des Tragständerpaares, die obeı ausführlich behandelt worden ist, vorkommt. In Estland fällt dann zuerst die mundartlich variierende Benennung painard $\sim$ paenard $\sim$ paenald $\sim$ pannald $\sim$ paanand $\sim$ painang $\sim$ painatus $\sim$ painates $\sim$ painat $\sim$ painajas $\sim$ painipuu auf, die, durch ein einheitliches Zeichen, Fig. 21: 2, auf der Karte verzeichnet. ein verbreitungsmässiges Gegenstück zu der finnischen Benennung hildet. Das Wort kann aus pain/utama, pain/duma,

1 Die Karte stützt sich auf Sammlungen in ER.I, AES, SS, K.I, SKS, Materialien zum wepsichen Wörterbuch in Helsinki und Privatsamml. von Prof. A. Saareste, Uppsala. 


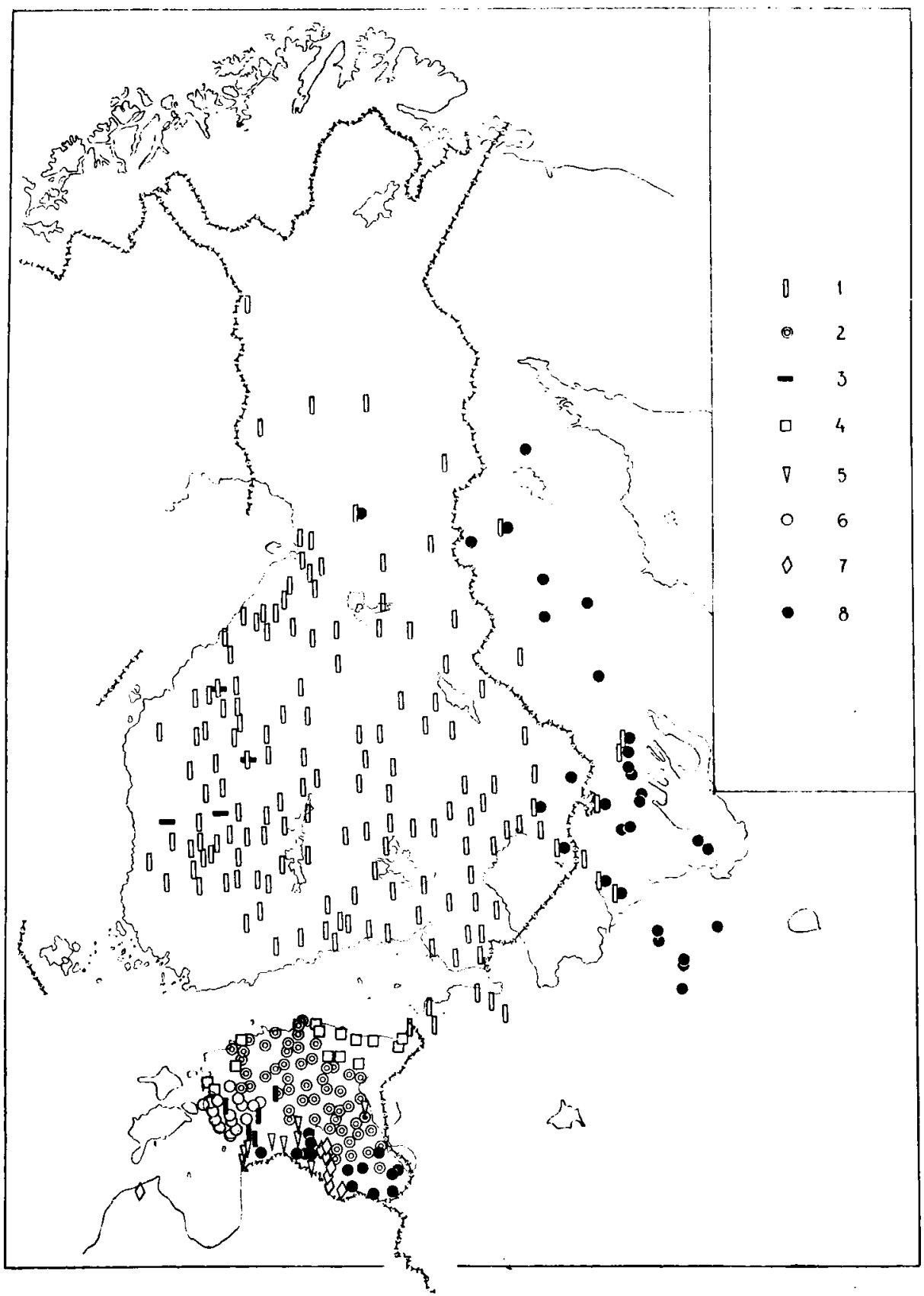

Fig. 21. Verbreitungskarte über Benennungen der östlichen Querverbindung des Schlittens. 1. paju, 2. painard u.s.w., 3. ketara, 4. pakk, 5. künnapas, 6. sugaras, 7. kaust, kaus(t)puu, 8. poikkipuolinen, pökpool u.s.w. 
"biegen. sich biegen", hergeleitet werden, und charakterisiert also den Gegenstand ron dem Gesichtswinkel des Herstellungsprozesses heraus. Das Verbreitungsgebiet der painard-Gruppe, welches sich in Form eines breiten, einheitlichen Gürtels vom südosten des Landes bis zum Finnischen Meerbusen erstreckt, ist, ebenso wie das Verbreitungsgebiet von paju in Finnland, als eine vordringende und agressive Erscheinung aufzufassen. Wenn paju in Finnland eine ältere Benennung (ketara) überflügelt, die ihre ursprüngliche Bedeutung eingebüsst hat und jetzt also als ein terminologisches Relikt anftritt, kann dasselbe mit einem noch grösseren Recht von painard in Estland behauptet werden. Wir stellen zuerst fest, dass painard das Verbreitungsgebiet einer anderen Benennung, namentlich pakk, Fig. 21: 4, im Norden des Landes überschwemmt und zersprengt hat. Die eine Hälfte des zersprengten Verbreitungsgebietes kann in Virumaa (Wierland) im Nordosten, die andere in Harjumaa und Läänemaa im Nordwesten des Landes, auf beiden Seiten von dem agressiven Terminus wahrgenommen werden. Das Wort pakk ist an und für sich für die Schlittengeschichte in Estland aufschlussreich und verdient etwas näher berührt zu werden. Es bedeutet eigentlich "Holzklotz», und ist als Schlittenterminus ursprünglich derjenigen klotzartigen Querverbindung im äussersten Westen und auf den Westinseln, die wir oben näher beleuchtet haben, zuzuschreiben. In dieser Eigenschaft kann das Wort nämlich in den genannten Gebieten noch allgemein belegt werden. ${ }^{1}$ Ausserdem kommt das Wort in derselben Bedeutung auch auf der anderen Seite des Finnischen Meerbusens in Uusimaa und, mit einer fallenden Frequenz, im Eigentlichen Finnland vor. ${ }^{2}$ Es ist, immer noch in

1 Z.B. Ki helk on na, AES I; Pö i d e, AES L; K a r ja, ERM Kv 54: 495; J ä m a ja, SammI. von Prof. SAareste; E m m a $\mathrm{t}$ e, AES W; P üh a le p a, ERA H II 41, $275=$ Estnisches Folkloristisches Archiv, Tartu; R is ti, Samml. von Prof. A. Saareste; Nis si, ERM Kv 54: 157; H a n i l a, briefl. Mitteil. vom Herrn J. Päri, Schweden, den 21. 3. 54; V a r b l a, briefl. Mitteil. vom Herrn W. Altmäe, Schweden, den 28. 3. 54; R i d a l a, briefl. Mitteil. vom Herrn W. MAAKER, Schweden, den 15. 3. 54, u.s.w.

ZZB. A n jala, Ruotsinp y $\mathrm{täa,}$ T u u s la, Loh ja, Perniö, Marttila, Vehmaa, SS. 
derselben Bedeutung, weiter im finnlandschwedischen Dialekt ron Nyland bezeugt, wo es als ein finnisches Lehnwort aufgefasst wird. ${ }^{1}$ Dieses abgebrochene Verbreitungsgebiet erlaubt anzunehmen, dass der in Frage stehenden Bedeutung des Wortes tatsächlich ein beträchtliches Alter zukommen muss, indem das Wort als Sclilittenterminus in Finnland wahrscheinlich mit den estnischen Auswanderungen zusammenhängt, die schon seit Mittelalter besonders nach Uusimaa erfolgt sind. ${ }^{2}$ Wenn dasselbe Wort nun in Estland aber auch in der Bedeutung der geschwungenen Querverbindung auftritt, muss angenommen werden, dass es hier $11 \mathrm{~m}$ eine Bedeutungsverschiebung handelt, dass wir mit anderen Worten wieder ein terminologisches Relikt vor uns haben. Die Annahme wird nachträglich dadurch bewiesen, dass die westliche Hälfte des zerspalteten Verbreitungsgebietes des betreffenden Wortes gerade innerhalb des Verbreitungsgebietes einer Kontaminationsform desjenigen Bindeständerschlittens liegt, bei welchem die Benennung pakk in ihrer ursprünglichen Bedeutung noch heute vorhanden ist. Es liegen dann auch keine Schwierigkeiten vor, damit zu rechnen, dass die östliche Hälfte desselben Verbreitungsgebietes, die innerhalb des Verbreitungsgebietes des osteuropäischen Schlittens liegt, ebenfalls von dem ehemaligen Vorhandensein einer westlichen Schlittenkonstruktion ein Zeugnis ablegt. Damit haben wir aber ein neues Licht auf die kulturhistorischen Verhältnisse der beiden Grundkonstruktionen des Schlittens in Estland werfen und das Resultat der vorhergehenden Sachanalyse weiter ausbauen können.

Die beiden behandelten Benennungen, paju in Finnland und die painard-Gruppe in Estland, müssen also augenscheinlich

1 Ralf Saxen, Finska lånord i östsvenska dialekter. Bidrag till kännedom om de svenska landsmålen ock svenskt folkliv XI. 3. Stockholm $1895-98$, S. 184 .

2 Gunvor KerkKonen, Västnyländsk kustbebyggelse under medeltiden. Helsingfors 1945, S. 59-81. - O. Liv, Iseloomustusi TallinnaSoome vahelisele kaubandusele peamiselt XVIII sajandi lópul ja Eesti koloniidest Soomes. Ajalooline Ajakiri 1929. Tartu 1930, S. 73-74. Oтто LıIv, Eestiläisten siirtymisestä Suomeen 1700-luvulla. Historiallinen Arkisto XLIII. Helsinki 1937, S. 15. 
als Dokumentierung des Vordringens derjenigen Konstruktion, die dem osteuropäischen Schlitten eigen ist, aufgefasst werden. Es kann dabei aber ein Unterschied in den Bewegungsrichtungen beobachtet werden. In Finnland ist die Bewegung gerade von Osten nach Westen, in Estland in grossen Zügen von Süden nach Norden oder Nordwesten gerichtet. Es wird zu dieser Differenz zwischen den Verbreitungsverhältnissen des osteuropäischen Schlittens in den beiden I Iändern, deren wir hier zum ersten mal begegnen, später noch mehrmals zurückzukommen sein. - Die beiden obenbehandelten Benennungen sind indes ganz lokalgeprägt und lassen keine schlüsse über weiteren historischen Zusammenhängen zwischen verschiedenen Teilen des kartierten Gebietes zu. Dasselbe kann auch von den meisten anderen Benennungen, die in einer beträchtlichen Anzahl im Süden und Südwesten Estlands auftreten, behauptet werden. Eine von ihnen, künnapas, Fig. 21: 5, die ebenso wie paju in Finnland auf einen Baumnamen, namentlich »Ulme», zurückgeführt werden kann, scheint früher eventuell ein grösseres Verbreitungsgebiet eingenommen zu haben, welches dann ebenso wie das Verbreitungsgebiet von pakk im Jorden von der vordringenden painard-Gruppe überschwemmt worden ist. Sugaras, Fig. 21: 6, im Südwesten, fällt auf den Gattungsnamen »Stock», "Prügel» zurück, der allgemein in den südlichen und östlichen Dialekten des Landes dokumentiert ist, ${ }^{1}$ und erbietet als Benennung der Querverbindung innerhalb ihres scharf abgegrenzten Verbreitungsgebietes nur ein geringes Interesse. Dasselbe muss von arangas in demselben Teil des Landes behauptet werden. ${ }^{2}$ Eine Sonderstellung unter den verschiedenen Benennungen, die in Südestland zum Unterschied von Finnland ein so buntes Gepräge aufweisen, kommt dagegen kaust oder kaus(t)puu, Fig. 21: 7, zu. Die schlittengeschichtliche Rolle dieser Benennung, welche ausser einem begrenzten Gebiet in SüdwestTartumaa (Kreis Dorpat), Ost-Valgamaa (Kreis Walck) und West-Võrumaa (Kreis Werro) auch im Livischen in Nord-

1 Wiedemann, op.cit., S. 1083. - AES.

2 Die Benennung geht auf einen Vogelnamen, namentl. "Elster", zurück, Wiedemann, op.cit., S. 38 . 
Kurland hezeugt ist. soll jedoch erst später besprochen werden. Im äussersten süden des Landes fällt aber schliesslich eine Benennung der Querverbindung Fig. 21: 8, auf, die plötzlich die Grenzen Estlands sprengt und eine Verbindung mit den weit vom Lande gelegenen Gebieten im Nordosten herstellt. Ihr Verbreitungsgebiet besteht einerseits aus einem ziemlich hreiten Gürtel an der Südgrenze Estlands, der sich vom Rigaer Meerbusen im Westen bis Setukesien im Usten erstreckt, andererseits aber aus ganz Olonetz- und Ostkarelien samt allen Besiedlungsgebieten der Wepsen östlich und südöstlich rom Ladogasee. Die Westgrenze des Verbreitungsgebietes im Nordosten fällt im grossen und ganzen mit der Ostgrenze Finnlands zusammen. Nur unmittelbar nördlich rom Ladogasee wird die alte Reichsgrenze um ein unbedeutendes überschritten. Ein vereinzelter Beleg ist weiterhin im Norden, im Kirchspiel Pudasjärvi diesseits der Reichsgrenze, zu notieren. Es ist zu bemerken, dass das Bild in der Grenzgegend überhaupt ein gemischtes ist, da die Benennung paju auch ihrerseits die Reichsgrenze überschreitet und in den westlichen Teilen des ostkarelischen Bodens zu belegen ist. Weiter im Osten a her herrscht die hier in Frage stehende Benennung ganz ungestört vor.

Der besprochene Terminus, der auf der Karte einheitlich verzeichnet worden ist, tritt mundartlich etwas verschieden auf. In Estland können folgende Formen notiert werden: pöikpool $\sim$ põipool $\sim$ põipul, ${ }^{1}$ põibas, ${ }^{2}$ põigus $\sim$ põigüs $\sim$ põik, ${ }^{3}$ põipuu. ${ }^{4}$ Im Karelischen und Wepsischen herrscht eine grössere Einheitlichkeit vor: poikkispuolin'e, ${ }^{5}$ poikkispuoline, ${ }^{6}$ poikkišpuålized pàijub, poikkipuol'in'e poikkipuol'in'i; ${ }^{7} \mathrm{im}$ Lüdi-

I Pólva, ERM Kv 54: 983; H e l m e, AES.

$2 \mathrm{~K}$ a r k i, AES.

3 Urvaste, Vastseli ina, Petseri, AES. - Samml. von Prof. A. SaAreste; R äp i n a, ERM Kv 54: 115.

$4 \mathrm{~S}$ a a $\mathrm{r}$ e, AES.

s $\mathrm{Su}$ is t a m o, SS.

6 $S$ ä äm äjärvi, SS.

? $\mathrm{N}$ e k k u la-R i i p ušk a la, SS.

s Jyskyjärvi, Paatene, Rukajärvi, I'htua, Tunku a, Petsa mo- K jestinki, va ok kiniemi, Ss. - Für die Belege aus dem Karelischen und Olonetzischen sowie den Inger- 
schen notiert man ganz identische Formen, sowie poikiispunline. -likišpuoling, ${ }^{1}$ poilipuol'in'e u.s.w.; ${ }^{2}$ im Wepsischen schliesslich poikpol'in'e, ${ }^{3}$ poikpol'n'e. ${ }^{4}$ - Es kann trotz den Verschiedenheiten, die von den gebrachten Belegen zwischen Estland einerseits und den karelisch-wepsischen Gebieten andererseits hervorgehen, keinen Zweifel darüber geben, dass man hier mit einem Terminus zu tun hat, der ethymologisch einheitlichen Ursprunges ist. Das Wort kann in seiner ostseefinnischen Urform etwa wie *poikikipoólinen rekonstruiert werden, und drückt etwas aus, das quer, in der Querrichtung, querüber liegt. Auf die verschiedenen Verkürzungen und Derivationen die das zusammengesetzte Wort in den südestnischen Dialekten erfahren hat, braucht man hier nicht näher einzugehen, zumal die Formen wie põikpool põipool põipul unmittelbar mit dem karelisch-wepsischen Material verglichen werden kann. Es liegt hier zum ersten mal eine Benennung eines Schlittendetails vor, die, ausschliesslich innerhalb des Verbreitungsgebietes des osteuropäischen Schlittens liegend, gemeinsam für die weit von einander gelegenen Teile des kartierten Gebietes ist. Das Verbreitungsgebiet der Benennung ist dazu ein ganz. merkliches, es ist peripherisch und abgebrochen, und muss damit von einem hohen Alter sein. (Obschon das Wnrt semasiologisch nicht so ausgelegt werden kann, als ob es ursprünglich mit Notwendigkeit gerade die geschwungene Querverbindung und nicht etwa eine solche irgendeiner anderen Konstruktion

manländischen Mundarten bin ich Herrn Prof. K. Nirvi. Helsinki, zu Dank verpflichtet.

1 Suoju: Vi i t a n a, P y häjär vi, Juно Kujola, Lyydiläismuretiden sanakirja. Helsinki 1944, S. 325.

2 M n närvi, Sunnunsuu. Päläniemi, Possinky. lä, Puikkoniemi, op.cit.

3 Kaskesoja, S o u t järvi, E. A. Tuskelo, Vepsän kielen äännehistoria. Helsinki 1946, S. 345,595 . - S i m j ä r v i, A l a ž a g aja, Korvoila, Materialien zum wepsischen Wörterbuch, Helsinki. - Für die Mitteilungen aus dieser Sammlung ist der Verf. Herrn fil. maist. R. Peltola, Helsinki, zu Dank verpflichtet.

- Lauri Kettunen. Lõunavepsä häälik-ajalugu II. Acta et Comm. Iniv: Dorp. B IIJ, 4. Tartu 1922, s. 11-. A l's a h t i, Mat. z. weps. $\mathrm{Wb}$. 
bezeichnet hat, ist die Möglichkeit doch nicht ausgeschlossen, dass wir hier auf einen 'lerminus gestossen sind, der schon von Infang an mit dem osteuropäischen Schlitten verknüpft gewesen ist. Der Ausschlag hängt von der nächsten Benenmungsgruppe, der wir uns nun zuwenden, ab.

Diese Gruppe umfasst die Benennungen eines von den wichtigsten Details des osteuropäischen Schlittens, namentlich ler Rutenbänder zwischen den Kufenenden und dem ersten ständerpaar. Das Material liegt in der Gestalt einer weiteren Verbreitungskarte, Fig. 22, vor. ${ }^{1}$ Es ist einleuchtend, dass dic Karte eine gewisse allgemeine Gleichheit mit der vorhergehenden Karte aufweist. Während Finnland von einer einheitlichen Benennung, namentlich kainalovitsa, Fig. 22: 1, beherrscht wird, welche ganz isoliert von den übrigen Teilen des kartierten Gebietes dasteht, leiten aus Estland wieder Verbindungen nach dem ostkarelisch-olonetzischen und wepsischen Sprachgebiet hinüber, wodurch ein abgebrochenes Verbreitungsgebiet desselben Charakters wie im vorhergehenden Falle, zum Vorschein kommt. Das Verbreitungsgebiet ist jetzt dazu ein verdoppeltes, es ist von zwei Benennungen die Frage, welche in der genannten Richtung wirksam sind.

Es soll zuerst diejenige von ihnen, welche die grösste Verbreitung aufweist, besprochen werden. Sie, Fig. 22: 2, deckt. in Estland das ganze Verbreitungsgebiet des osteuropäischen Schlittens und ist in der Regel entweder als seb'ä'vits, im Süden des Landes sebivits oder sepivits, oder aber auch bloss als seb 'ä' belegt. Die topographische Verteilung der beiden Formen kommt auf der Karte nicht zum Vorschein; es sei hier nur bemerkt, dass sie ganz vermischt miteinander auftreten. ${ }^{2}$ Der

1 Siehe S. 245, Note 1.

${ }^{2}$ seb'ävits, sepivits z.B. in Kirchsp. Ku us a Iu, V a ivara,

Fig. 22. Verbreitungskarte über Benennungen der Rutenbänder zwischen den Kufenenden und vordersten Ständern bei dem osteuropäischen Schlitten. 1. kainalovitsa, 2. sepävitsa, seb'a' , 3. semmivits u.s.w., 4. zufällige Benennungen, 5. tšoappavitsa, 6. Die nördliche Verbreitungsgrenze der primitiven Variante des osteuropäischen Schlittens in Estland. 


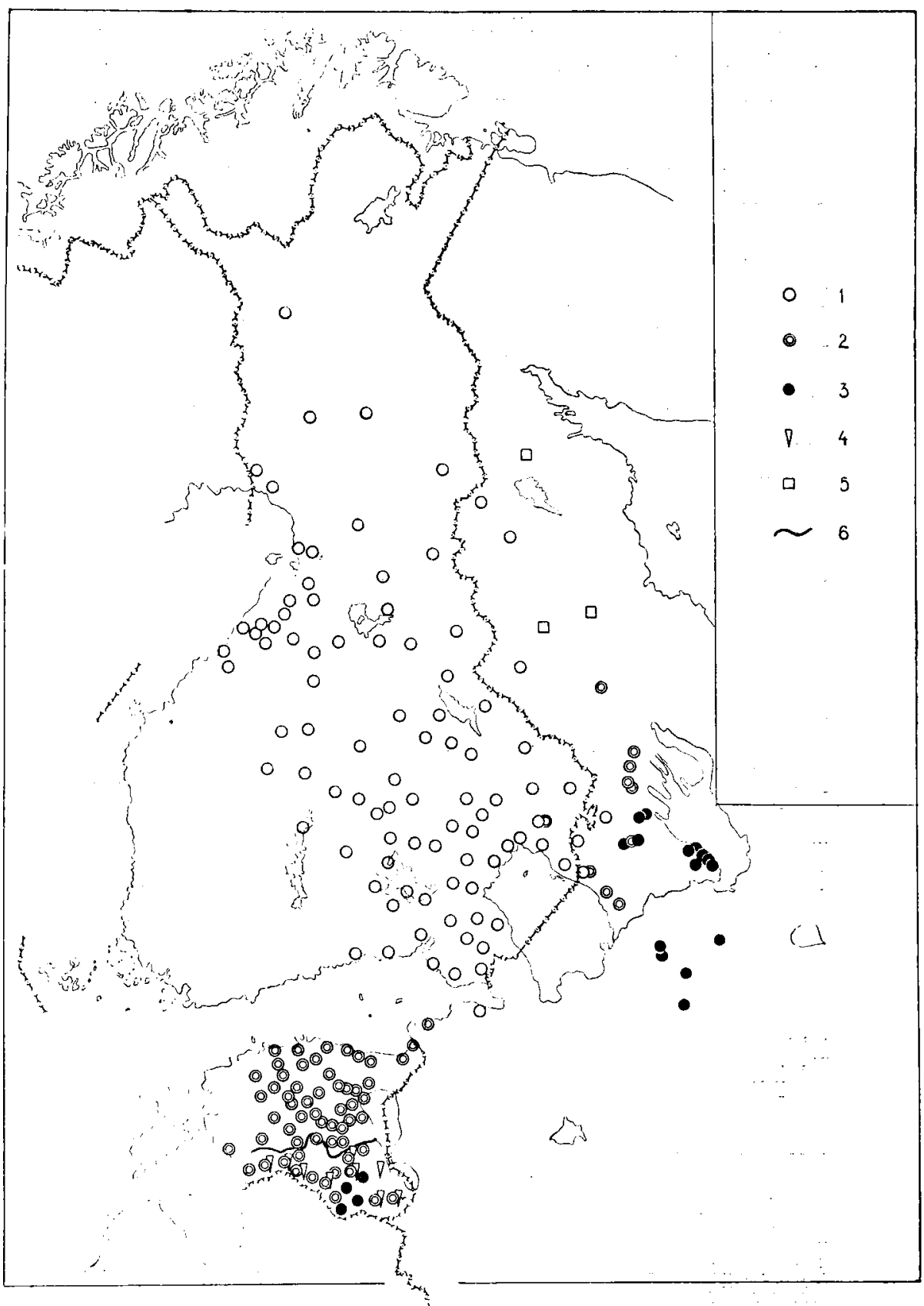


Bedeutungsinhalt wird durch die alternativen Erscheinungsformen der Benennung nicht geändert. Es soll aber dagegen vorbehalten werden, dass die beiden Formen der Benennung südlich von derjenigen Grenzlinie, welche in dem südlichen 'Teil des Landes auf der Karte, Fig. 22: 5, verzeichnet worden ist, überwiegend in einer gewissen verschobenen Bedeutung vorkommen. Auf die terminologischen Verhältnisse hier wird noch später zurückzukommen sein. Dies hindert nicht, die Betrachtungen über den vorliegenden Terminus erst im allgemeinen zu vollziehen. Die andere Hälfte des Verbreitungsgebietes desselben liegt in Olonetz zwischen Ladoga- und Onegasee. Der nördlichste Beleg kann aus dem Kirchspiel Paatene nordwestlich vom Onegasee gebracht werden; noch nördlich davon dringt die aus dem Russischen entlehnte Benennung tšoappacitsa in Ostkarelien ein. ${ }^{1}$ Es soll im Auge behalten werden, dass die Benennung im Ladogagebiet nur in den karelischen und teilweise auch lüdischen Mundarten, d.h. in dem westlichen Teil des angegebenen Gebietes, aber nicht mehr im Wepsischen im Osten begegnet. Der Terminus ist hier ausschliesslich als Kompositum belegt, das mit der aus Estland vorgeführten Zusammensetzung seb'ä'vits direkt verglichen werden kann. ${ }^{2}$ Es ist nun gerade dieselbe Zusammensetzung, deren Schlussglied eben als "Rute» übersetzt werden soll, welche in diesem $\mathrm{Zu}-$ sammenhange einen Beweiswert besitzt. Das Wort seb'ä', welches wir in Estland in derselben Bedeutung wie das Kompositum vorgefunden haben, ist nämlich als Schlittenterminus auch sonst, und zwar innerhalb des ganzen Verbreitungsgebietes des osteuropäischen Schlittens bei den ostsee-

Jó e lehtme, Kursi, Otepää, Ka mbja, Vastseli ina u.s.w.; se' $\ddot{a}$ ' in I i a k u, A m b la, S u u re - J a a n i, T or i, H e lm e u.s.w., AES.

1 Z.B. Tunkua, Rukajärvi, Pe tsamo-kiestinki, SS. - Vgl. Tolkovyj slovar Živago velikoruskago jazyka 4. VLADimira Dalja. S. - Peterburg-Moskva 1882, S. 599.

2 M i e k k u la-R i i p ušk a la: sebätoitśsu, SS; Vi tel e: sebäoiiśàd, Eıno Leskinen, Karjalan kielen näylteitä II. Aunuksen ja Rajakarjalan murteita. Helsinki 1934, S. 21; P a a t e n e: sebävittśs, SS; P y häjär vi, M u n d är vi, K o n t u p o h j a: sebäsittše, šebävitš, šebävits, Kujola, op.cit., S. 380 . 
finnischen Völkern bekannt. Es bezeichnet, als sepä oder sepi auftretend, in Finnland entweder den Vorderteil des Schlittens oder die vorderen, aufgebogenen Enden der Kufen, oder aber, als Zusammensetzung sepäpaju, diejenige Querverbindung, die sich zwischen den Kufenendenden vorne befindet. ${ }^{1}$ Die Verbreitung des Wortes in den angegebenen Bedeutungen fällt in Finnland mit demjenigen Gebiet zusammen, das im Westen von der Verbreitungsgrenze des osteuropäischen Schlittens abgegrenzt wird. Auf der anderen Seite der Grenze begegnet man ganz anderen Benennungen auf die hier nicht näher eingegangen wird, die aber in gewissem Fall charakteristischerweise auch ausserhalb des Verbreitungsgebietes des osteuropäischen Schlittens in Westestland vorkommen. ${ }^{2}$ Dieselben Bedeutungen des Wortes, die sich auf den Vorderteil des Schlittens im allgemeinen beziehen, können auch in Ingermanland, in den karelischen und lüdischen Mundarten in Olonetz, sowie im Wepsischen konstatiert werden. ${ }^{3}$ Das Wort ist an und für sich in allen finnisch-ugrischen Sprachen belegt, bedeutet aber ursprünglich "Hals», auch »Kragen» $\mathrm{u}$. dgl. ${ }^{4}$ Es ist also leicht zu ersehen, dass es bei dem Schlittenterminus um eine Bedeutungsübertragung handelt, und dass das Wort in seinem übertragenen Bedeutung im allgemeinen den Vorderteil des Schlittens, d.h. den "Schlittenhals", bezeichnet. Es ist nun besonders im Auge zu behalten, dass diejenige Übertragung sich nur in den ostseefinnischen Sprachen vollzogen hat. Der Terminus grenzt damit das Verbreitungsgebiet des osteuropäischen Schlittens bei den Ostseefimnen nicht nur im Westen,sondern auch gegen die übrigen finnisch-ugrischen Sprachgebiete im Osten ab. Es braucht nicht besonders unterstrichen zu werden, dass diese 'Tatsachen einerseits für einen historischen Zusammen-

1 SS 109.

2 Z.B. (jalaksen) rinta, -nokka, SS 109. - AES.

3 SS. - Leskinen, op.cit, S. 21. - Kujola, op.cit., S. 388. Heikk I Ojansuu, Juho Kujola, Jalo Kalima, Lauri Kettunen, Lyydiläisiä kielennäytteitä. MSFOu LXIX, S. 4. - KETTuNen, Lõunavepsa..., S. 117. - LauRi Kettunen, Vepsän murteiden lauseopillinen tutkimus, MSFOu LXXXVI, S. 272, 273.

4 E. N. SetäL Ä, Zur finnisch-ugrischen lautlehre, Vorläufige mitteilungen aus einer grösseren arbeit. FUF 1902. Heft III, S. 262. 
hang innerhalb des Verbreitungsgebietes dieses Schlittens bei den genannten Völkern spricht, andererseits aber als ein allgemeines chronologisches Indizium verwertet werden kann. Dies hindert jedoch nicht, demjenigen begrenzten terminologischen Verbreitungsgebiet, welches wir in der Peripherie haben ausscheiden können, bei der Beurteilung der Frühgeschichte des Schlittens ein besondres Gewicht beizulegen.

Die andere Benennung der Rutenbänder, Fig. 22: 3, welche eine analoge, zur gleichen Zeit aber eine viel engere und peripherischere Verbreitung aufzeigt, ist in Estland nur aus vier Kirchspielen der südöstlichst liegenden Landschaft Võrumaa belegt, und lautet semmivits; in einem Falle, namentlich im Kirchspiel Urvaste, parallel damit auch semmipuu. ${ }^{1}$ Die andere Hälfte des Verbreitungsgebietes umfasst sodann die zerstreuten, südöstlich vom Ladoga und am Strande des Onegasees liegenden wepsischen Besiedlungsgebiete, sowie den südlichen Teil des westlich von dem zuletztgenennten See befindlichen lüdischen Sprachgebietes. Das Wort ist innerhalb des abgerissenen Gebietes folgendermassen belegt: s.-weps. $t$ šęm;2 mittel-weps.

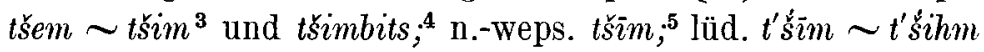
$\sim t^{\prime}$ simimi $^{6}$ Die Bedeutung ist durchgehend »die Rutenbänder zwischen den Vorderenden der Kufen und den ersten Ständern des Schlittens.»

Das estnische Wort ist mit den wepsisch-lüdischen Wörtern ethymologisch bisher noch nicht verbunden worden. Das erstgenannte ist in der hier besprochenen Bedeutung in der Literatur überhaupt nicht bekannt. J. KaLIMA, der den Ursprung des Wortes aus dem Wepsischen heraus untersucht hat, kommt zum Ergebnis, dass es hier um ein lappisches Lehnwort handelt, das ausser dem Wepsischen auch noch im Lüdischen belegt

1 H a rgla, Rõuge, Urvaste, AES; Räpinä, Urvas t e (semmipuu), Samml. von Prof. A. SAareste.

2 A r s k a h t i, Mat. zum weps. Wb. - Vgl. auch Kettunen, Löunavepsa.... S. 4, Tunkelo, op., S. 302.

${ }^{3}$ No i d a la, E n a a, Mat. zum weps. Wh.

4 Si mjärvi, ebenda.

5 Ebenda. Vgl. auch Tunkelo, op.cil., S. 302.

- Vi ida na, P y häjärvi, Lismi, Kujola, op.cit., S. 443. 
sei. ${ }^{1}$ Diesem Standpunkt hat sich später anch E. A. Tuxkelo angeschlossen. ${ }^{2}$ Da die Frage von unserem Problem heraus von einem besonderen Interesse ist, soll sie hier unter Heranziehen der estnischen Belege kurz behandelt werden.

Die lappischen Entsprechungen, die man vorgeführt hat, sind folgende: schw.-lapp. ěima "curvamen, flexura»;3 norw.lapp. čibmâ »bojning, krumning (opad) på ski, sledemej, kjerris, knivsegg", "det krumme stycke man skjoter på sledemej etc», ${ }^{4}$ (Nesseby) ćibìm. "vordere, nach oben gebogene Spitze des Schlittens»; ${ }^{5}$ finn.-lapp. (Utsjoki) $\check{c}$ ipma "vorderer Teil des (4 cm dicken) Renntierschlittenstammbaumes mit der Vorderspitze». ${ }^{6}$ Es ist aus diesen Worterklärungen zu entnehmen, dass das lappische Wort eine »Biegung" oder "Krümmung» imı allgemeinen bedeutet, welche Bedeutung dann auf die meist verschiedenen Gegenstände, die eine entsprechende Eigenschaft aufweisen, projiziert werden kann. Unter den verschiedenen Bedeutungsaspekten findet sich keine, die sich auf dasjenige Schlittendetail bezieht, das mit den estnischen und wepsischlüdischen Wörtern bezeichnet wird. Es kann auch keine geben, da der osteuropäische Schlitten bei den Lappen nicht vorkommt oder erst von einem späten Ursprung ist. Die obenzitierte»Biegung der Schlittenkufe» ist zu allgemein, und die aus Nesseby gebrachte Bedeutung wordere, nach oben gebogene Spitze des Schlittens» bezieht sich - wie eben die nächstfolgende aus Utsjoki - auf den wohlbekannten, bootförmigen Renntierschlitten. Die Annahme eines weiten Bedeutungsinhalts des Wortes bewährt sich, wenn man auch diejenigen Aspekte desselben in Betracht zieht, die in gewissen anderen verwandten Sprachen belegt sind. So notiert man aus dem Wotjakischen

I Jalo Kalima, Eräiden sanojen alkuperästä. Virittäjä 1928, S. 102111.

2 TUNKELo, op.cit., Ṡ. 302.

3 Kalima, op.cit., S. 110. - Tunkelo, op.cit.

- Tunkelo, op.cit. - Vgl. auch H. Paasonen, Die finnisch-ugrischen $s$-laute. MSFOu XLI, S. 21.

5 Tunkelo, op.cit. - Vgl. Eliel Lagfrcrantz, Lappisches Wortschatz I. Helsinki 1939, S. 82.

- Ebenda.

17 - Finnisch-ugrische Forschungen 
"dachboden; zimmer im oberteile des hauses", aber auch "gewölbe, spitze», und weiter wwölben, bewölben, mit dachboden versehen (das gebäude)"; aus dem Syrjänischen "gewölbe», und, als eine Zusammensetzung, "horizont, himmel". Die Bedeutung "Gewölbe" kommt übrigens auch im Lappischen vor. Im Ostjakischen begegnet man dann wieder demselben Wort in verschiedenen Zusammensetzungen in der Bedeutung von "biegung der schlittenkufe», "biegung des kummetbogens", "suksen etupuoli mäystimestä alkaen = Biegung des Skis vom Anfang der Krümmung an», aber auch "ulme», und, ohne Zusammensetzungsglied, "rücklehne in der ostjakischen wiegen. ${ }^{1}$ Es ist offenbar, dass man hier einem uralten Wort in den finnisch-ugrischen Sprachen begegnet, das ursprünglich eine weite Bedeutung vol etwas "gebogenes, gekrümmtes" gehabt hat, welche auf verschiedene Gegenstände, darunter auch auf die Schlittenkufe, appliziert auftritt. Zu den gebrachten Bedeutungen kann noch die Benennung semm $\sim$ sõmm "Bogen zum Schlagen der Wolle", aus dem Estnischen gefügt werden - ein Gegenstand, das ebenfalls von einer gebogenen, gekrümmten Form gekennzeichnet wird. Die Benennung ist in der Gestalt von semmepuu, auch semmelpuu aus mehreren Kirchspielen in Võrumaa und ebenfalls aus Setukesien belegt. ${ }^{2}$ Es ist dazu zu bemerken, dass die vorgeführte Benennung, obschon das Gerät selbst auch bei den anderen finnisch-ugrischen Völkern bekannt gewesen ist, nur aus dem Estnischen belegt ist, während in den anderen Kulturgebieten ganz andere Benennungen in Betracht kommen, die aber den Gegenstand immerhin von seinergekrümmten Form herans kennzeichnen. ${ }^{3}$ - Der semasiologischen Schwierigkeiten, die sich bei der Vergleichung der wepsisch-lüdischen Belege mit den lappischen darbieten, sind sich Kalima und 'Tunkelo bewusst gewesen, und haben dieselben durch eine Amnahme von Bedeutungsverschiebung überbrücken wollen.

1 H. Paasonen, op.cit., S. 103-104, - Kalima, op.cit.

2P. Ariste, Lõuna-Eesti villavakmine. Eesti Rahva Muuseumi Aastaraamat XIV. Tartu 1939, S. 57-63. - Vgl. auch Wiedemann op.cit., S. 1031.

${ }^{3} \mathrm{Vgl.} \mathrm{KustaA} \mathrm{Vilkuna,} \mathrm{Ullbågen.} \mathrm{Budkavlen} \mathrm{XIII.} \mathrm{Abo} \mathrm{1934'}$ s. $76-77$. 
Die Schwierigkeiten fallen weg, wenn wir von dem vorgeschlagenen lappischen Lehnverhältnis absehen und annehmen, dass das wepsisch-lüdische Wort auf Grund seiner speziellen Bedeutung näher mit den estnischen Belegen verbunden werden kann. Irgendwelche lautgeschichtlichen Schwierigkeiten dürften dabei nicht vorliegen. Schon die vorhergenannten Verfasser haben das russische Wort чимдиц. aus dem Vytegradialekt vorgeführt, das sie als *tšimvittsa, d.h. "tšsim-Rute», rekonstruiert und als eine Entlehnung aus dem Wepsischen oder Lüdischen angesehen haben. Als Bedeutung wird stuomipuinen vitsas, jolla reen jalaksen koukistuva pää kiinnitetään kaplaaseen $=$ Rute aus Faulbaum, womit man das gekrümmte Ende der Schlittenkufe an den Ständer befestigt», angegeben. Wir haben nun oben erfahren können, dass die Zusammensetzung tšimbits in der Tat im Mittelwepsischen belegt ist. Dieses Wort kann aber direkt mit dem estnischen semmivits verglichen werden. Die Zusammensetzung kann etwa wie die Rute, vits, welche an das gekrümmte Ende der Schlittenkufe, semm, tšem u.s.w. angebracht ist, ausgedeutet werden. Am gebrachten semasiologischen Hintergrunde, der dem Worte semm mit seinen Entsprechungen in den verwandten Sprachen eigen ist, gibt es keine Schwierigkeiten, eine solche Bedeutungsentwicklung $\mathrm{zu} \mathrm{er-}$ klären. Die kürzere Form im Wepsischen und Lüdischen soll dann durch Wegfallen des Schlussgliedes der Zusammensetzung erklärt werden - eine Erscheinung, die in der Sprachtheorie wohlbekannt ist. Wir haben hier also mit einem weitverbreiteten und damit uralten Wort in den finnisch-ugrischen Sprachen zu tun, das aber in der Gestalt von jener speziellen Zusammensetzung und in einer speziellen Bedeutung nur in den zwei nahverwandten ostseefinnischen Sprachen, dem Estnischen einerseits und Wepsisch-Lüdischen andererseits, auftritt. Unter solchen Umständen erscheint die Entlehnungstheorie aus dem Lappischen zum Wepsischen unnötig, oder aber soll ihre Rolle bis zu einer Unbedeutenheit reduziert werden. Eine nähere geographische Orientierung des wepsisch-lüdischen Wortes soll nicht in der nördlichen, sondern in der südlichen Richtung gesucht werden.

Da nun die letztbehandelte Benennung semmivits u.s.w. 
sich ohne geringsten Zweifel auf den osteuropäischen Schlitten bezieht, gibt sie ein wichtiges chronologisches Kriterium für die Stellung des genannten Schlittens bei den ostseefinnischen Völkern ab. Ihr Verbreitungsgebiet ist abgebrochen und liegt in der äussersten südöstlichen Peripherie der Besiedlungsgebiete dieser Völker. Die weiten Gebiete, welche die beiden Hälften ihres Verbreitungsgebietes von einander abtrennen, werden heute von der grossrussischen Bevölkerung bewohnt. Wenn man eine Verbindung zwischen den Hauptbruchstücken des Verbreitungsgebietes herstellen will, soll man sich in diejenige Zeit zurückdenken, wo die russische Bevölkerung auf diesen Breitgraden noch nicht vorhanden war. Die slavische Kolonisation aus dem Süden erreichte die Nachbarschaft der Ostseefinnen in der mittleren Eisenzeit. Über eine nähere Zeitbestimmung hat die Forschung sich noch nicht einigen können. Während man einerseits mit dem 8 . Jh. als die früheste Zeitgrenze gerechnet hat, ${ }^{1}$ ist diejenige neulich von H. Moora ins 5. Jh. versetzt worden. Der genannte Verfasser hat dazu noch eine Karte vorgelegt, welche die Verbreitung der slavischen Gräber aus der Mitte des ersten Jahrtausends zwischen dem Peipus und dem Ilmensee sowie sporadisch auch am Wolchowflusse dokumentiert. ${ }^{2}$ Wie es mit der genauen Zeitbestimmung auch sei - der Kolonisationsprozess ist natürlich unter einer längeren Zeitspanne vollzogen worden - kamn das Verbreitungsgebiet des Wortes semm $\sim$ tšem nicht erklärt werden, ohne dass man zwischen den zersprengten Teilen desselben einen ehemaligen Kontakt annimmt, welche dann durch die vorrückende slavische Ansiedlung gebrochen worden ist. J)as setzt aber von seiner Seite voraus, dass der osteuropäische Schlitten, von welchem ja der in Frage stehende Terminus ein Zeugnis ablegt, schon vor der Ankunft der Slaven, d.h. Crrossr'ussen, bei den Ostseefinnen bekannt gewesen ist.

Wir haben gesehen, dass das Verbreitungsgebiet des zuletzt-

1 Vgl. z.B. J. J. MıkкоLA, Ije älteren Berührungen zwischen Ostseelinnisch und Russisch. MSFOu LXXV, S. 9.

2 H. Moora, Eesti rahva ja naaberrahvaste kujunemisest arheoloogia andmeil. Eesti rahva etnilisest ajaloost. Tallinn 1956, S. 106107. 
behandelten Terminus nicht das einzige seiner Art ist. Auch eine der verschiedenen Benennungen der Querverbindung, Fig. 21: 8, weist ein analoges, zersprengtes Verbreitungsgebiet auf, obschon dasselbe sich jenseits des Ladogasees viel weiter nach dem Norden erstreckt und in ganz Ostkarelien belegt ist. Das Wesentliche bei dem Charakter des Verbreitungsgebietes wird dadurch nicht geändert. Obgleich die ursprüngliche Verknüpfung dieser Benennung mit dem osteuropäischen Schlitten semasiologisch nicht direkt bewiesen werden konnte, spricht sowohl die vorhergehende Analogie als aluch die ganze verbreitungsmässige Situation dafür, dass man auch in diesem Falle mit einem genuinen Terminus bei dem genannten Schlitten zu tun haben dürfte. Zu diesen zwei Verbreitungsgebieten gesellt sich dann ein drittes, das Verbreitungsgebiet von sebävits u.s.w., das nicht mehr vollständig denselben peripherischen Charakter aufzeigt. Da die Benennung auch im westlichsten Ingermanland belegt ist, könnte man hier eine Brücke vermuten, die nach dem Ladogagebiet herübergeleitet hat und für eine spätere Verbreitung der Benennung sprechen könnte. Man muss jedoch zur gleichen Zeit beachten, dass die nordöstliche Hälfte des Verbreitungsgebietes sich immer noch östlich von der Reichsgrenze Finnlands lokalisiert und auch ins lüdische sprachgebiet hineingreift, welches nicht auf eine allzu späte Provenienz hindeutet. Man kamn nun nicht umhin, aus dieser Wiederholung der Verbreitungsgebiete, ron welchen zwei bestimmt älter sind als die slavische Kolonisation im Norden, einen frühen schlittenhistorischen Zusammenhang zwischen den berührten Gebieten, Südestland einerseits und der Gegend des Ladoga- und ()negasees andererseits, herauszulesen. Die entsprechenden Benennungen, die ausserhalb dieser Gebiete vorkommen, verbinden die verschiedenen Teile der Karte nicht, sondern rufen im Gegenteil eine terminologische Zersplitterung hervor, welche von einer neueren Schichtung bezeugt. Man dürfte deshalb, soweit es alte, für den osteuropäischen schlitten genuine Benennungen mit präzisierten Bedeutungen gilt, von zwei wesentlichen terminologischen Grenzen sprechen, von denen die eine in Estland liegt und die andere nördlich von Ladoga zwischen Finnland und Olonetz nebst Ostkarelien hinläuft. Es liegt die 
Vermutung nahe, dass die genannten Grenzlinien auch tatsächliche Grenzzeichen in der Geschichte des nsteuropäischen Schlittens auf dem Territorium der Ostseefinnen sein könnten, und dass die frühesten Spuren desselben somit in der äussersten südlichen und südöstlichen Peripherie des genannten Territoriums gesucht werden müssen. Dass diejenige Spuren uns damn in eine Zeit zurückführen die vor der slavischen Kolonisation liegt, sollte schon aus dem Vorhergehenden hervorgegangen sein.

\section{IV}

Es fragt sich nun, ob sich solche Spuren auch im gegenständlichen Sinne finden lassen?

Das ist tatsächlich der Fall. Es soll hier jetzt diejenige primitive Variante des osteuropäischen Schlittens, die schon oben kurz erwähnt wurde, in die Erörterung eingeschaltet werden. Die genannte Variante wird eben aus einem der südlichsten Kirchspielen Estlands, namentlich Hargla, Fig. 23, abgebildet. Sie weicht von dem üblichen, oben beschriebenen osteuropäischen Schlitten dadurch ab, dass die Rutenbänder zwischen den Kufenenden und ersten Ständern nicht aus besonderen Stücken, sondern aus Verlängerungen der Seitenstänge bestehen. Die Seitenstänge des Schlittens sind nämlich aus schmalen runden Birkenstämmen hergestellt, deren schmeidige Wipfelenden hinter den Kufenenden hindurchgezogen, dann wieder rückwärts geschlungen und in der Nähe der ersten Ständer durch Umbinden festgesetzt sind. Irgendwelche eingemeisselten Löcher für die Ständer sind in den Seitenstängen nicht vorhanden. Die Seitenstänge sind an den entsprechenden Stellen einfach gespaltet und die oberen Enden der Ständer in den Spalten dermassen festgeklemmt worden, dass sie an den Seitenstängen hindurchreichen und auf den Oberseiten derselben mit Hilfe von Holzpflöckchen zurückgehalten werden. Um der Zerklüftung der Seitenstänge vorzubeugen, sind sie auf den beiden Seiten eines jeden Ständers mit Schnur umbunden. Wenn man noch damit rechnet, dass auch die um den Ständern geschwungenen Querverbindungen nur ganz einfach teils von 


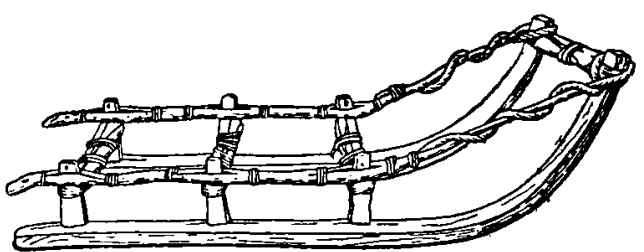

Fig. 23. Arbeitsschlitten aus Hargla, Estland. ERM A 339: 1.

Rutenringen, teils von umwickelter Schnur zusammengehalten werden, kann mall sich eine primitivere, zur gleichen Zeit aber geschmeidigere Schlittenkonstruktion kaum vorstellen. Die grösste Aufmerksamkeit ist dabei selbstverständlich der Konstruktion der Seitenstänge zuzuwenden, die hier eine Lösung aufzeigt, bei welcher die natürliche Beschaffenheit des Materials mit einer minimalen Bearbeitung auf das effektivste ausgenutzt ist. Es dürfte gar keinem Zweifel unterliegen, dass der ordinäre osteuropäische Schlitten im Vergleich mit der hier vorliegenden Variante typologisch und auch entwicklungsgeschichtlich eine sekundäre Form darstellt.

Die vorgeführte Variante kann nun ausser dem Kirchspiel Hargla noch aus mehreren anderen waldreichen Gegenden Südestlands, namentlich Rõuge, ${ }^{1}$ Räpina, ${ }^{2}$ Otepää, ${ }^{3}$ Urvaste, ${ }^{4}$ Sangaste, ${ }^{5}$ Helme $^{6}$ und Saarde ${ }^{7}$ direkt bewiesen werden. Das Verbreitungsgebiet derselben, welches mit anderen Worten die Landschaften Võrumaa, Valgamaa und die südlichen Teile von Tartumaa und Pärnumaa umfasst, fällt sehr nahe mit dem Verbreitungsgebiet der Querverbindungsbenennung pôikpool u.s.w., Fig. 21: 8, zusammen, dessen andere Hälfte, wie wir soeben gesehen haben, im Ladoga- und Onegagebiet, weit entfernt von Estland liegt. Das Verbreitungsgebiet der Benennung

1 AES KT XIV: 24.

2 AES I.

3 ERM A 331: 51 .

4 AES L.

B ERM EA 35: 749.

- AES I

AES L. 
semmirits im äussersten Südosten des Landes, das ja gleichfalls nur einen Bruchstück eines zersplitterten Verbreitungsgebietes gleichen Charakters darstellt, wird ron dem Verbreitungsgebiet der besprochenen Schlittenvariante ganz umschlossen. Es soll nun bemerkt werden, dass die zuletztgenannte Benennung in Estland in der Regel eben die mit den Seitenstängen zusammenhängenden Rutenbänder derjenigen primitiven Konstruktion bezeichnet, die oben beschrieben worden ist. ${ }^{1}$ Ausserhalb des beschränkten Gebietes wo diese Benennung in Estland vorkommt, teilweise aber auch schon in der Peripherie desselben, ist dann sebivits, sepivits, ${ }^{2}$ sebävits, ${ }^{3}$ sebäpuu, ${ }^{4}$ oder auch einfach seb $\ddot{a}^{5}$ als Benennung der besprochenen Seitenstangenkonstruktion belegt. Wir kommen hiermit auf diejenige Bedeutungsverschiebung beim Terminus sebärits $\sim$ sebivits oder sebä in Südestland zu sprechen, auf welche schon oben aufmerksam gemacht worden ist. Es kann nämlich festgestellt werden, dass das Wort hier ausser den schon belegten Bedeutungen, die sich also entweder auf die bekannten Rutenbänder, oder, soweit eine solche vorhanden ist, auf die soeben besprochene Seitenstangenkonstruktion vom Hargla-Typus beziehen, auch in der Bedeutung von gewöhnlichen Seitenstängen beim osteuropäischen Schlitten vorkommt, also bei einem Schlitten, wo die Seitenstange eine rechteckige ( uerschnitt aufzeigt und mit ordentlichen, eingemeisselten Löchern für die Ständerenden versehen ist, und wo die Rutenbänder vorne aus besonderen Stücken hergestellt sind. Die genannte Bedeutung des Wortes kann aus mehreren Kirchspielen, die das oben abgerissene Verbreitungsgebiet der besprochenen primitiven Schlittenvariante im Norden und Osten umschliessen, belegt werden. ${ }^{6}$ Der

1 Siehe S. 256, Note 1.

2 II a r g l a, AES; daneben auch seebivits; ERM A 339: 1; 01 e p ä ä, ERM A 331: 51 .

$3 \mathrm{~S}$ a a r d e, AES L.

- S a n g a s t e, auch seebäpuu, ERM EA 35: 749.

- S a $\mathrm{n}$ a s te, ebenda; $\mathrm{H}$ e $\mathrm{lm}$ e, AES I.

- Pa is t u, K a rksi, H a ll is t e, H ä äd e me es te: $\operatorname{seb}^{\circledR} \ddot{a}$, AFS; Kolg a - J a a n i, seba, ERM Kv 54:409; K a r u la, Võnn u: sebapuu, AES; Rōngu: sebavits; AES; Vas t s e li in a, $\mathrm{K}$ a $\mathrm{mhj}$ a: sebirits, AES; Setu Vilo: sepivits, ERM Kv 54: 523. 
Terminus ist in der angezeigten Funktion unerwartet. Die Seitenstange des Schlittens, ganz abgesehen davon, welche von den beiden Grundkonstruktionen es gilt, wird sonst in den ostseefinnischen Sprachen $\mathrm{kaust} / \mathrm{a}$ genannt. ${ }^{1}$ Da diese Benennung allgemein ist - sie kommt in allen ostseefinnischen Sprachen ausser dem Livischen vor, wo sie eine sekundäre Bedeutungsverschiebung erfahren hat welche später zu besprechen sein wird - soll sie als der alte genuine Terminus für das entsprechende Schlittendetail aufgefasst werden. Dies besagt aber, dass das Wort $\operatorname{seb}(\ddot{a})$-als Benennung der Seitenstange des Schlittens in Südestland von einem späteren Ursprung ist, und dass hier besondere Ursachen für eine Bedeutungsverschiebung vorliegen müssen. Dies kann wohl dadurch erklärt werden, dass das Wort in seiner angezeigten Bedeutung eine terminologische Reminiszenz ist, welche auf die aus dem Kirchspiel Hargla beschriebene Seitenstangenkonstruktion zurückweist. Die Annahme liegt desto näher, weil aus etlichen Kirchspielen gerade die Zusammensetzung $\operatorname{seb}^{\left(\ddot{a}^{\prime}\right.}$ vits $\sim$ sebivits $\sim$ sepivits, d.h. dieselbe Benennung wie für die Seitenstangenkonstruktion aus Hargla, angegeben wird. ${ }^{2}$ Daraus ergibt sich aber schliesslich, dass diejenige primitive Variante des osteuropäischen Schlittens, die wir oben in gewissen südlichsten Kirchspielen Estlands noch vorgefunden haben, ehemals über ganz Südestland verbreitet gewesen ist. Die Nordgrenze ihrer Verbreitung ist auf der Karte Fig. 22: 5 verzeichnet worden. Sie fällt mit einiger Abweichung mit der Grenze zwischen den beiden estnischen Hauptdialekten zusammen.

Dass die in südestland auftretende Benennung seb( $\ddot{a}^{\prime}-$ in der Bedeutung von gewöhnlichen, kurzen Seitenstängen auf die besprochene Schlittenvariante als eine im Vergleich mit den ordinären osteuropäischen Schlitten ältere Konstruktion hinweist, dürfte ohne weiteres klar sein. Zur Begründung dieses Verhältnisses können aber noch ein paar weitere terminologischen Tatsachen vorgelegt werden. Innerhalb des auf der Karte abgerissenen Gebietes wo die Variante verbreitet ist bzw. ver-

1 Siehe z.B. Torvonen, op.cit., S. 174.

2 Siehe S. 264, Note 6. 
breitet gewesen ist, kommen gewisse ganz zufällige Benennungen für diejenigen Rutenbänder vorne am Schlitten vor, die aus besonderen Stücken hergestellt sind. Von den Benennungen, welche mit einem einheitlichen Zeichen, Fig. 22: 4, auf der Karte verzeichnet worden sind, können etwa solche wie päämalk, ${ }^{1}$ päävits, ${ }^{2}$ juhivits, ${ }^{3}$ päävahr, ${ }^{4}$ auch seba ots, d.h. "das (vordere) Ende der seba», ${ }^{5}$ genannt werden. Währen diese Benennungen auf der einen Seite ein Zeugnis davon ablegen, dass der osteuropäische Schlitten ordinärer Konstruktion im Gebiet bekannt und gebräuchlich ist, beweisen sie andererseits durch ihren umschreibenden und zufälligen Charakter, dass demselben daselbst im Vergleich mit der besprochenen Variante aus Hargla eine sekundäre Stellung zukommt. Die obenbehandelten Benennungen der vorderen Rutenbänder des osteuropäischen Schlittens vom Typus seb $(\ddot{a})$ vits wie auch semmivits haben in Südestland mit anderen Worten ursprünglich eben derjenigen primitiven Variante zugehört, deren Verbreitung sich bis zur obengenannten Dialektgrenze erstreckt hat. ${ }^{6}$ Sie sind mit anderen Worten für die älteste Schicht des osteuropäischen Schlittens charakteristisch die auf dem ostseefinnischen Boden heute überhaupt noch gespürt werden kann.

Der Eintausch der alten Seitenstangenbenennung kaust/a gegen die oben besprochenen, neueren Termini, findet eine Erklärung, wenn man annimmt, dass der osteuropäische Schlitten in der Gestalt der beschriebenen primitiven Variante einmal ins Land eingefallen ist, diejenige Terminologie, welche einem früheren Schlittentypus eigen gewesen, teilweise verdrängt, und ihre eigene, von einer speziellen Konstruktion bedingte Terminologie eingeführt hat. Das Wort kaust als Schlittenterminus ist dabei doch nicht vollständig verschwunden. Es kommt als Benennung von Seitenstange ein paar mal spo-

$1 \mathrm{H}$ a 11 is $\mathrm{t} e$, AES.

$2 \mathrm{Karksi}, \mathrm{V}$ as $\mathrm{tseli}$ in a Set $\mathrm{u}$, AES.

${ }^{3} \mathrm{~K} \mathrm{a} \mathrm{m} \mathrm{b} \mathrm{j} \mathrm{a,} \mathrm{AES.}$

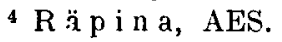

s $\mathrm{K} \backsim \lg$ a - J a a n i, AES.

- Dass dieselben Benennungen dann bisweilen auch als Bezeichnung für die aus besonderen Stücken hergestellten Rutenbänder vorkommen, 
radisch in Form von kauspuu, kaust zum Vorschein, ${ }^{1}$ und liegt dazu in verschiedenen Kirchspielen neben den oben berührten sekundären Benennungen als Zusammensetzung kaustvits vor." Es braucht nicht besonders unterstrichen zu werden, dass das zusammengesetzte Wort sich dann durch sein Schlussglied, dass als "Rute" übersetzt werden soll, an die spezielle Konstruktion der besprochenen primitiven Variante des osteuropäischen Schlittens angepasst hat. Das Wort kaust tritt aber in Südestland ausserdem noch - woriuf wir schon oben aufmerksam gemacht haben - ganz unerwartet auch als Benennung der Querverbindung auf. Das Verbreitungsgebiet des Wortes in dieser Bedeutung, Fig. 21: 7 , ist wohl abgeschlossen und begrenzt sich auf die Grenzgegenden zwischen den Landschaften Võrumaa und Valgamaa, also in einem Gebiet, das noch unlängst von dem primitiven Vorläufer des ordinären osteuropäischen Schlittens beherrscht wurde. Man wird sich kaum irren, wenn man annimmt, dass hier eine Bedeutungsverschiebung des Terminus vorliegt, die von dem Vordringen einer neuen Konstruktion, d.h. der besprochenen primitiven Variante des osteuropäischen Schlittens, veranlasst worden ist. Dass die Bedeutungsverschiebung nicht von einer späten Herkunft sein kann, geht daraus hervor, dass das Wort in identischer Bedeutung auch im Livischen in Nord-Kurland belegt ist. ${ }^{3}$ Der Terminus ist in seiner verschobenen Bedeutung also für die zwei südlichsten ostseefinnischen Sprachen, welche seit Jahrhunderten keinen direkten Kontakt miteinander mehr besitzt haben, gemeinsam, und geht somit wenigstens in eine frühgeschichtliche Zeit zurück. Dies besagt aber weiter, dass das Verbreitunsgebiet der hier in Frage stehenden primitiven Variante des osteuropäischen Schlittens sich nicht nur auf das heutige Südestland beschränkt, sondern wahrscheinlich auch das ehemals im Süden angrenzende Besiedlungsgebiet der Liven umfasst hat. Die Annahme gewinnt an Wahrscheinlichkeit,

z.B. sebivits, Va s t s e I i n a; seebivits, O t e p ä ä, AES; semmivits, $\mathrm{R}$ ö u g e, AES KT, widerlegt das allgemeine Verhältnis nicht.

I S a a r d e, R äp i n a: kaust; R ö u ge: kauspuu, AES.

ot@ pää, Polva, Räpina, Urvaste, AES.

3 Lauri Kettunen, Livisches Wörterbuch. Helsinki 1938, S. 148 a. 
wenn man zu dem vorhergehenden Terminus noch das livische Wort sehà-ritsà oder tšebà-vĭtsà legt, das »lange gerte; . . .eine lange gerte ohne äste...) bedeutet. Denn die angegebene Bedeutung des Wortes kann nur erklärt werden, wenn man annimmt, dass sie über einen Schlittenterminus, der sich gerade auf die besprochene primitive Seitenstangenkonstruktion bezogen zul haben scheint, ausgebildet worden ist. Die südestnische Variante des osteuropäischen Schlittens ist demnach vormals in Kurland vorhanden gewesen, obschon, wie oben dargetan worden, der typische Schlitten heute daselbst von einer Kontaminationsform repräsentiert wird. Es verwundert dann kaum, diese Variante noch in der Tat gegenwärtig südlich von der Grenze Estlands vorzufinden. Aus Allasch im heutigen Nordlettland hat A. Bielexsters einen Schlitten abgebildet, der in bezug auf die Seitenstangenkonstruktion mit der Variante aus Hargla verglichen werden kann. Obschon die Seitenstänge jenes Schlittens einen rechteckigen Querschnitt aufweisen und somit einer avancierteren Bearbeitung unterzogen worden sind, sind ihre schmalen Wipfelenden auf derselben Weise wie es bei der Variante aus dem genannten südestnischen Kirchspiel der Fall war, hinter den Kufenenden hindurchgezogen und dann wieder bis zu den ersten Ständern zurückgeschlungen. ${ }^{2}$ Da die Abbildung sonst alle für einen osteuropäischen Schlitten typischen Merkmale aufzeigt, steht es sicher, dass wir hier mit derselben primitiven Variante dieses Schlittens zu tun haben, welche aus Südestland nachgewiesen worden ist.

Wir haben also in den südlichsten Grenzgegenden Estlands eine primitive Variante des osteuropäischen Schlittens vorgefunden und nachweisen können, dass das Verbreitungsgebiet derselben ehemals nach Norden hin das Gebiet his zu der südestnischen Dialektgrenze, nach dem Süden hin aber das frühere livische Besiedlungsgebiet umfasst hat. Von den rein typologischen Kriterien ganz zu schweigen, muss die besprochene Schlittenvariante auf Grund derjenigen terminologischen Verhältnisse, welche in Südestland zum Vorschein kommen, daselbst für

I Kettunen, op.cit., S. 357 a.

2A. Bielenstein, Die Holzbauten und Holzgeräte der Letten 2. Petrograd 1918, S. 557, Fig. 512. 
älter als der osteuropäische Schlitten ordinärer Konstruktion angesehen werden. Gewisse gemeinsame Termini, die einerseits in den südestnischen Dialekten, andererseits aber im Livischen konstatiert werden können, erlauben in der Tat anzunehmen, dass die Variante innerhalb des abgerissenen Gebietes spätestens schon in der frühgeschichtlichen Zeit vorhanden gewesen ist. Wie das livische Besiedlungsgebiet im Süden, werden aber auch die zwischen dem Ladoga- und Onegasee, sowie südlich und nördlich davon liegenden Besiedlungsgebiete der Wepsen und Karelen schlittenterminologisch mit Südestland verbunden. Fs ist nun von einer ausschlaggebenden Bedeutung, feststellen zu können, dass dieselbe primitive Variante des osteuropäischen Schlittens, die in der südwestlichen Peripherie der ostseefinnischen Besiedlungsgebiete verbreitet gewesen ist, auch innerhalb jenes peripheren Gebietes im Nordosten nachgewiesen werden kann. Die Konstruktion wird von I. Maxxixex namentlich aus Ostkarelien genannt. ${ }^{1}$ Wir können ihre Verbreitung hier zwar nicht näher abgrenzen, können aber feststellen, dass sie wenigstens teilweise mit der nordöstlichen Hälfte desjenigen abgebrochenen terminologischen Verbreitungsgebietes, das oben kartographisch dargelegt und kommentiert worden ist, zusammenfallen muss. Es ist uns mit anderen Worten gelungen, einerseits einen in die vorhistorische Zeit zurückreichenden (xürtel von gemeinsamen Termini für den osteuropäischen Schlitten in der südlichen und östlichen Peripherie der Wohnsitze der Ostseefinnen auszuscheiden, andererseits aber eine primitive Variante desselben Schlittens innerhalb dieses Gürtels nachzuweisen. Da nun dieselbe Variante keine zufällige Erscheinung ist, sondern innerhalb ihres südwestlichen Verbreitungsgebietes in Südestland und im heutigen Nordlettland beweislich die älteste Manifestationsform für den osteuropäischen schlitten bildet, muss die angedentete Übereinstimmung als Beweis dafür angenommen werden können, dass das früheste Verbreitunsgebiet des genannten Schlittens innerhalb des Besiedlungsgebietes der Ostseefinnen tatsächlich einmal auf jene peripheren Gegenden beschränkt gewesen ist.

1 Manninen, op.cit., S. 223. 
Es soll schliesslich ein Versuch gemacht werden die Frage zu beantworten, in welcher Richtung dieser Schlitten, der also, wie es aus der terminologischen Analyse hervorgegangen sein dürfte, innerhalb des abgerissenen Gebietes von einem vorhistorischen Ursprung ist, sich bewegt, wann und von welcher Seite er die ostseefinnischen Besiedlungsgebiete erreicht hat. Eine Bewegung von Norden nach Süden, von Ostkarelien und Olonetz nach Baltikum, ist in jener Zeit worauf es hier ankommt, schon auf Grund der allgemeinen Richtung des Kulturstroms, die, wie wir unten näher ausführen werden, gerade die gegensätzliche gewesen ist, kaum wahrscheinlich. Die Theorie von einer Invasion von Osten her verliert ebenso ihre Wahrscheinlichkeit, da die vermittelnde Rolle der ostslavischen Ansiedlung aus chronologischen Gründen wegfällt, und da auf der anderen Seite keine Anhaltspunkte zur Verknüpfung derjenigen Terminologie, weiche den osteuropäischen Schlitten in den ostseefinnischen Sprachen auszeichnet, mit den östlichen finnisch-ugrischen Sprachen im heutigen Russland vorliegen. Es bleibt dann nur die südliche Richtung übrig. Die Analyse der terminologischen Verhältnisse in Südestland hat gezeigt, dass die althergebrachte Stellung der obenbesprochenen primitiven Variante des osteuropäischen Schlittens daselbst auf einer Weise dokumentiert wird, die innerhalb des nordöstlichen Teils les in Frage stehenden Gebietes nicht möglich ist. Der genannten Variante kommt hier weiter ein ganz umfassendes Verbreitungsgebiet zu, das sich ausser Südestland in einer früheren Zeit auch über die Besiedlungsgebiete der Liven im heutigen Nordlettland erstreckt hat. Das legt die Vermutung nahe, dass die Ostseefinnen mit dem osteuropäischen Schlitten zum ersten mal durch Vermittlung der baltischen Stämme bekannt geworden sind.

Es ist angebracht in diesem Zusammenhange num auf die in den ostseefinnischen sprachen allgemein bekannte Benennung les Arbeitsschlittens, finn. reki, estn. regi, hinzuweisen, welche in derselben Bedeutung auch im Lettischen und Littauischen vorkommt und schon seit langem als baltisches Lehnwort im 
Ostseefinnischen anerkannt worden ist. ${ }^{1}$ Es scheint berechtigt zu sein, anzunehmen, dass es hier um ein wirkliches Kulturwort handelt, das auf der ostseefinnischen Seite ursprünglich als Bezeichnung für eine neuartige Schlittenkonstruktion aufgenommen ist. Die ursprüngliche Bedeutung des Wortes ist bekanntlich "Horn, Geweih", welche ausser in den baltischen auch in den meisten slavischen Sprachen belegt ist. ${ }^{2}$ Die Bedeutungsverschiebung, die sich nur im Lettischen und Littauischen vollzogen hat, würde begreiflich erscheinen, wenn man von den hornähnlich hochgebogenen Kufenenden bei den osteuropäischen Schlitten ausgeht, welche das meist in die Augen stechendes Typmerkmal dieses Schlittens ausmachen und denselben auf die markanteste Weise von dem obenbeschriebenen, vollständig flachen Bindeständerschlitten unterscheiden. Als eine Parallele dafür, dass die hornähnlich hochgebogenen Kufenenden auch in anderen Kulturgebieten Anlass zur Benennungsbildung für Schlitten abgegeben haben, kann z.B. der aus den Alplandschaften der Schweiz allgemein bekannte Hornschlitten oder Hori, in den romanischen Distrikten traîneau à cornes, genannt werden. ${ }^{3}$ Es kann deshalb angenommen werden, dass die aus dem Baltischen entlehnte Benennung sich zuerst gerade auf denjenigen Schlitten den wir heute osteuropäisch nennen, bezogen hat, dass sie aber später allmählich als eine universelle Bezeichnung für den Arbeitsschlitten überhaupt in den ostseefinnischen Sprachen Geltung gewonnen hat. Das Lehnwort gibt indes an und für sich keinen Anhaltspunkt für eine nähere Datierung des Gegenstandes. Die baltischen Lehnwörter im Ostseefinnischen verteilen sich auf eine geraume Zeitperiode, deren Beginn von der Forschung dazu noch ständig zurückgeschoben und newerdings schon sogar ins Spätneolithikum

1 JaLo Kalima, Itämerensuomalaisten kielten balttilaiset lainasanat. Helsinki 1936, s. 153.

2 Kalima, op.cit. - Reinhold Trautmann, Baltisch-Slavisches Wörterbuch. Töttingen 1923, S. 235.

3 Anni Walmeier-Brockmann, Sammelwirtschaft in den Schweizer Alpen, eine ethnographische Studie. Schweizerisches Archiv für Volkskunde 39, S. 7. - G. Huв E, Les apellations du traîneau et ses parties dans les dialectes de la Suisse Romane. Wörter und Sachen. Beiheft 1919 , S. $4-5$. 
versetzt worden ist. ${ }^{1}$ Als Unterlage zu der letzterwähnten frühen Zeitbestimmung ist von der archäologischen Seite die Theorie vorgeführt worden, dass die Träger der Streitaxtkultur, welche am Anfang des zweiten vorchristlichen Jahrtausends bekanntlich das ganze Baltikum nebst den westlichen Teilen von Finnland überschwemmt haben, frühe baltische Stämme gewesen seien. ${ }^{2}$ Es soll hier auf diese Theorie nicht näher eingegangen werden. Von unserem Problem heraus gilt es nur festzustellen, dass das früheste Verbreitungsgebiet des osteuropäischen Schlittens bei den Ostseefinnen sich nicht mit dem Verbreitungsbilde der Streitaxtkultur in Baltikum und Finnland verbinden lässt. ${ }^{3}$ Namentlich in Finnland, wo die Streitaxtkultur nur die westlichen Teile des Landes umfasst, welche noch in der Gegenwart nicht von dem osteuropäischen Schlitten eingenommen worden sind, sind die Verbreitungsverhältnisse gerade die gegensätzlichen. Einer so frühen Datierung des hier besprochenen Terminus scheint auch diejenige Tatsache zu widersprechen, dass das Wort, wie oben schon bemerkt worden, im Baltischen eine Verschiebung von einer allgemeineren zur beschränkteren Bedeutung durchlaufen hat, von welchen die letztere, also die Schlittenbenennung, nur im Lettischen und Littauischen vorkommt. Das alles zwingt eine spätere Entlehnungszeit anzunehmen, welche andererseits aber hinreichend früh angesetzt werden muss, um die Verbreitung des Wortes in allen ostseefinnischen Sprachen erklären zu können. Es ist dann vorzugsweise auf die eisenzeitliche Periode unter Jahrhunderten um die Zeitrechnungswende zu denken. Von der Mitte der ersten vorchristlichen Jahrtausends an vermag die Archäologie schon die Wohnsitze der baltischen Stämme unmittelbar südlich von Estland und dem heutigen Nordlettland klar auszuscheiden. ${ }^{4}$

1 P. Ariste, Läänemere keelte kujunemine ja vanem arenemisjärk. Eesti rahva etnilisest ajaloost. Tallinn 1956, S. 11. - Ders., Vanimast läänemerelaste pöllundusest keeleliste andmete põhjal. Ajaloo-keeleteaduskonna töid. Tartu Riikliku Ülikooli Toimetised 38. Tallinn 1955, s. 199.

2 Moora, op.cit., S. 58-63.

3 Vgl. entspr. Karten bei Moors, op.cit., Fig. 2 und 3.

- Moora, op.cit., S. 68-69; vgl. bes. Karte Fig. 5. 
Unter der römischen Eisenzeit d.h. den vier ersten Jahrhunderten unserer Zeitrechnung, werden die direkten baltischen Kultureinflüsse in heutigen Nordlettland und Südestland dermassen überwiegend, dass man ron einer Kulturgrenze sprechen darf, welche die nördlichen Teile Estlands vom übrigen Baltikum abtrennt. Die genannte Grenze fällt in grossen Zügen mit der heutigen südestnischen Dialektgrenze zusammen, welche ihrerseits, wie wir schon oben festgestellt haben, mit der früheren Nordgrenze des Verbreitungsgebietes der besprochenen primitiven Variante des osteuropäischen Schlittens identisch ist. Wir dürfen dann, weil das genannte Verbreitungsgebiet sich wenigstens schon in der frühgeschichtlichen Zeit nachspüren lässt, damit rechnen, dass es in irgendeiner Ausstreckung noch in eine viel frühere Zeit zurückreicht und vielleicht in einer eisenzeitlichen Periode entstanden sein kann, wo die direkten baltischen Kultureinflüsse in der südlichen Peripherie der ostseefinnischen Besiedlungsgebiete kulminiert haben.

Eine untere Zeitgrenze für das erste Vordringen des osteuropäischen Schlittens in das von den Ostseefinnen bewohnte Gebiet lässt sich aus unserem Material heraus gleichwohl nicht bestimmen. Die obere Grenze ist dagegen, wie schon oben ausgeführt, mit der ostslavischen Kolonisation gegeben, welche den terminologischen Zusammenhang zwischen Südestland und den Gegenden um den Ladoga- und Onegasee abgebrochen hat. Sie soll also in die Zeit vor dieser Kolonisation verlegt werden. Denn insofern der Schluss von der baltischen Herkunft des osteuropäischen Schlittens bei den Ostseefinnen stichhaltig ist, kann auch keinen Zweifel darüber geben, dass derselbe Schlitten sich von seinem am frühesten bezeugten Verbreitungsgebiet heraus in der nordöstlichen Richtung bewegt hat, wodurch eben dasjenige periphere Verbreitungsgebiet, von welchem nunmehr hauptsächlich nur noch terminologische Bruchstücke bezeugen, zustande gekommen ist. Eine allgemeine kulturelle Ausstrahlung von Estland, bzw. Nordlettland nach Osten und

1 Moora, op.cit., S. 93-96; vgl. auch Karte Fig. 11. - Ders., Die Vorzeit Estlands. Tartu 1932, S. 45.

18 - Finnisch-ugrische Forschungen 
Nordosten lässt sich von der römischen Eisenzeit an archäologisch vielfach beweisen. Ausser den zufälligen Fünden estnischer oder baltischer Herkunft, unter welchen die bekannten, von verschiedenen Stellen im nordwestlichen und mittleren Russland angetroffenen ovalen Feuerschlagsteine $\mathrm{zu}$ nennen sind, ${ }^{1}$ soll hier besonders auf einige Grabanlagen aus dem Kreis Staraja Russa am Ilmensee, sowie nördlich der Stadt Luga hingewiesen werden. Es handelt sich um Steinsetzungen die denjenigen Estlands und Nordlettlands analog sind, und von einem starken Kultureinfluss oder sogar von einer Kolonisation von den genannten Gebieten aus bezeugen. ${ }^{2}$ Mit einer Kolonisation zur Ausbeutung der Waldreichtümer von Südestland heraus nach dem südlichen Ladogaufer rechnet A. M. Tallaren. $^{3}$ Die späteisenzeitliche Kultur, welche sich hauptsächlich in den vikingerzeitlichen, äusserst zahlreichen Grabhügeln am südlichen Ladogaufer zwischen den Flüssen Wolchow und Swir dokumentiert, ist auf der archäologischen Seite indes noch allzu umstritten, um irgendwelche sicheren Schlüsse über ihren Ursprung ziehen zu können. Es scheint doch nunmehr wenigstens allgemein angenommen zu werden, dass man bei dieser Kultur, welche ihr internationelles Gepräge und ihre handelswirtschaftliche Aktivität durch das skandinavische sog. Variagertum erhielt, mit einer finnisch-ugrischen, d.h. am nächsten baltisch-ostseefinnischen Grundschicht zu rechnen hat. Dass dieselbe Kultur dann später auch Gebiete auf der Westseite vom Ladogasee beeinflusst, und zur Blüte der karelischen Kultur zur Zeit der Kreutzzüge in Finnland beigetragen hat, wird gleichfalls ganz allgemein anerkannt. ${ }^{4}$ Von unserem

1 H. Moora, J. MÄgiste, Rooma raua-aeg. Eesti ajalugu I. 'Tarí.। 1936 , S. 85 .

2 H. Moora, Die Eisenzeit in Lettland bis etwa 500 n.Chr. II. Verhandl. d. Gelehrten Estn. Gesellschaft XXIX. Tartu 1939, S. 18, $631-$ 32; vgl. auch Karte, Abb. 90. - B. V. Alexandrov und A. M. TAllGREN, Funde aus der römischen Eisenzeit im Gouv. Novgorod. ESA V. S. 100-108.

3 A.M.T., Varhaishistorian Suomi ja Itämeren alue. Suomen Musen 1935 , S. 92.

- Vgl. z.B. Tallgren, op.cit., S. 92-94. - Ders., Eräitä suomalaisugrilaisen nuoremman rautakauden kulttuuripiirejä. Kalevalaseuran 
Problem heraus ist es von Bedeutung festzustellen, dass die russischen Forscher in der letzten Zeit in Alt-Ladoga (Aldejgjuborg) Fünde gemacht haben, die schon aus dem 6 . Jh. stammen, und also - wie auch von der archäologischen Seite zugegeben wird - das frühere siedlungsbild wesentlich ändern. ${ }^{1}$ Es ist dabei besonders zu beachten, dass die Kultur, die hier also schon in der Völkerwanderungszeit bodenständig war, bereits ein landwirtschaftliches Gepräge trägt, womit man in einer so frühen Periode bisher noch nicht gerechnet hatte. ${ }^{2}$ Ohne auf die speziellen Probleme der Ladogakultur hier näher einzugehen, scheint es möglich zu sein, die von unserem Material bewiesene frühe Verbreitung des osteuropäischen Schlittens mit dem gebrachten vorhistorischen Hintergrund in einen guten Einklang zu bringen. Es ist dabei im Auge zu behalten, dass der genannte Schlitten ein Fuhrwerk darstellt, das, in der Regel von einem Einzelpferd gezogen, durch seine ganze Konstruktion ausgezeichnet in diejenigen Verhältnisse hineinpasst, die beim Urbarmachen des Waldbodens durch Schwenden zu bezwingen sind. Dass der besprochene Schlitten in einer späteren Zeit in Finnland der eigentliche Schwendeschlitten gewesen ist und sich gerade in dieser Eigenschaft über grosse Gebiete verbreitet hat, wird gleich unten zu begründen sein. Es scheint deshalb vom ethnologischen Gesichtspunkt aus natürlich, anch die vorhistorische Verbreitung dieses Schlittens von seiner frühesten Basis auf dem ostseefinnischen Boden heraus nach dem Ladogaufer hin, als ein Komplement in einer primitiven Brandwirtschaft aufzufassen. Das setzt allerdings eine innere ostseefinnische Kolonisation aus Südestland und dem heutigen Nordlettland gegen Nordosten voraus, die älter als das Vorrücken der Ostslaven in diesen Gegenden gewesen sein muss. Es ist nicht unmöglich, eine solche Kolonisation mit der nach Norden gerichteten Expansion der baltischen stämme in Verbindung zu setzen, welche sich auf Kosten der Besiedlungs-

vuosikirja 7. Helsinki 1927, S. 120-23. - Ella KIvixoskı, Zur Herkunft der Karelier und ihrer Kultur. Acta Archaeologica XV, S. 1-28.

1 Kivikoski, op.cit., S. 4.

2 S. N. Orlov, Ostatki selskochozjaistvennogo inventarja VII-X v. iz Staroj Ladogi. Sov. Archeologija XXI. 
gebiete der Ostseefinnen im heutigen Nordlettland etwa von der Mitte des ersten Jahrtausends an vollzieht. ${ }^{1}$ Ob die ganze ostseefinnische Besiedlung am südlichen Ladogaufer und den Gegenden östlich davon in der Völkerwanderungszeit durch die angenommene Kolonisation erklärt werden kann, oder ob es hier nur um eine Kulturüberführung im Zusammenhange mit einer zusätzlichen Bevölkerungsbewegung handelt, was wohl wahrscheinlicher erscheint, kann von unserem beschränkten Ausgangspunkt heraus natürlich nicht entschlossen werden. Ohne einen starken Kulturstrom von der südlichen Peripherie des ostseefinnischen Besiedlungsgebietes aus kann das auf uuseres spezielles Material gebaute Ergebnis von der frühen Verbreitung des osteuropäischen Schlittens jedenfalls nicht erklärt werden.

Dass wenigstens von dem Ausgang der römischen Eisenzeit an gewisse landwirtschaftliche Novationen aus dem estnischbaltischen Gebiet nach Osten und Nordosten vermittelt geworden sein können, scheint auch durch die obenerwähnten Fünde aus Alt-Ladoga bestätigt zu werden. Es gibt mehrere Gegenstände, die von dem oben angenommenen Kulturstrom gegen Norden getragen zu sein scheinen. In diesem Zusammenhange möchte der Verf. nur noch auf einen Hakenpflugtypus hinweisen, den Gustav RäNK neulich in einer Untersuchung über die Pflüge in Estland Stockpflug genannt hat. ${ }^{2}$ Der genannte Hakenpflug ist früher über das ganze Baltikum verbreitet gewesen, ist aber in einer späteren Periode von der von Osten her einbrechenden Zoche verdrängt worden. ${ }^{3}$ Eine Schar, die ohne Zweifel dem in Frage stehenden Hakenpflug zugehörig gewesen ist, ist nun in einer Kulturschicht aus dem 7 . Jh. in Alt-Ladoga angetroffen worden. ${ }^{4}$ Wenn man mit der heute von der Forschung allgemein geteilten Auffassung rechnet,

1 H. Moora, Keskmine raua-aeg. Eesti ajalugu I. Tartu 1936, S. 128.

2 Gustav Ränk, Die Hakenpflüge Estlands. Suomen Museo 1955, S. 5-42.

s RãNK, op.cit. - Vgl. auch H. Hagar, Zur Geschichte des baltischen Hakenpfluges. Aphophoreta Tartuensia. Stockholm 1949, S. 119128.

- Orlov, op.cit., Abb. 1. 
dass die Zoche ein spezielles, ursprïnglich von der ostsla vischen Kolonisation gegen Norden getragenes Kulturelement darstellt, ${ }^{1}$ die aber, wie die Fünde aus der ebengenannten Fundstätte in Alt-Ladoga erweisen, daselbst erst in den Kulturschichten aus dem 9. und 10. Th. angetroffen wird, ${ }^{2}$ soll man den dort früher vorhandenen Stockpflug einer vorslavischen Periode zuschreiben. Das Vorhandensein dieser Pflugkonstruktion in jener Zeit so weit im Norden wäre schwer zu erklären, wenn man auch hier nicht mit einem Verbreitungsweg gleicher Richtung, wie für den osteuropäischen Schlitten angenommen worden, rechnet. Der Stockpflug wäre dann ebenso wie der osteuropäische Schlitten als ein Beweisstück einer primitiven, auf die Schwendewirtschaft basierten, vom Baltikum ausstrahlenden Ackerbaukultur in der vorslavischen Ladogagebiet anzusehen. - Es verdient hier zusätzlich noch, um die althergebrachte Stellung und bedeutungsvolle Rolle der Schwendekultur namentlich in der Ladoga- und Onegagegend hervorzuheben, auf die beträchtliche Anzahl von verschiedenen Benennungen des Schwendelandes hinzuweisen, die aus dem Ostseefinnischen, vorzugsweise aus dem Wepsischen, auch Olonetzisch-Karelischen, ins Russische entlehnt worden sind. ${ }^{3}$ In dem entgegengesetzten Lehnverhältnis aus dem Russischen ins Ostseefinnische, ist dagegen keine einzige Benennung dieser Gruppe registriert worden. ${ }^{4}$

Wir haben somit die älteste Etappe in der Geschichte des osteuropäischen Schlittens auf dem ostseefinnischen Boden abgeschlossen. Die spätere Geschichte desselben ist in ihren Hauptzügen schon aus der Analyse der Verbreitungskarten hervorgegangen. In Estland hat sich die Verbreitung in nördlicher Richtung bis zum Finnischen Meerbusen fortgesetzt.

1 Vgl. KustaA Vilkuna, Gaffelplogen. Finskt Museum 1935, S. $59-74$.

2 Orlov, op.cit., S. 344, Abb. 5. - Vgl. auch A. Moora, Ajaloolisetnograafilistest valdkondadest Eestis. Eesti rahva etnilisest ajaloost. Tallinn 1956, S. 248.

3 Jalo Kalima, Die ostseefinnischen Lehnwörter im Russischen. MSFOu XLIV, S. 254.

- Kalima, Slaavilaisperäinen sanastomme. 
Wann das geschehen ist, können wir nicht näher angeben, wir laben aber konstatieren können, dass die Konstruktion im Westen des Landes noch in unseren Tagen im Vorrücken ist. Der Verbreitungsvorgang kann in grossen Zügen weiter von der Verbreitungskarte über die Benennungen der Querverbindung, Fig. 21, abgelesen werden. Während die Verbreitung in Estland ¿lso ihre ursprüngliche süd-nördliche Richtung beibehalten hat, ist dieselbe in Finnland eine ost-westliche gewesen. Die nächste Verbreitungsbasis hat in bezug auf Finnland in den Gegenden sïdöstlich und östlich von Ladoga gelegen. Von hier aus hat sich der osteuropäische Schlitten dann als eine östliche Novation gegen Westen und Nordwesten verbreitet. Es ist nicht möglich auf Grund unseres Materials anzugeben, wann der genannte Schlitten die heutige Reichsgrenze Finnlands überschritten hat. Dass die ganze Verbreitung desselben innerhalb Finnlands jedoch nicht von einem besonders hohen Alter sein kann, wird schon von der obenanalysierten, aus dem Russischen entlehnten Ständerbenennung kaplas angedeutet, welche in Finnland, wie wir gesehen hahen, auch das wirkliche Vordringen des Gegenstandes dokumentiert. Das genannte Lehnwort, welches, wie man aus dem oben Angeführten verstehen kann, nicht für die ursprüngliche Herkunft des osteuropäischen Schlittens bei den Ostseefinnen ausschlaggebend ist, hat sich augenscheinlich der Schlittenterminologie angeschlossen, bevor der besprochene Schlitten seine Wanderung gegen Westen begonnen hat. Das kann aber nicht früher geschehen sein, als die Russen die östliche Peripherie des ostseefinnischen Besiedlungsgebietes kulturell penetriert hatten. Zu dor genannten Ständerhenennung gesellt sich noch ein anderes russisches Lehnwort. saceriklo, das ursprünglich denjenigen Rutenring, später auch einen Eisenhaken bezeichnet, womit die Femerstänge des osteuropäischen Schlittens an den Kufen befestigt werden. Das Wort kommt ausser dem Finnischen ebenfalls nur in den östlichsten ostseefinnischen Sprachen vor, ${ }^{1}$ und soll damit ebenso wie kaplas als ein sekundärer Zusatz in der Schlittentermino-

1 Kalima, op.cit., S. 157. - Vgl. auch KuJoLA, op.cit., S. 419. Für das Finnische SS 109. 
logie beurteilt werden. Die mächtige Verbreitung des osteuropäischen Schlittens in Finnland ist nach allem zu beurteilen im Zusammenhang der ('rosschwendewirtschaft erfolgt, welche wie bekannt, etwa von dem 14.Jh. ab in Karelien zum Haupterwerb wurde und unter den folgenden Jahrhunderten eine Auswanderung von Osten her in die Waldeinöden in den mittleren und nördlichen Teilen des Landes veranlasst hat. ${ }^{1}$ Wenn man die Besiedlungskarte Finnlands ${ }^{2}$ mit der Verbreitungskarte über die Schlittenkonstruktionen, Fig. 1, vergleicht, kann man feststellen, dass zwischen den beiden eine Korrelation besteht. Für das erste ist der überaus grösste 'Teil von denjenigen Gebieten in den mittleren und nördlichen Teilen des Landes, die am Anfang des 16. Jahrhunderts noch unbesiedelt waren, d.h. keine feste Besiedlung besassen, von dem osteuropäischen Schlitten eingenommen worden. Für das zweite ist der eigentliche Bindeständerschlitten, Fig. 1: 2-5, nebst derjenigen von den Kontaminationsformen, Fig. 1: 6-7, die dem eigentlichen Bindeständerschlitten am nächsten steht, im Westen des Landes auf diejenigen Gebiete beschränkt, die schon im Ausgang der vorhistorischen Zeit eine feste Ansiedlung besessen hatten. Hier, im östlichen und mittleren Häme, fällt die Verbreitungsgrenze des osteuropäischen Schlittens in grossen Zügen mit der frühhistorischen Besiedlungsgrenze zusammen, welcher Umstand natürlich auch eine untere Zeitgrenze für das Vordringen des genannten Schlitten in diesem Teil des Landes spüren erlaubt. Nördlich davon, in Nord-Satakunta und Süd-Ostbottnien, läuft die Schlittengrenze dagegen durch ein Gebiet, das in seinen inneren 'Teilen erst unter das 16. .Jh. eine beständige Ackerbaubesiedlung erhalten hat. ${ }^{3}$ Die neue Ansiedlung in diesen Gebieten wird als ein Resultat von einem Zusammenspiel zwischen den östlichen und westlichen Kolonisten bezeichnet. ${ }^{4}$ Es ergibt sich daraus, dass die Verbreitungsgrenze

1 Eino Jutikкala, Asutuksen leviäminen Suomessa 1600-luvun alkuun mennessä. Suomen kulttuurihistoria I. Jyväskylä-Helsinki 1933, S. $68,96-100$.

\footnotetext{
2 op.cit., S. 91, Fig. 15.

3 op.cit., S. 100.

4 op.cit.; siehe auch Karte Fig. 15.
} 
des osteuropäischen Schlittens hier noch von einer weit jüngeren Herkunft als im Süden sein muss. In den genannten rebieten in Süd-Ostbottnien und Satakunta hat das Kerngebiet einer der Kontaminationsformen gelegen, die durch ihr einheitliches, östliches Ständersystem dem osteuropäischen Schlitten besonders nahe steht, Fig. 1:9. Wir haben oben, bei der Besprechung der Verbreitungskarte, die Vorbehaltung gemacht, zu dem Verbreitungsgebiet dieses Schlittens noch zurückzukommen. Es kann nun festgestellt werden, dass die zerstreuten Belege von dieser Konstruktion, die bis tief in die südliche Teile der Landschaft Satakunta vorkommen, genau mit denjenigen Ortschaften zusammenfallen, in welchen eine im 16. Jh. von Osten und Norden vorrückende Schwendebesiedlung konstatiert worden ist. ${ }^{1}$ Die funktionelle Sonderstellung des osteuropäischen Schlittens nebst den von demselben kräftig beeinflussten Kontaminationsformen geht besonders deutlich hervor, wenn man das Material in den Grenzgegenden zwischen den Verbreitungsgebieten verschiedener Schlittenformen, wo also Schlitten von einander abweichenden Konstruktionen zur gleichen Zeit vorkommen, untersucht. Es erweist sich dann, dass der osteuropäische Schlitten im Gegensatz zu den westlichen Varianten namentlich zu längeren Frachten bestimmt gewesen ist, ${ }^{2}$ oder aber stellt man fest, dass gerade diejenige von den vorhandenen Kontaminationsformen, die sich durch ein Übergewicht östlicher Konstruktionsdetails auszeichnet, charakteristischerweise metsäreki, "Waldschlitten», oder dgl. genannt wird. $^{3}$ Derselbe funktionelle Unterschied zwischen den verschiedenen Schlittenformen würde zum Vorschein kommen, wenn man das Schlittenmaterial von dem Ausgangspunkt der Bespannungsvorrichtungen aus einteilen möchte, worauf hier jedoch verzichtet wird. Es ist deutlich, dass diese Beobachtungen dafür sprechen, dass die Verbreitung des osteuropäischen Schlittens, sowie dann auch des von demselben weit nach dem Westen hin ausgestrahlten konstruktiven Einflusses, in Finn-

1 op.cit., S. 100.

2 Z.B. P y 1 kö n m äk i, SS 109.

3 Z.B. Orives i, SS 109 . 
land als ein Ausschlag der nach dem Ausgang der vorhistorischen Zeit einsetzenden, auf der Grosschwendewirtschaft basierten, und nach dem Westen gerichteten Besiedlung aufgefasst werden muss. Der osteuropäische Schlitten hat in Finnland also dieselbe, durch seine spezielle Konstruktion besonders angebrachte Rolle von Ansiedlerschlitten bis zu einer späten Zeit weiterspielen können, welche ihm im Süden wahrscheinlich schon in einer vorhistorischen Zeit beschert gewesen war. Mit dem Aufhören der Grosschwendewirtschaft im Lande hat derselbe Schlitten dann auch einen Rückschlag erfahren. Die auf der Verbreitungskarte Fig. 1: 10 verzeichnete Variante, die sich in der Gegenwart als eine westliche Novation gegen Osten bewegt, ist demnach als ein Ausschlag der Umgestaltung der Landwirtschaft zu bewerten. Der westliche Einfluss hat sich in der jüngsten Zeit tatsächlich viel mehr bei der alten Konstruktion des osteuropäischen Schlittens merkbar gemacht, als die Verbreitungskarte darzutun vermag. Es liegen z.B. Berichte vor die bezeugen, wie die früher hochgebogenen Kufen ausdrücklich im Zusammenhange der entweichenden Schwendewirtschaft verschwinden und durch niedrigere, aus dem natürlich krummgewachsenen Material hergestellten Gegenstücke ersetzt werden. ${ }^{1}$ Vielfach sind jedoch die hohen Kufen beibehalten, die kurzen Seitenstänge aber dermassen verlängert worden, dass sie an den Innenseiten der gekrümmten Kufenenden fixiert werden können. ${ }^{2}$ Auf alle diese neueren Erscheinungen wird hier nicht mehr eingegangen werden.

Unsere Aufgabe, die ältere Geschichte des osteuropäischen Schlittens bei den Ostseefinnen zu verfolgen, kann damit als abgeschlossen betrachtet werden. Das hauptsächliche Resultat kann kurz folgendermassen zusammengefasst werden. Der osteuropäische Schlitten ist in diesen beiden Ländern im Vergleich zu dem sog. Bindeständerschlitten sekundär. Sein frühestes Verbreitungsgebiet hat im livisch-südestnischen Sprachgebiet gelegen, wo es vorhistorischer Herkunft ist und auf eine südliche Kulturvermittlung durch die baltischen Stäm-

1 Hirvensalmi, SS 109.

2 SS 109. 
me zurückgeht. Von hier aus hat sich der Schlitten dann mit einem vorhistorischen Kulturstrom, der wahrscheinlich in irgendeiner Ausstreckung mit einer auf die Schwendewirtschaft basierte Kolonisation verbunden war, in der nordöstlichen Richtung nach der Gegend des Ladoga- und Onegasees verbreitet. Erst in einer frühhistorischen Zeit bricht der besprochene Schlitten von dieser östlichen Peripherie aus in Finnland ein, wo sich seine Verbreitung unter den folgenden Jahrhunderten hauptsächlich als ein Komplement in der nach Westen und Norden gerichteten Schwendekolonisation vollzieht. In weiten östlichen und nördlichen Gebieten Finnlands soll der osteuropäische Schlitten dabei als das erste landwirtschaftliche Fuhrwerk überhaupt aufgefasst werden. Der vorhistorische Bindeständerschlitten, dessen früheres Vorhandensein daselbst u.a. durch ein konstruktives Relikt bei dem osteuropäischen Schlitten noch heute dokumentiert wird, soll aller Wahrscheinlichkeit nach als ein handgezogener Schlitten beurteilt werden.

Das rezente Verbreitungsgebiet des osteuropäischen Schlittens, welches heute ganz Osteuropa umfasst, ist somit irreführend, wenn man daraus für die ältere Kulturorientierung der ostseefinnischen Besiedlungsgebiete gültige Schlüsse ziehen will. Das riesige Verbreitungsgebiet im Osten ist erst danach entstanden, wenn der besprochene Schlitten in das ostseefinnische Territorium schon eingeführt war. Es dürfte aber keinem Zweifel unterliegen, dass die spätere Verbreitung dieses Schlittens mit der grossrussischen Kolonisation zusammenhängt, ebenso dass die nach dem Norden und Osten vorrückenden grossrussischen Stämme damals schon im Besitz von demselben Schlitten gewesen sein können. Die Frage der "Urheimat» des osteuropäischen Schlittens wird in diesem Zusammenhange nicht erörtert. Es ist nicht unwahrscheinlich, dass eine solche einmal in der Zukunft in einem weiten Gebiet südlich von der Ostsee entdeckt wird. ${ }^{1}$

Helmut HaGak

1 Kurz nach der Drucklieferung des vorliegenden Aufsatzes hat der Verf. an einer kleineren, aber verdienstvollen Abhandlung über den estnischen Arbeitsschlitten von A. ViIres teilnehmen können (Eesti tööree ajaloost. Eesti Teaduste Akadeemia Toimetised. VII köide. 
('hiskonnateaduste seeria. 1958, $\mathrm{nr}$ 1). In der genannten Abhandlung führt Vures gewisse alternative Standpunkte vor, die von denjenigen des Verf. einigermassen abweichen. Für das erste rechnet Virres mit der Möglichkeit, dass der sog. Hargla-Typus des osteuropäischen Schlittens, bei welchem die Seitenstänge und vorderen Rutenbänder aus ein und demselben Stück hergestellt werden, in Südestland von einem jüngeren Ursprung als der ordinäre osteuropäische Schlitten sein könnte. Als Beweggründe hat er vorgeführt, dass das Wort seba nur eine sekundäre Benennung der aus besonderen Stücken hergestellten Seitenstänge sein könne, da es ursprünglich nur die vorderen Rutenbänder bezeichnet habe, und dass der ordinäre osteuropäische Sichlitten mit den aus den besonderen Stücken hergestellten Rutenbändern in Südestland folglich älter sein könne als der Hargla-Typus. Dieser terminologischen Argumentierung, mit welcher auch der Verf. früher gerechnet hat, können wir nicht mehr beipflichten. Es ist offenbar, dass man bei dem in Frage stehenden Terminus von der Zusammensetzung seba-vits, d.h. 'sebaRute', ausgehen soll - ebenso wie es auch mit semm o.s.w. der Fall ist - und dass die Seitenstangenkonstruktion bei dem Hargla-Typus, die ja bloss aus einer langen Rute besteht, sich also in die terminologischen Zusammenhänge auch sachlich gut einordnen lässt. Das Wort seba o.s.w. darf in seiner übertragenen Bedeutung als Schlittenterminus nicht allzu eng, als etwa nur 'Schlittenhals', aufgefasst werden, sondern vielmehr als der 'Vorderteil des Schlittens' überhaupt, welches ja auch aus den verschiedenen Bedeutungsvariationen des Wortes im Finnischen wie auch im Wepsischen hervorgeht. Als Bezeichnung der Rutenbänder bekommt das Wort dann erst dadurch seine Motivierung, dass dieselben mit dem Vorderteil des Schlittens in Verbindung stehen. Da nun die Rutenbänder sich bei dem Hargla-Typus auf grund einer primitiven Technik über den ganzen Schlitten hinziehen, gibt es keinen Grund zu bezweifeln, dass auch die angesprochene Benennung bei denselben primär ist. Eine vollständige Parallele, obschon aus anderen semasiologischen Zusammenhängen ausgehend, stellt der Terminus semm dar. Welche kulturhistorische Stellung sodann die ältere Benennung der Seitenstange, namentl. kaust, im Verhältnis zum seba in Südestland einnimıt, glauben wir schon oben hinreichend begründet zu haben.

Es ist dann eine weitere Frage, warum die aus Südestland bekannten terminologischen Verhältnisse nur auf diesen Teil des Landes beschränkt sind, und nicht etwa auch in den anderen Teilen des Verbreitungsgebietes des osteuropäischen Schlittens vorkornmen. Dazu soll zuerst gemerkt werden, dass eine terminologische Beweisführung in den sachgeschichtlichen Zusammenhängen stets mit gewissen zufälligen Beweggründen zu rechnen hat, die sich oft unserem Urteil entziehen. Dass z.B. die südestnische Benennung seba für die aus den besonderen Stücken angefertigten Seitenstänge nicht in den nördlichen Teilen des Landes anzutreffen ist, ist wahrscheinlich dadurch zu erklären, dass sie hier 
durch die ältere Benennung kaust, die aus einer Schicht vor der Einführung des osteuropäischen Schlittens herstammt, wieder ersetzt worden ist. Mit einer solchen älteren schlittenhistorischen Schicht kann - wie es schon hervorgegangen sein dürfte - innerhalb des ganzen, von uns abgerissenen Gebietes, gerechnet werden. Es ist aber immerhin zu merken, dass die für Südestland charakteristische Seitenstangenbenennung seba sporadisch auch in Finnland verspürt werden kann. Aus dem Kirchspiel S y s m ä in Ost-Häme liegt z.B. ein Bericht vor, laut welches die Seitenstänge des Schlittens in der früheren Zeit sevät gehiessen hätten (SS 109). Wahrscheinlich hat man hier mit einer terminologischen Reminiszenz zu tun auf welche ich hier nicht näher eingehen kann. - Zur gleichen Zeit bilden doch die oben angesprochenen terminologischen Hauptgrenzen in Südestland einerseits und an der Reichsgrenze Finnlands andererseits eine Barriere, die aus den oben angegebenen Ursachen ein älteres, peripheres Verbreitungsgebiet von einem späteren, inneren Verbreitungsgebiet des osteuropäischen Schlittens in den genannten Ländern abtrennt. Wann die weitere Verbreitung desselben Schlittens in Finnland erfolgt ist, haben wir oben beleuchten können. Betreffs Estland hat dies nicht geschehen können. Zur Beleuchtung der Verbreitungsverhältnisse zwischen den beiden Grundtypen des Arbeitsschlittens in Estland hat A. Vinres u.a. gewisse lexikographische Notizen über Benennungen der Querverbindungen angeführt, die beweisen sollen, dass die Grenze zwischen den beiden Grundtypen sich innerhalb der lezten zweihundert Jahre nicht wesentlich verändert habe. Ohne hier auf nähere Kommentare darauf eingehen zu können, will der Verf. vorbehalten, dass dieser Zeitabschnitt allzu spät ist, um von der älteren Geschichte des osteuropäischen Schlittens bezeugen zu können. 